Rômulo Rodrigues Alves Smiderle Corti

\title{
Uma Metodologia para Cálculo de Seafastening em
}

Campanhas Offshore

\author{
Projeto de Graduação \\ Projeto de Graduação apresentado ao Departamento de Engenharia \\ Mecânica da PUC-Rio \\ Orientador: Ivan Fabio Mota de Menezes \\ Coorientador: Marcelo Brasil
}

Rio de Janeiro

Junho de 2020 


\section{Agradecimentos}

Agradeço à minha família, namorada e amigos por todo o apoio e suporte que sempre me deram durante todo o curso de engenharia. Agradeço também a todos os colegas de trabalho pela efetiva ajuda disponibilizada. Finalmente, ao professor Ivan Fabio Mota de Menezes por todo apoio, incentivo e orientação não só nesse trabalho, mas em toda a graduação. 


\section{Resumo}

A produção de óleo e gás no Brasil se concentra na exploração offshore, que apresenta altos desafios tecnológicos por operar em mar aberto, geralmente distante da costa e em altas profundidades. Neste contexto, a atividade de transporte e movimentação de cargas nos navios em alto mar se torna de extrema relevância, sendo necessário implementar um eficiente sistema de amarração das cargas transportadas em barcos e navios. Por esta razão, antes de qualquer campanha offshore é necessário a elaboração de um estudo que garanta que nenhum equipamento vai se mover no deck do navio durante as operações. Este estudo, denominado de seafastening, é imprescindível uma vez que dá ao projeto a segurança nas diversas atividades de transporte em ambientes marítimos.

O presente trabalho objetivou desenvolver uma metodologia para elaboração de um relatório de cálculo de seafastening. Foram aplicadas as diretrizes definidas em normas internacionais para calcular as acelerações, a capacidade mínima das cintas de amarração e os esforços em batentes e soldas usados para a fixação dos equipamentos. Foram utilizados os dados típicos de navios, equipamentos e dispositivos de fixação de projetos atuais de campanhas offshore com o propósito de simular suas disposições no deck do navio e avaliar sua condição de estabilidade.

Os resultados revelaram que a aplicação da sistemática de cálculos por meio das equações definidas nas normas se mostrou muito prática e eficaz. A simulação com a metodologia desenvolvida resultou em um diagnóstico confiável na avaliação da condição se estabilidade. A utilização dos dispositivos de fixação aplicados resultou na estabilidade de todos os equipamentos avaliados.

\section{Palavras-Chave}

Seafastening, PLSV, DNV, Estruturas Offshore. 


\section{Abstract}

Oil and gas production in Brazil focuses on offshore exploration, which presents high technological challenges for operating in the open sea, usually far from the coast and at high depths. In this context, the activity of transport and movement of cargo on ships on the high seas becomes extremely relevant, being necessary to implement an efficient system of mooring of cargo transported in boats and ships. For this reason, before any offshore campaign it is required to prepare a study that ensures that no equipment will move on the deck of the ship during all operations. This study, called seafastening, is essential since this study gives the project safety in the various transport activities in maritime environments.

The present work aimed to develop a methodology for the preparation of a seafastening report. The guidelines defined in international standards were applied to calculate the accelerations, the minimum capacity of the mooring straps, and the stresses in stops and welds used for the fixation of the equipment. Typical data of ships, equipment, and fixation devices conventional of current offshore campaign projects were used to simulate their provisions on the ship's deck and evaluate their stability condition.

The results revealed that the application of the calculation system through the equations defined in the norms proved to be very practical and useful. The simulation with the methodology developed resulted in a reliable diagnosis in the evaluation of the condition of stability. The use of the clamping devices applied resulted in the stability of all equipment.

\section{Keywords}

Seafastening, PLSV, DNV, Offshore Structures. 


\section{Sumário}

$\begin{array}{lr}\text { 1. Introdução } & 16\end{array}$

$\begin{array}{ll}\text { 1.1. Apresentação } & 16\end{array}$

$\begin{array}{ll}\text { 1.2. Objetivo } & 16\end{array}$

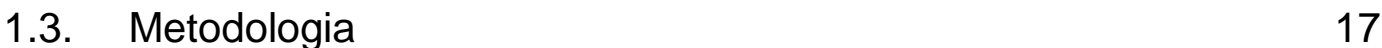

$\begin{array}{lr}2 . & 18\end{array}$

3. Embarcação PLSV 21

4. Equipamentos transportados 25

4.1. Concrete mattress - Mantas de concreto 25

4.2. Modular Spreader Bar - Barra de Içamento 26

4.3. Pipeline End Termination - PLET 26

4.4. Pipeline End Manifold - PLEM 27

4.5. Pig Launch Receiver-PLR 28

4.6. Grout Bags $\quad 29$

4.7. Primary Compressor - Compressor Primário 30

$\begin{array}{ll}\text { 4.8. Container } & 31\end{array}$

4.9. Wooden box - Caixas de madeira 32

5. Apresentação teórica 34

5.1. Acelerações 34

5.2. Estabilidade 40

5.3. Amarração diagonal para evitar o tombamento - Diagonal lashing

to avoid tilting 42

5.3.1. Amarração por atrito para evitar o deslizamento - Frictional lashing to avoid sliding $\quad 43$

5.3.2. Amarração por atrito para evitar o tombamento - Frictional lashing to avoid tilting 44

5.4. Componentes auxiliares $\quad 46$ 
$\begin{array}{lll}\text { 5.4.1. Batentes } & 46\end{array}$

5.4.1.1. Tensões no cordão de solda 48

5.4.1.2. Tensões no batente 50

5.4.1.3. Olhal do batente 51

6. Componentes, embarcação e equipamentos utilizados 54

6.1. Cintas $\quad 54$

6.2. Manilhas $\quad 54$

6.3. D-Ring $\quad 54$

6.4. Batentes 55

6.5. Embarcação PLSV 55

6.6. Equipamentos 56

$\begin{array}{ll}\text { 7. Resultados e análises } & 61\end{array}$

$\begin{array}{ll}\text { 7.1. Acelerações } & 61\end{array}$

$\begin{array}{ll}\text { 7.2. } & \text { Estabilidade }\end{array}$

$\begin{array}{ll}\text { 7.3. } & \text { Batentes } \\ \end{array}$

$\begin{array}{lll}\text { 7.3.1. } & \text { Esforços na solda } & 69\end{array}$

$\begin{array}{ll}\text { 7.3.2. } & \text { Esforços no batente }\end{array}$

$\begin{array}{lll}\text { 7.3.3. } & \text { Esforços nos olhais } & 71\end{array}$

8. Conclusões 73

9. Sugestões para trabalhos futuros $\quad 74$

10. Referências Bibliográficas 75

ANEXO 1 - Cálculo das acelerações $\quad 77$

ANEXO 2 - Cálculo dos esforços no batente 78

ANEXO 3 - Cálculo dos esforços nos olhais 80

ANEXO 4 - Datasheet da cinta 82

ANEXO 5 - Datasheet da manilha 83

ANEXO 6 - Datasheet do D-ring 84 


\section{Lista de figuras}

Figura 1 - Árvore de natal molhada amarrada ao deck de uma embarcação.

Figura 2 - PLSV Seven Oceans da Subsea 7.

Figura 3- Eixos de movimento de uma embarcação. 22

Figura 4 - Linha sendo lançada a partir do moonpool. 23

Figura 5 -Estrutura de casco de navio. 24

Figura 6 - Simulação de uma manta de concreto sendo posicionada acima de um flowline.

Figura 7 - Arranjo de barras de içamento transportando equipamento. 26

Figura 8 - Pipeline End Termination. 27

Figura 9 - PLEM sendo lançado. 28

Figura 10 - Pig Launch Receiver. 29

Figura 11 - Grout bag com linha apoiada corrigindo imperfeição no fundo do mar.

Figura 12 - Interior de um primary compressor usado em campanha offshore.

Figura 13 - Test cabin. 32

Figura 14 - Wooden box. 33

Figura 15 - Valor de kv em determinada posição 39

Figura 16 - Teste de estabilidade da norma EN12195-1 41

Figura 17 - Amarração direta diagonal 42

Figura 18 - Amarração por atrito para evitar deslizamento 44

Figura 19 - Amarração por atrito para evitar o tombamento 45

Figura 20 - Batentes posicionados em contato com o equipamento para evitar o movimento 
Figura 21 - Dimensões do batente e do cordão de solda

Figura 22 - Gráfico carga versus deslocamento 48

Figura 23 - Seção da garganta na solda e as tensões atuantes 49

Figura 24 - Deck layout $\quad 57$

Figura 25 - Tanque dentro de um skid 68 


\section{Lista de tabelas}

Tabela 1 - Dimensões, peso e coordenadas do centro de gravidade dos equipamentos.

Tabela 2 - Parâmetros de amarração dos equipamentos com amarração por atrito e batentes 58

Tabela 3 - Parâmetros de amarração dos equipamentos com amarração direta 59

Tabela 4 - Parâmetros de amarração do equipamento com amarração por atrito 60

Tabela 5 - Acelerações nos equipamentos de amarração por atrito e batentes

Tabela 6 - Forças atuantes nos equipamentos de amarração por atrito e batentes

Tabela 7 - Acelerações nos equipamentos de amarração direta 62

Tabela 8 - Forças atuantes nos equipamentos de amarração direta .......62

Tabela 9 -Aceleração no equipamento de amarração por atrito 63

Tabela 10 - Forças atuantes nos equipamentos de amarração por atrito 63

Tabela 11 - Estabilidade dos equipamentos com amarração por atrito e batente 65

Tabela 12 - Forças totais atuantes e capacidade mínima da cinta dos equipamentos de amarração por atrito e batente

Tabela 13 - Estabilidade dos equipamentos com amarração direta 66

Tabela 14 - Forças totais atuantes e capacidade mínima da cinta dos equipamentos de amarração direta

Tabela 15 - Estabilidade dos equipamentos com amarração por atrito....67

Tabela 16 - Forças totais atuantes e capacidade mínima da cinta dos equipamentos de amarração por atrito 


\section{Lista de símbolos}

$L=$ Comprimento do navio $[\mathrm{m}]$

$C_{w}=$ Coeficiente de onda $[-]$

$C_{v}=$ Coeficiente auxiliar para o cálculo da aceleração comum [-]

$C_{v 1}=$ Coeficiente auxiliar para o cálculo da aceleração comum [-]

$V=$ Velocidade máxima de navegação [nós]

$C_{b}=$ Coeficiente de block do navio [-]

$g_{0}=$ Aceleração da gravidade $\left[\mathrm{m} / \mathrm{s}^{2}\right]$

$a_{0}=$ Aceleração comum $\left[\mathrm{m} / \mathrm{s}^{2}\right]$

$a_{x}=$ Aceleração devido ao movimento de surge $\left[\mathrm{m} / \mathrm{s}^{2}\right]$

$\theta=$ Ângulo do movimento de pitch [rad]

$T_{p}=$ Período do movimento de pitch $[\mathrm{s}]$

$x_{c g}=$ Coordenada $\mathrm{x}$ do centro de giração do navio [m]

$x_{i}=$ Coordenada $\mathrm{x}$ do centro de massa do equipamento $\mathrm{i}[\mathrm{m}]$

$z_{c g}=$ Coordenada $z$ do centro de giração do navio [m]

$z_{i}=$ Coordenada $\mathrm{z}$ do centro de massa do equipamento $\mathrm{i}[\mathrm{m}]$

$R_{p}=$ Distância em metro do centro de massa do equipamento ao centro de giração do navio $[\mathrm{m}]$

$a_{p}=$ Aceleração tangencial devido ao movimento de pitch $\left[\mathrm{m} / \mathrm{s}^{2}\right]$

$R_{p x}=$ Projeção vertical de $R_{p}[\mathrm{~m}]$

$a_{p x}=$ Componente longitudinal da aceleração de pitch $\left[\mathrm{m} / \mathrm{s}^{2}\right]$

$a_{l}=$ Aceleração ao longo do eixo longitudinal do navio combinando os movimentos de surge e pitch $\left[\mathrm{m} / \mathrm{s}^{2}\right]$

$a_{y}=$ Aceleração devido ao movimento de sway $\left[\mathrm{m} / \mathrm{s}^{2}\right]$ 
$k=$ Coeficiente auxiliar para o cálculo do ângulo de roll [-]

$c=$ Coeficiente auxiliar para o cálculo do ângulo de roll [-]

$B=$ Boca moldada do navio $[\mathrm{m}]$

$\varphi=$ Ângulo do movimento de roll [rad]

$k_{r}=$ Raio de giração de roll do navio [m]

$G M=$ Altura do metacentro do navio $[\mathrm{m}]$

$T_{r}=$ Período de movimento de roll $[\mathrm{m}]$

$y_{i}=$ Coordenada y do centro de massa do equipamento $\mathrm{i}[\mathrm{m}]$

$R_{R}=$ Distância do centro de massa do equipamento ao eixo de rotação de roll $[\mathrm{m}]$

$a_{r}=$ Aceleração tangencial devido ao movimento de roll $\left[\mathrm{m} / \mathrm{s}^{2}\right]$

$R_{R y}=$ Projeção vertical de $R_{R}[\mathrm{~m}]$

$a_{r y}=$ Componente transversal da aceleração de roll $\left[\mathrm{m} / \mathrm{s}^{2}\right]$

$a_{t}=$ Aceleração ao longo do eixo transversal do navio combinando os movimentos de sway e roll $\left[\mathrm{m} / \mathrm{s}^{2}\right]$

$k_{v}=$ Coeficiente para o cálculo da aceleração vertical combinada [-]

$a_{v}=$ Aceleração vertical combinada $\left[\mathrm{m} / \mathrm{s}^{2}\right]$

$F_{x x}=$ Força no corpo no sentido longitudinal na combinação de acelerações vertical e longitudinal $\left[\mathrm{m} / \mathrm{s}^{2}\right]$

$F_{x z}=$ Força no corpo no sentido vertical na combinação de acelerações vertical e longitudinal $\left[\mathrm{m} / \mathrm{s}^{2}\right]$

$F_{y y}=$ Força no corpo no sentido transversal na combinação de acelerações vertical e transversal $\left[\mathrm{m} / \mathrm{s}^{2}\right]$

$F_{y z}=$ Força no corpo no sentido vertical na combinação de acelerações vertical e transversal $\left[\mathrm{m} / \mathrm{s}^{2}\right]$

$c_{x}=$ Coeficiente de aceleração na direção longitudinal [-] 
$c_{y}=$ Coeficiente de aceleração na direção transversal [-]

$c_{c}=$ Coeficiente de aceleração na direção vertical [-]

$m=$ Massa do equipamento $[\mathrm{kg}]$

$s=$ Altura do ponto de amarração [m]

$p$ = Distância do ponto de amarração até a lateral oposta do equipamento

$[\mathrm{m}]$

$d=$ Altura do centro de gravidade do equipamento [m]

$t$ = Distância entre a base do equipamento e o deck do navio [m]

$w=$ Largura do equipamento $[\mathrm{m}]$

$b=$ Distância horizontal do centro de gravidade à lateral do equipamento no sentido transversal $[\mathrm{m}]$

$l=$ Comprimento do equipamento $[\mathrm{m}]$

$b_{2}=$ Distância horizontal do centro de gravidade à lateral do equipamento

no sentido longitudinal $[\mathrm{m}]$

$r$ = Distância horizontal entre a lateral do equipamento e o ponto de tombamento $[\mathrm{m}]$

$\alpha=$ Ângulo vertical do ponto de amarração [graus]

$\beta_{x}=$ Ângulo horizontal do ponto de amarração na direção longitudinal [graus]

$\beta_{y}=$ Ângulo horizontal do ponto de amarração na direção transversal [graus]

$F_{r}=$ Força de contenção da cinta de amarração [tnf]

$F_{t}=$ Força de tensão na cinta de amarração [tnf]

$\mu=$ Fator de atrito $[-]$

$w=$ Largura do equipamento $[\mathrm{m}]$

$n=$ Número de cintas de amarração [-] 
$f_{s}=$ Fator de segurança $[-]$

$a_{s}=$ Tamanho da garganta da solda [mm]

$L_{s}=$ Tamanho do cordão de solda [mm]

$I_{S}=$ Momento de inércia na seção da garganta da solda [mm^4]

$F_{d}=$ Força exercida pelo equipamento no batente $[\mathrm{kN}]$

$M=$ Momento causado pela força exercida pelo equipamento $[\mathrm{kN} . \mathrm{mm}]$

$h=$ Altura da chapa do batente $[\mathrm{mm}]$

$\sigma_{\perp}=$ Tensão normal perpendicular ao plano da garganta [MPa]

$\tau_{\perp}=$ Tensão de cisalhamento perpendicular ao plano da garganta [MPa]

$\tau_{11}=$ Tensão de cisalhamento paralela ao plano da garganta [MPa $]$

$\sigma_{e q}=$ Tensão equivalente na seção da garganta da solda [MPa]

$\sigma_{\text {eq.long }}=$ Tensão equivalente na seção da garganta da solda para o

batente posicionado na longitudinal dos equipamentos [MPa]

$\sigma_{\text {eq.transv }}=$ Tensão equivalente na seção da garganta da solda para o

batente posicionado na transversal dos equipamentos [MPa]

$f_{u}=$ Limite de ruptura do material $[\mathrm{MPa}]$

$\sigma_{\text {adm.solda }}=$ Tensão admissível na seção da garganta da solda [MPa]

$\beta_{w}=$ fator de correlação do material [-]

$\eta_{0}=$ fator de utilização da solda [-]

$L_{b}=$ Comprimento da chapa do batente $[\mathrm{mm}]$

$t_{b}=$ Espessura da chapa do batente $[\mathrm{mm}]$

$A_{b}=$ Área da base da chapa do batente $\left[\mathrm{mm}^{2}\right]$

$I_{b}=$ Momento de inércia na base do batente $\left[\mathrm{mm}^{\wedge} 4\right]$

$\sigma_{f}=$ Tensão de flexão na base do batente [MPa] 
$\tau_{f}=$ Tensão de cisalhamento na base do batente [MPa]

$\sigma_{e q_{b}}=$ Tensão equivalente na seção da base do batente [MPa]

$\sigma_{a d m_{b}}=$ Tensão admissível na seção da base do batente [MPa]

$\sigma_{e q_{b} . l o n g}=$ Tensão admissível na seção da base do batente posicionado

na longitudinal dos equipamentos [MPa]

$\sigma_{e q_{b} . \text { transv }}=$ Tensão admissível na seção da base do batente posicionado

na transversal dos equipamentos [MPa]

$f_{y_{b}}=$ Limite de escoamento do material do batente $[\mathrm{MPa}]$

$\eta_{0_{b}}=$ Fator de utilização do material do batente [-]

$d_{\text {furo }}=$ Diâmetro do furo do olhal [mm]

$d_{\text {pino }}=$ Diâmetro do pino da manilha a ser utilizada $[\mathrm{mm}]$

folga $=$ Folga entre o diâmetro do furo e diâmetro do pino determinado

pela norma [mm]

$A_{\text {manilha }}=$ Tamanho da abertura da manilha $[\mathrm{mm}]$

$F_{\text {olhal }}=$ Força teórica no olhal $[\mathrm{MPa}]$

$f_{c g}=$ Fator de incerteza no centro de gravidade [-]

$f_{c p}=$ Fator de contingência de peso $[-]$

$f_{d c}=$ Fator de desvio de carga $[-]$

$F A D=$ Fator de amplificação dinâmica para içamento no mar [-]

$F_{\text {linga }}=$ Força resultante da cinta no olhal $[\mathrm{MPa}]$

$F_{\text {pino }}=$ Força atuante no pino da manilha $[\mathrm{MPa}]$

$t_{\text {olhal }}=$ Espessura do olhal [mm]

$f_{p}=$ Força de contato entre o pino e o furo do olhal [MPa]

$R=$ Raio do olhal [mm] 
$f_{v}=$ Força de cisalhamento na área efetiva do olhal [MPa]

$b_{1}=$ Coeficiente para cálculo da tração na área líquida efetiva do olhal [-]

$f_{a}=$ Força de tração na área líquida efetiva na região do furo [MPa]

$F_{\text {max.long }}=$ Força máxima que um equipamento exerce no batente posicionado no sentido longitudinal $[\mathrm{kN}]$

$F_{\text {max.transv }}=$ Força máxima que um equipamento exerce no batente posicionado no sentido transversal $[\mathrm{kN}]$ 


\section{Introdução}

\subsection{Apresentação}

A indústria petrolífera é uma das mais importantes do mundo e possivelmente a mais importante de nosso tempo. A produção de óleo e gás no Brasil se concentra na exploração offshore, que apresenta altos desafios tecnológicos por operar em mar aberto, geralmente distante da costa e em altas profundidades. Isto faz com que as empresas necessitem enfrentar problemas que não teriam que se preocupar na exploração terrestre.

Neste contexto, a atividade de transporte e movimentação de cargas nos navios em alto mar para as campanhas offshore se torna de extrema relevância, sendo exercida desde a descoberta e perfuração dos poços e se mantendo ao longo de todo ciclo de produção. Para realizar esta atividade torna-se necessário implementar um eficiente sistema de amarração das cargas transportadas em barcos e navios. Para este fim, antes de qualquer campanha offshore é necessário a elaboração de um relatório de seafastening, essencial para a sua realização, uma vez que esse estudo dá ao projeto a segurança de que nenhum equipamento vai se mover no deck do navio durante toda a operação.

\subsection{Objetivo}

O principal objetivo deste trabalho é descrever o processo de elaboração de um relatório de seafastening, essencial para as campanhas offshore. Este estudo dá ao projeto a segurança de que nenhum equipamento vai se mover no deck do navio durante toda a operação. Para tanto, foram utilizadas dimensões de uma embarcação PLSV (Pipe Laying Support Vessel) para calcular as acelerações e considerados alguns equipamentos comumente utilizados para simular suas disposições no deck do navio da forma mais segura possível. Foram utilizadas normas técnicas reconhecidas internacionalmente para calcular as acelerações, a capacidade mínima das cintas de amarração, além de conhecimentos na área de comportamento mecânico dos materiais para verificação dos esforços em batentes e soldas usados para a fixação os equipamentos. 


\subsection{Metodologia}

Uma das primeiras premissas no projeto é considerar as características dos equipamentos a serem transportados. Como regra geral considera-se que os mais críticos devem estar nas posições de menores acelerações para que os esforços tanto no deck do navio quanto nas cintas de amarração sejam menores. Estes equipamentos são os mais sujeitos a tombamentos pela altura do seu centro de gravidade ou os mais pesados, que, por causa da sua massa, serão os que terão forças maiores devido às acelerações. Uma vez escolhidas suas posições, será definido o tipo de amarração para cada um de forma independente, dependendo da sua geometria, peso, centro de gravidade e posição no deck.

Para realizar o cálculo das acelerações, foi utilizado o software Microsoft Excel, que seguiu os critérios da norma DNV Rules for Ships - Part 3 Chapter 1 de Janeiro/2011 [1].

A norma ES/EN 12195-1 de Novembro/2010 [2] foi utilizada para determinar os tipos de amarração a serem executados e também verificar se as cintas de amarração atendiam à necessidade do projeto. A partir da escolha dos tipos de amarração foi elaborada uma planilha, também no software Microsoft Excel, para poder calcular a estabilidade dos equipamentos.

Para o cálculo dos esforços das soldas, foi usada a norma DNVGL-OSC102 Structural Design of Offshore Ships [3] e todas as suas recomendações.

Para verificar se os olhais dos batentes estão aptos às cargas de projeto, foram utilizados os testes de verificação da norma NB-2683 da Petrobras [4].

Com estes valores e utilizando os critérios de aprovação definidos nas normas foi avaliada a condição de estabilidade para cada equipamento permitindo a elaboração o relatório de seafastening. 


\section{Seafastening}

Seafastening é o sistema de amarração e estaiamento de carga existente em um convés de trabalho. Ao transportar uma carga em um deck de navio, a mesma fica sujeita a diversas forças, sejam elas geradas pela movimentação do navio - 3 translações e 3 rotações - ou geradas pelo ambiente, como as relativas ao vento. Devido à estas forças e à combinação de seus diversos efeitos, uma carga solta pode não se manter estagnada no mesmo local, mas movimentar-se pelo deck. Portanto, é essencial restringir estes movimentos. Todos os acessórios e materiais utilizados para esta restrição possuem um projeto chamado seafastening design.

O seafastening de equipamentos utiliza cintas que são amarradas ao equipamento e presas no deck do navio. Esta amarração varia de acordo com o equipamento, uma vez que deve ser levado em conta o seu peso, geometria, se há pontos de amarração ou não, fragilidade, posição do centro de gravidade, etc. Uma vez amarradas, as cintas são presas por meio de $D$-Rings soldados no deck do navio ou por stoppers presos com manilhas e soldados no deck do navio. Cintas, manilhas, stoppers e $D$-rings possuem capacidades diferentes e a escolha de cada um desses itens varia conforme a necessidade do projeto.

Uma das normas mais utilizadas para realizar os cálculos das amarrações de seafastening é a EN12195-1, que faz o estudo de métodos de fixação de cargas para transporte rodoviários e transporte em navios. Ela foi criada para fornecer um meio de conformidade com os requisitos essenciais de segurança dos conjuntos de retenção de carga a serem utilizados no mercado e, assim, permitir o transporte de cargas com segurança. A Figura 1 ilustra a amarração de uma árvore de natal no deck do navio com as cintas presas ao equipamento e aos olhais. 


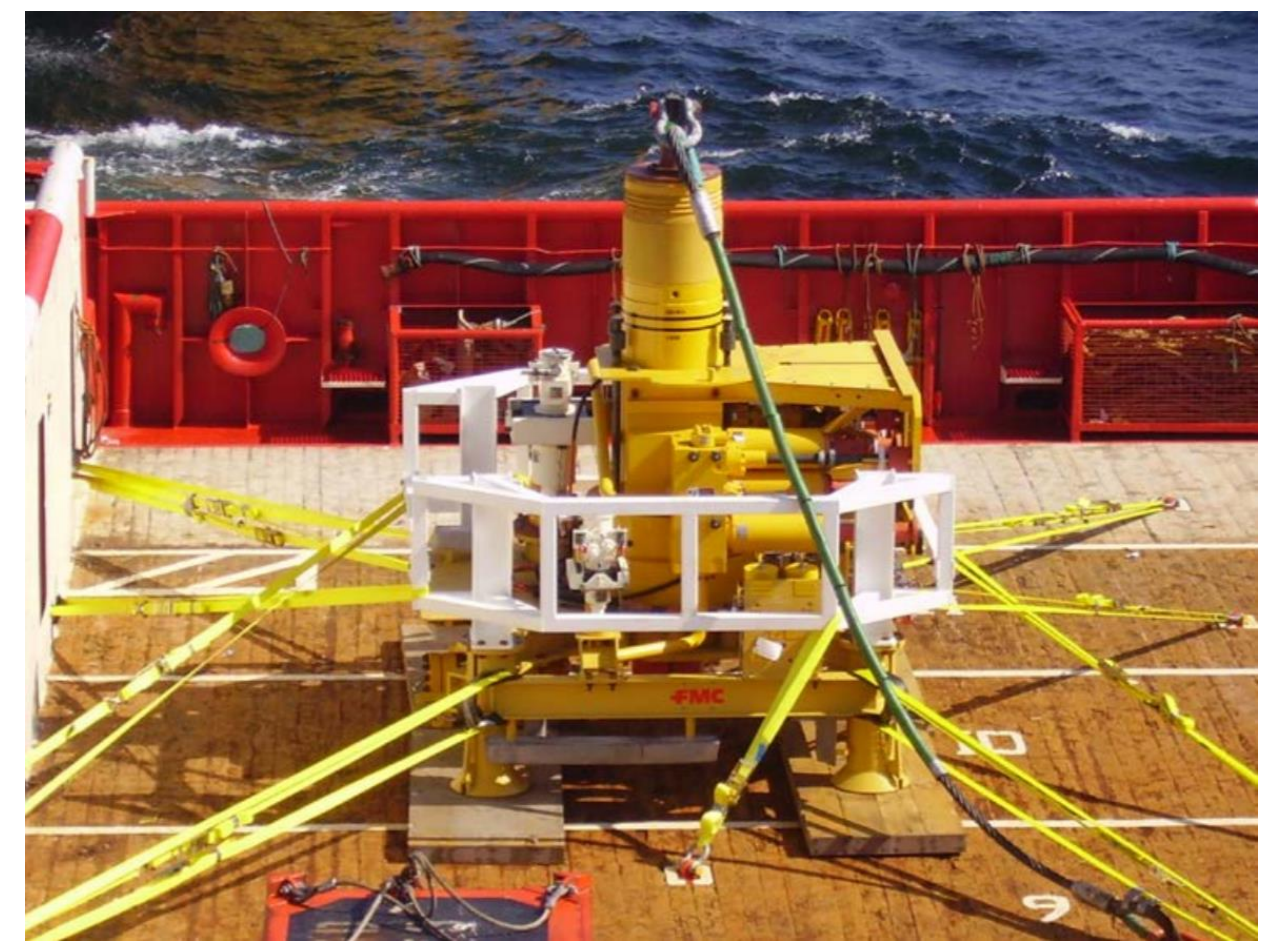

Figura 1 - Árvore de natal molhada amarrada ao deck de uma embarcação.

Fonte: http://www.g-omo.info/wp-content/uploads/2016/09/20160613-Non$\underline{\text { Routine-Cargo-Shipments.pdf [12] }}$

De uma forma geral, um relatório de seafastening é composto por:

- Lista de equipamentos que vai a bordo, suas propriedades físicas e tipo de amarração de cada um dos equipamentos;

- Layout do deck com os equipamentos e a posição x, y e $z$ do centro de gravidade de cada um deles;

- Posição do sistema de coordenada utilizado;

- Características da embarcação, cintas, manilhas, D-rings e batentes utilizados;

- Cálculo das acelerações para cada um dos equipamentos;

- Cálculo da estabilidade e da força máxima atuante nas cintas de amarração;

- Cálculo e verificação dos esforços nos batentes;

- Cálculo e verificação do movimento de uplift nos equipamentos; 
- Cálculo das forças de quartering e verificação dos esforços no deck do navio.

O movimento de uplift é gerado quando aplicadas as combinações de aceleração, fazendo com que o equipamento se desprenda do deck do navio. As forças de quartering também estão associadas a esse movimento. Quando o equipamento tende a se desprender do deck, o peso do equipamento se concentra em uma menor área de contato com o deck, aumentando assim as forças compressivas no deck do navio. Neste trabalho não foi realizado o cálculo dos movimentos de uplift e nem as forças de quartering para verificar os esforços no deck do navio. 


\section{Embarcação PLSV}

Existem vários modelos e tipos de embarcações utilizados em transportes de cargas marítimas. As embarcações do tipo PLSV - Pipelay Support Vessel são as mais usadas para fazer o carregamento e lançamento tanto de equipamentos e linhas, quanto para fazer instalação de tubulações submarinas. Uma mesma empresa pode ter vários PLSV's diferentes, variando seu tamanho, layout do deck, tipo de dutos a serem lançados — rígidos, flexíveis ou ambos e tipo de lançamento dos dutos - Reel lay, S-Lay e J-Lay - atendendo assim a diferentes tipos de requerimento e executando diferentes tipos de escopo de trabalho. A Figura 2 ilustra uma embarcação PSLV, onde podemos ver os diversos equipamentos de movimentação de cargas no seu deck.

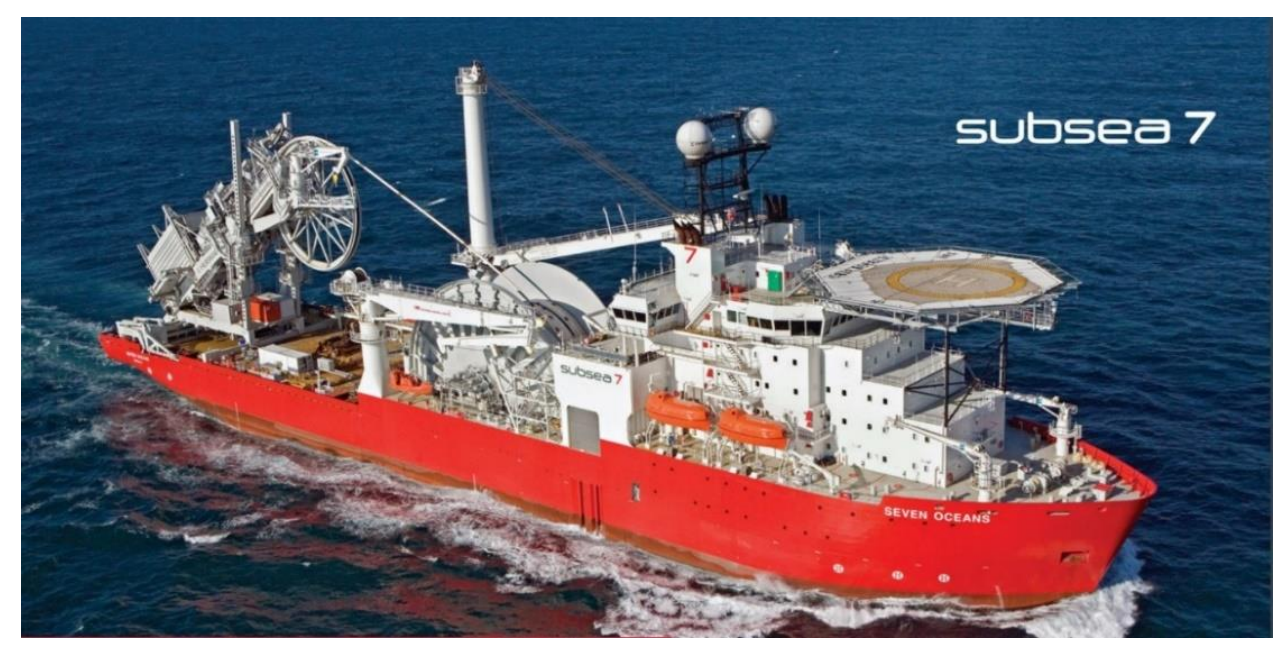

Figura 2 - PLSV Seven Oceans da Subsea 7.

Fonte: https://www.subsea7.com/ [13]

Para avaliar os esforços da embarcação é preciso observar que um navio possui 6 tipos de movimentos, sendo 3 de rotação e 3 de translação. A Figura 3 ilustra os eixos de rotação do navio. Os de rotação são denominados de roll, em que há uma rotação da embarcação sobre seu eixo longitudinal proa-popa, de pitch, que é o movimento de rotação da embarcação sobre seu eixo transversal bombordo-estibordo e de yaw, em que a embarcação tem rotação em seu eixo vertical. Os movimentos lineares são o de heave, sway e surge. Heave é o movimento da embarcação para baixo ou para cima, na direção do seu eixo 
vertical. O movimento de sway é o movimento lateral do navio bombordo-boreste e é causado pelas correntes de água, vento ou pela inércia do navio enquanto gira. O movimento de translação de surge ocorre no eixo longitudinal do navio.

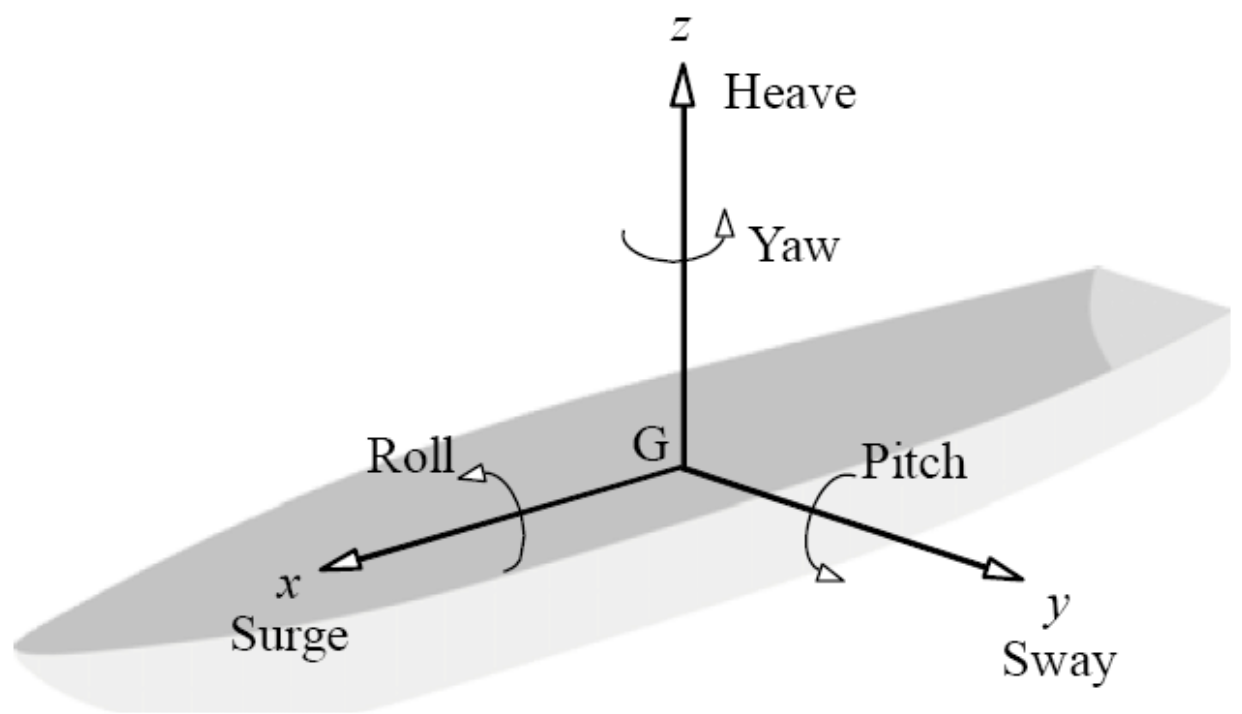

Figura 3- Eixos de movimento de uma embarcação.

Fonte: https://www.researchgate.net/figure/Six-degrees-of-freedom-for-shipmotion fig1 327901742 [14]

A posição longitudinal da carga no navio deve ser selecionada com cautela: quanto mais afastada a carga estiver do centro de rotação do navio, maiores serão as acelerações. Isso significa que as cargas críticas - pesadas ou instáveis devem ser colocadas o mais próximo possível do centro de movimento da embarcação. No entanto, isto nem sempre é possível, pois o layout do deck é geralmente governado por considerações operacionais. A posição transversal da carga na embarcação tem pouca influência nas acelerações calculadas, uma vez que em posições longe do meio do navio, a componente da aceleração causada pelo movimento de pitch é mais dominante que as do movimento de roll.

Outro fator importante no estudo para acomodação dos equipamentos é a posição do equipamento em relação ao moonpool, que é uma abertura na base do casco do navio que permite o acesso à água e de onde é possível lançar equipamentos e até mesmo linhas. Equipamentos muito altos ou que não serão lançados são posicionados mais afastados do moonpool, evitando assim que 
atrapalhe a movimentação dos equipamentos comumente feita por guindaste. A Figura 4 mostra uma linha sendo lançada a partir do moonpool.

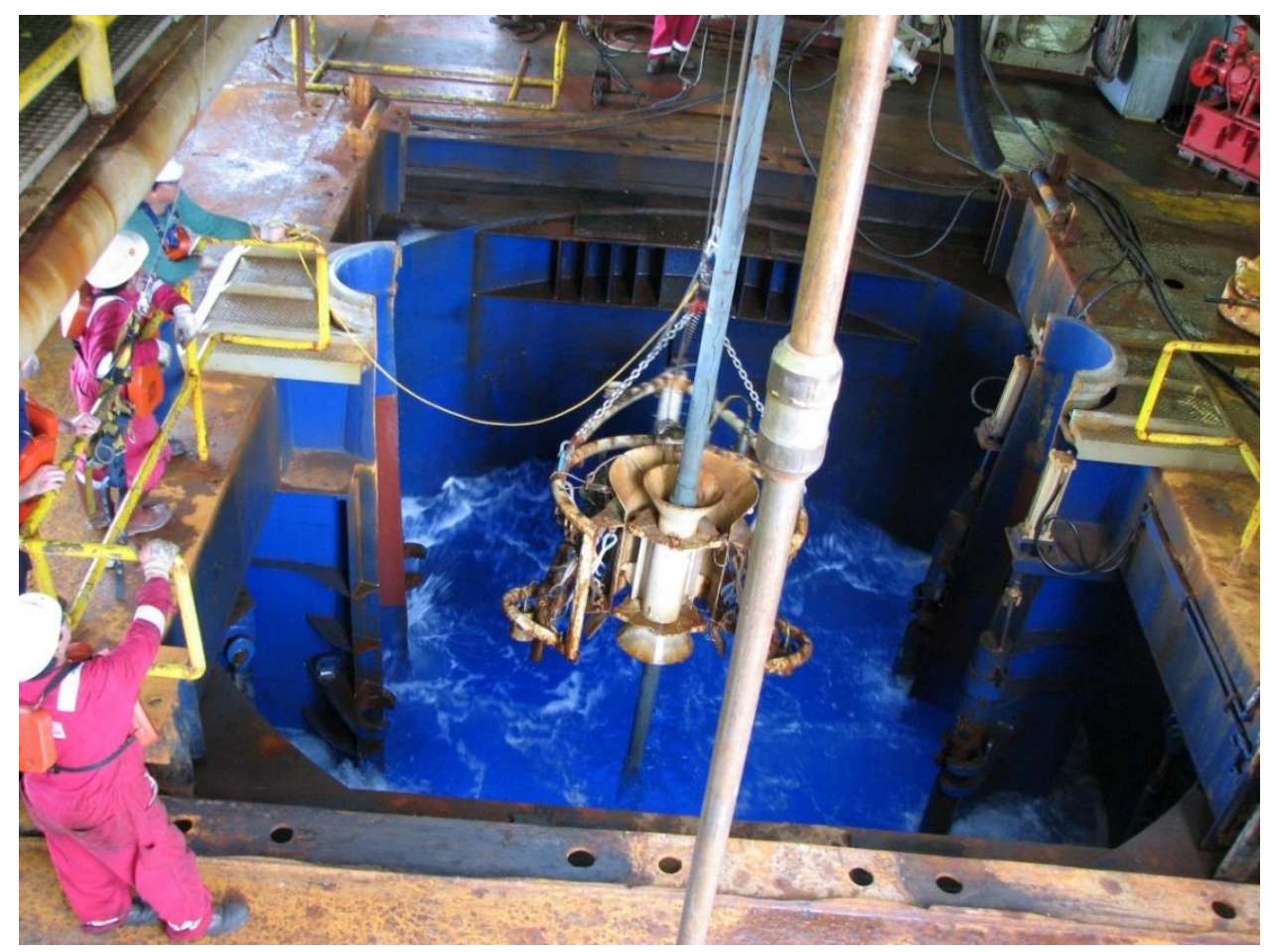

Figura 4 - Linha sendo lançada a partir do moonpool.

Fonte: https://joidesresolution.org/moon-pool-2/ [15]

Por se tratar de uma região crítica, a estrutura dos navios é feita de forma que as acelerações na região do moonpool sejam baixas por questões de segurança. Com isso, os equipamentos posicionados mais perto do moonpool e, consequentemente, mais longes da caverna zero (definida a seguir) serão os que encontrarão menores acelerações.

Um componente estrutural importante na avaliação das cargas são as cavernas, constituídas de chapas em perfil T que dão forma ao casco do navio e sustentam o chapeamento da embarcação. Existem as chamadas cavernas gigantes, que são estruturas mais robustas e espaçadas ao longo da embarcação. Normalmente, uma caverna gigante é colocada entre algum número prédeterminado de cavernas pequenas, como por exemplo, a cada 3 ou 4 cavernas pequenas. Já o espaçamento entre cavernas pequenas é determinado por normas, como a ABS (American Bureau of Shipping) e depende do comprimento 
da embarcação. A primeira caverna gigante de popa à proa da estrutura do navio é denominada de caverna zero, local onde será estabilizado nosso sistema de coordenadas. A Figura 5 ilustra de forma esquemática a estrutura de casco de navio.

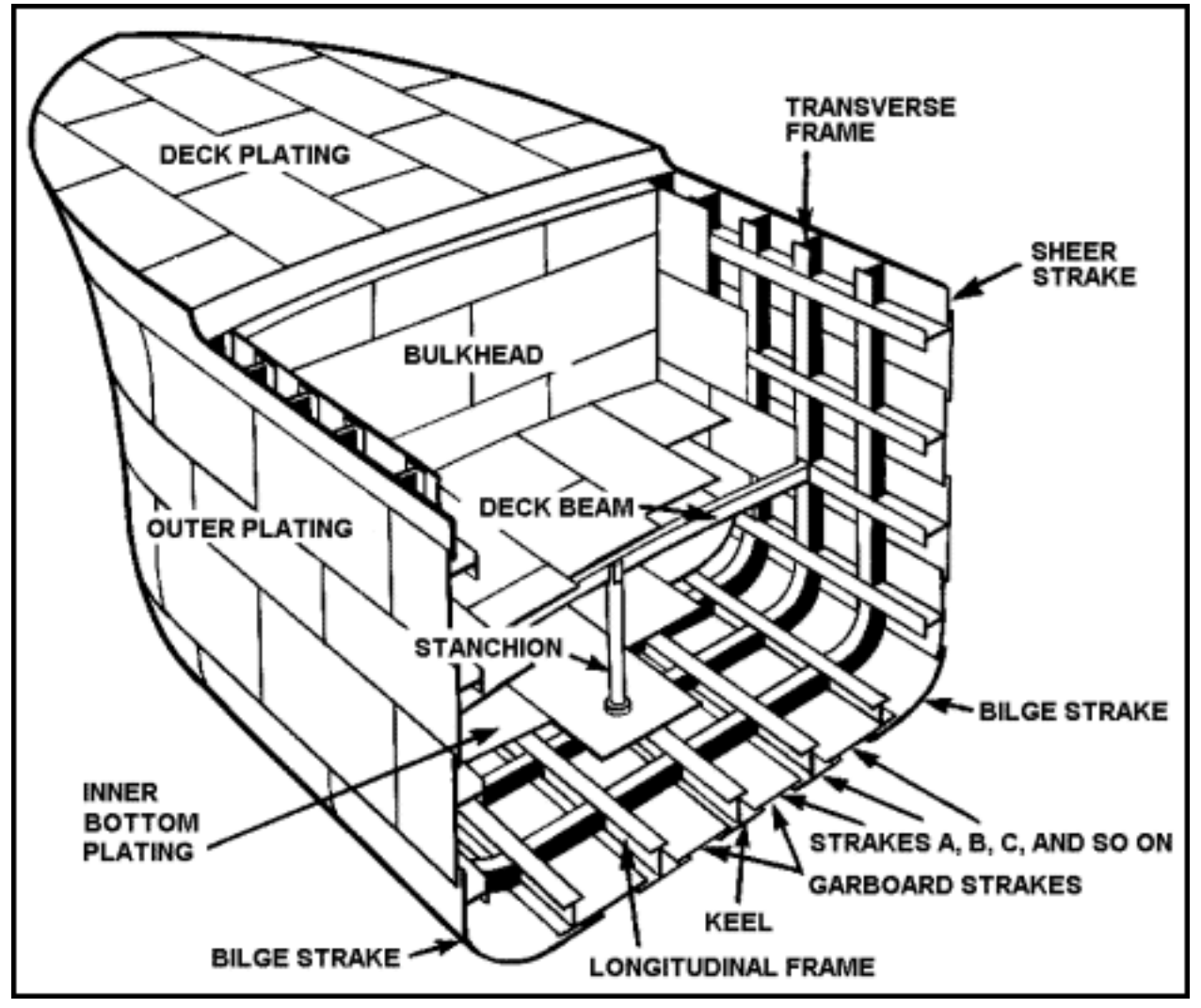

Figura 5 -Estrutura de casco de navio.

Fonte: https://fas.org/man/dod-101/sys/ship/beginner.htm [16] 


\section{Equipamentos transportados}

São diversos os equipamentos que podem ser levados para uma campanha offshore. A seguir, será feita uma breve descrição dos equipamentos que são mais comuns nas campanhas e que serão considerados para o cálculo de seafastening.

\subsection{Concrete mattress - Mantas de concreto}

As mantas de concreto são muito utilizadas na construção do campo subsea para fazer a estabilização de linhas de umbilical lançadas no fundo do mar. Entre diversas aplicações são também colocadas por cima das linhas e as protegem dos movimentos causados por correntes marítimas ou outros agentes externos. Por serem de baixo custo, pela versatilidade e pela facilidade de instalação, é muito comum o uso dessas mantas em operações offshore. A Figura 6 ilustra de forma esquemática uma manta de concreto sendo posicionada acima de um flowline.

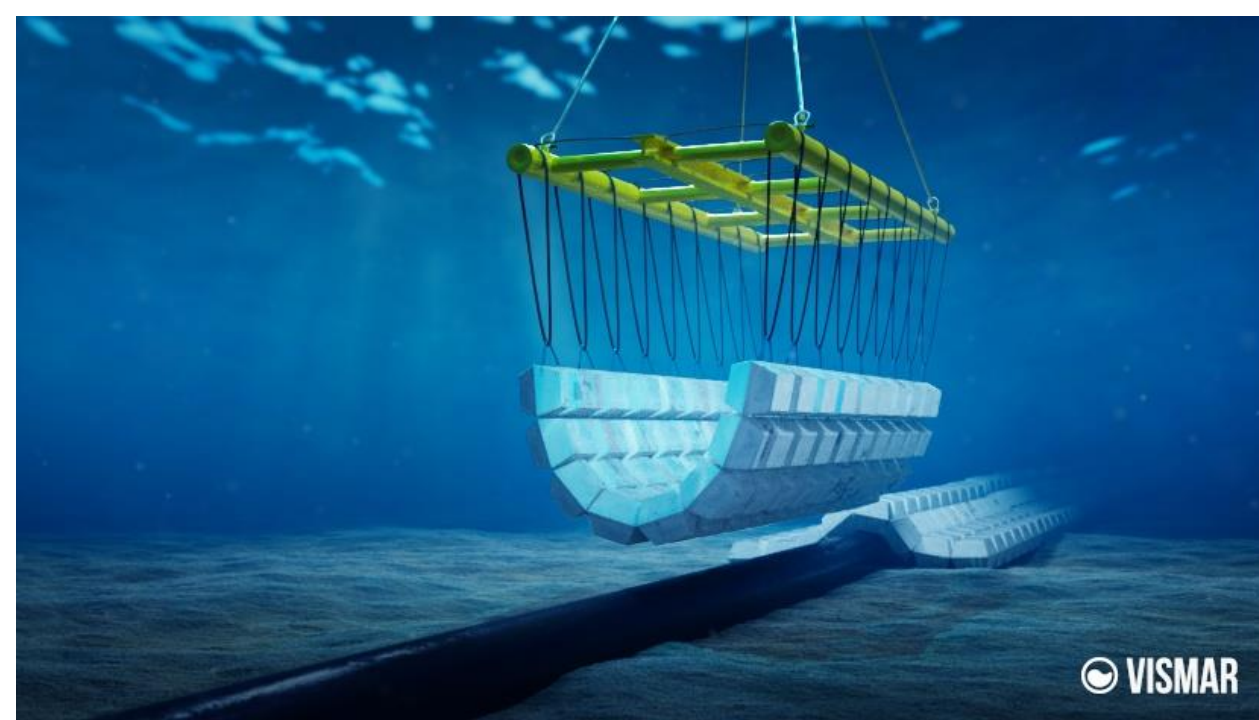

Figura 6 - Simulação de uma manta de concreto sendo posicionada acima de um flowline.

Fonte: https://vismar.co.uk/portfolio/subsea-mattress/ [17] 


\subsection{Modular Spreader Bar - Barra de Içamento}

As barras de içamento ou balancins são equipamentos comumente usados para auxiliar o movimento de cargas e lançamento de equipamentos. Eles se mostram necessários para auxiliar o equilíbrio dos equipamentos, pois separa o ponto de amarração em 2. Para equipamentos mais complexos, podem ser usados sistemas com vários balancins. A Figura 7 mostra um arranjo de içamento no transporte de equipamento.

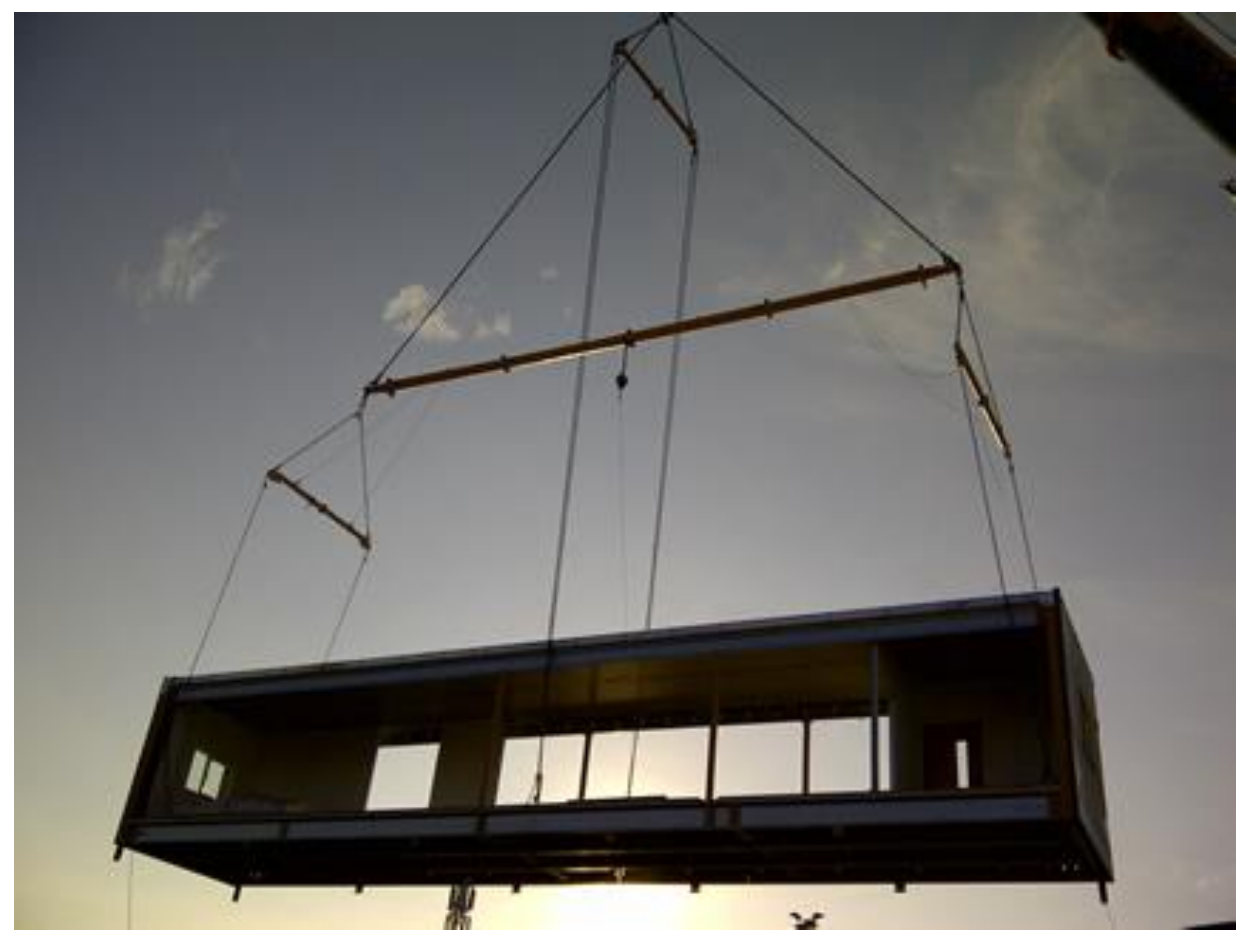

Figura 7 - Arranjo de barras de içamento transportando equipamento.

Fonte: http://www.sectionlift.co.uk/ content/modular spreader beams.html

[18]

\subsection{Pipeline End Termination - PLET}

Os PLETs são estruturas usadas para fazer a conexão ou interligação entre dutos flexíveis e rígidos com um conector vertical ou entre dutos flexíveis e dutos rígidos. O equipamento fica apoiado no fundo do mar e garante que a conexão do 
final da linha de escoamento fique voltada para cima. Na Figura 8 podemos visualizar uma estrutura do PLET pronta para ser içada.

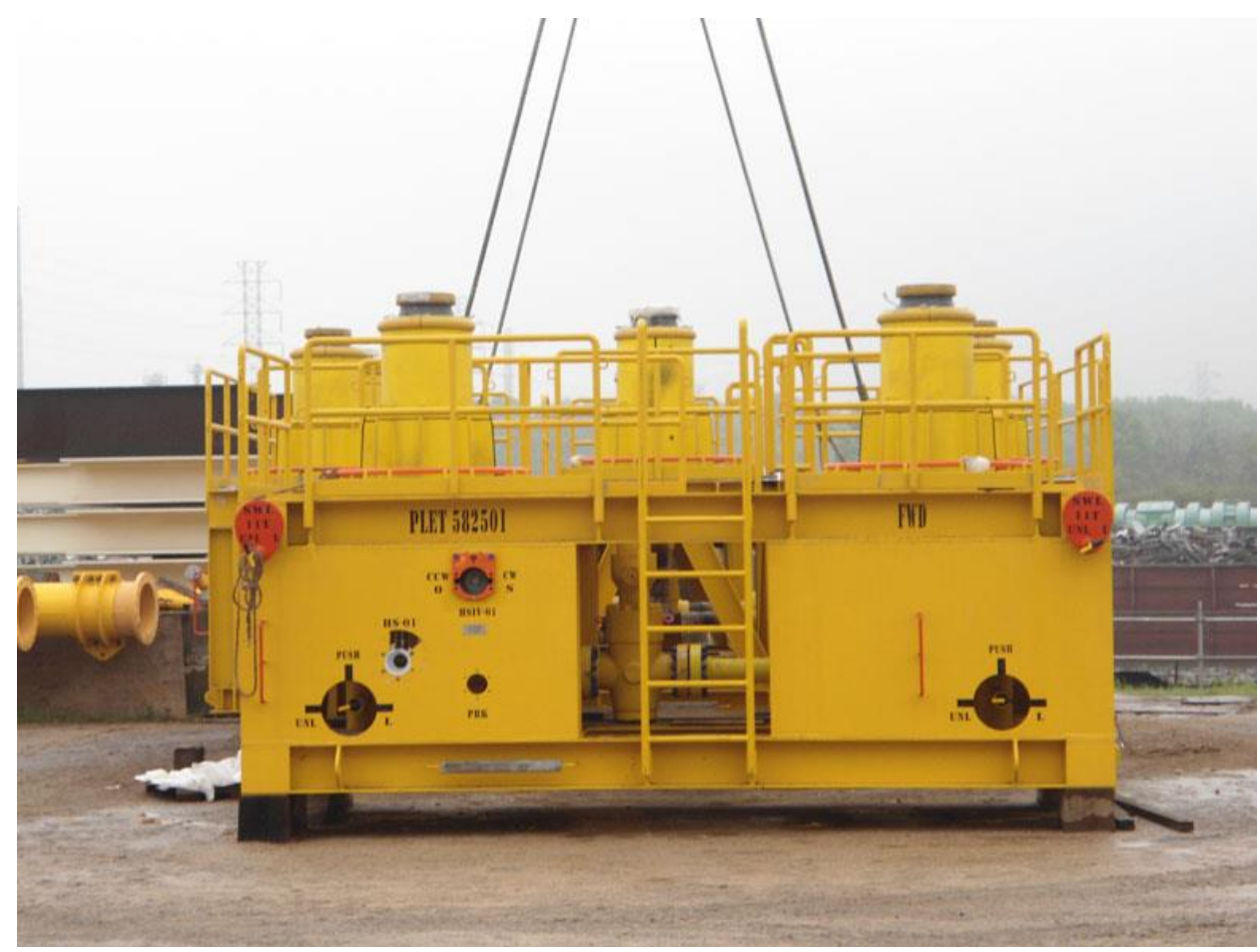

Figura 8 - Pipeline End Termination.

Fonte: http://nfatmala.blogspot.com/2016/02/pipeline-ending-manifoldplemplet.html [19]

\subsection{Pipeline End Manifold - PLEM}

Assim como os PLETs, os PLEMs são colocados na extremidade do duto para fazer a sua conexão com outros tipos de equipamentos. Este equipamento também serve para dividir o fluxo da produção em diferentes direções, que podem, por exemplo, alimentar uma refinaria e uma unidade FPSO (Floating Production Storage and Offloading).

O PLEM é um tipo de manifold simples, posicionado ao final de uma linha, sendo usado para conectar um duto, rígido ou flexível, com uma outra estrutura subsea, como um manifold ou uma árvore de natal molhada. Esta conexão é feita por meio de jumpers, que são trechos curtos de risers ou flowlines, que fazem a 
conexão entre equipamentos. Na Figura 9 podemos visualizar uma estrutura do PLEM, pronta para ser lançada na locação.

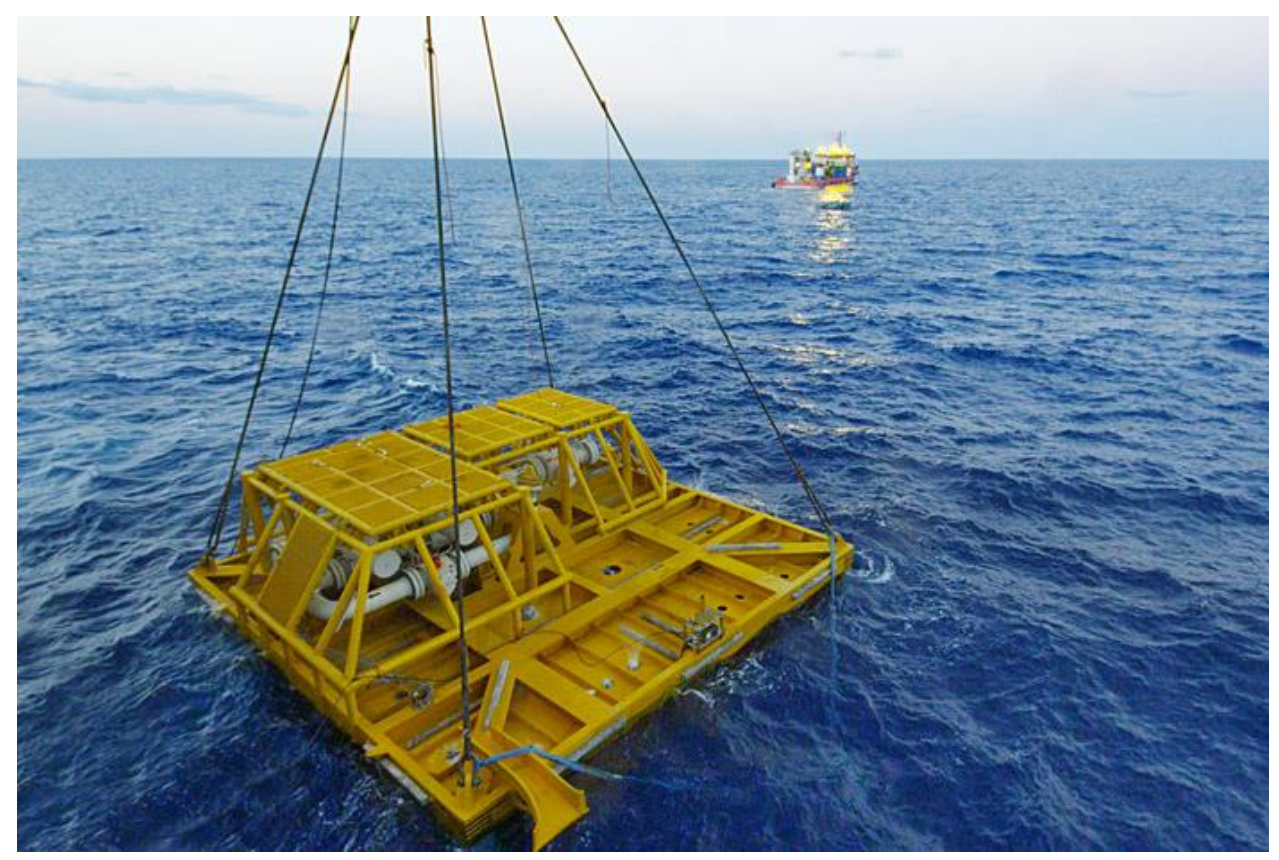

Figura 9 - PLEM sendo lançado.

Fonte: https://sal-heavylift.com/uploads/tx salext/gallery/plem06 01.jpg [20]

\subsection{Pig Launch Receiver - PLR}

PIGs são equipamentos que possuem múltiplas funcionalidades nas campanhas offshore. Por esta razão existem vários tipos de PIGs, a depender do objetivo da aplicação, como PIGs de inspeção, de limpeza e manutenção das linhas. A inspeção das linhas se mostra necessária com o passar dos anos devido à possibilidade de danos comuns ao ambiente marinho, como erosão, corrosões e falhas mecânicas que podem afetar sua integridade. Além disso, a limpeza dos dutos impede interferência no escoamento dos fluidos causada por acúmulo de impurezas dentro do mesmo. A Figura 10 mostra a estrutura de um lançador/recebedor de pig. 


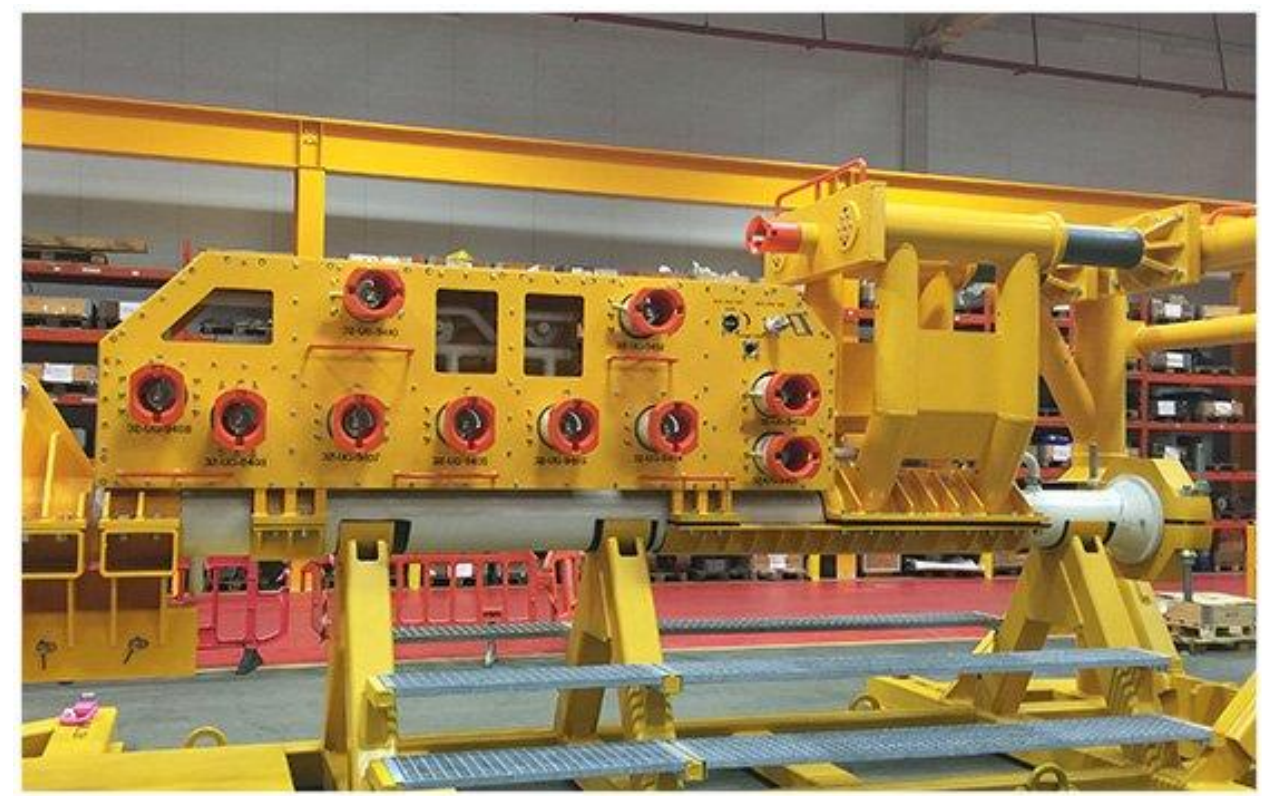

Figura 10 - Pig Launch Receiver.

Fonte: https://www.fogt.com/subsea-pig-launchers-and-receiver-systems-plr [21]

\subsection{Grout Bags}

Os grout bags são sacos preenchidos com rejunte que são colocados para corrigir possíveis buracos ou imperfeições no fundo do mar. Eles evitam que as linhas apoiadas no fundo do mar fiquem com curvaturas devido a essas imperfeições, o que, a longo prazo, pode dificultar o escoamento do fluido ou até mesmo causar a falha da linha. A Figura 11 ilustra uma linha apoiada em um grout bag. 


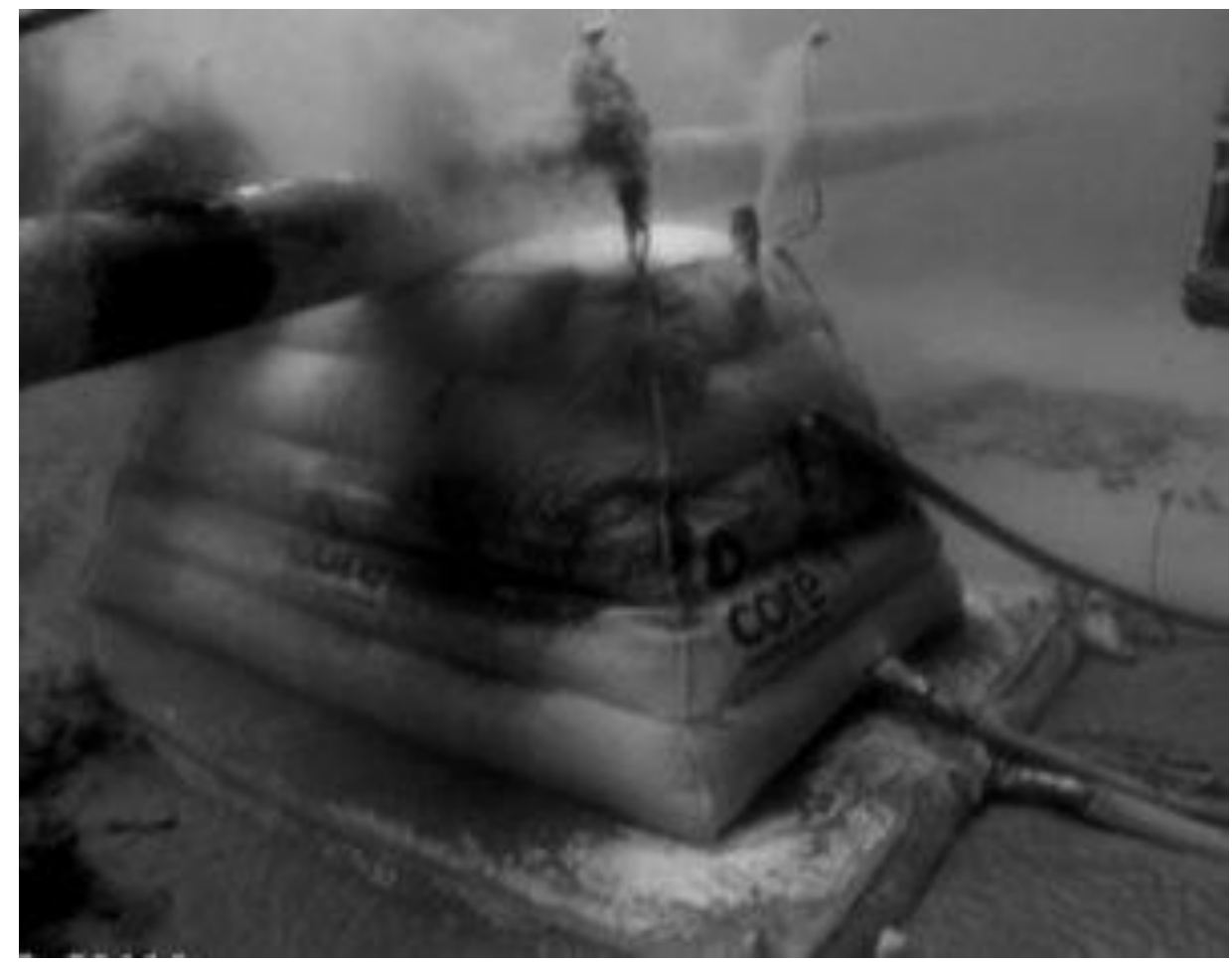

Figura 11 - Grout bag com linha apoiada corrigindo imperfeição no fundo do mar.

Fonte: https://coregrouting.com/services/integrity-repair-grout-bags/ [22]

\subsection{Primary Compressor - Compressor Primário}

Os primary compressor são equipamentos instalados dentro de containers com a função de comprimir o ar ambiente para ser utilizado no pré comissionamento das linhas, na secagem do interior das linhas e outras atividades que necessitam de ar sob pressão no dia a dia da operação. Na Figura 12 podemos ver este equipamento inserido dentro do container. 


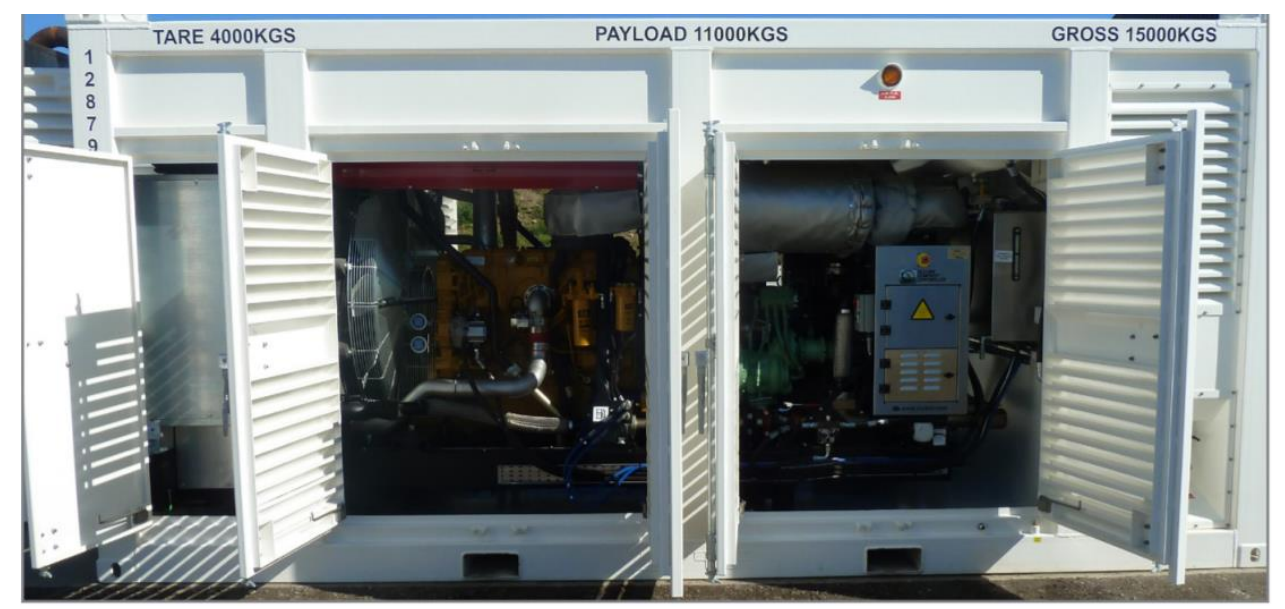

Figura 12 - Interior de um primary compressor usado em campanha offshore.

Fonte:

https://www.halliburton.com/content/dam/ps/public/bc/contents/Data Sheets/152 5SCFM-1300SCFM-Primary-Compressor-H012676.pdf [23]

\subsection{Container}

Container é um equipamento comumente utilizado para acomodar cargas durante o transporte marítimo. Para campanhas offshore; é utilizado para levar diversos objetos e peças, desde ferramentas até grout bags a serem lançados no fundo do mar. Também pode ser utilizado como sala no deck do navio para fazer testes, ou seja, como uma test cabin. Embora possam variar de tamanho, os mais utilizados são os de 20 e 40 pés - 6 e 12 metros - e variam de peso conforme o seu carregamento. Na Figura 13 é apresentado um container com a função de uma test cabin. 


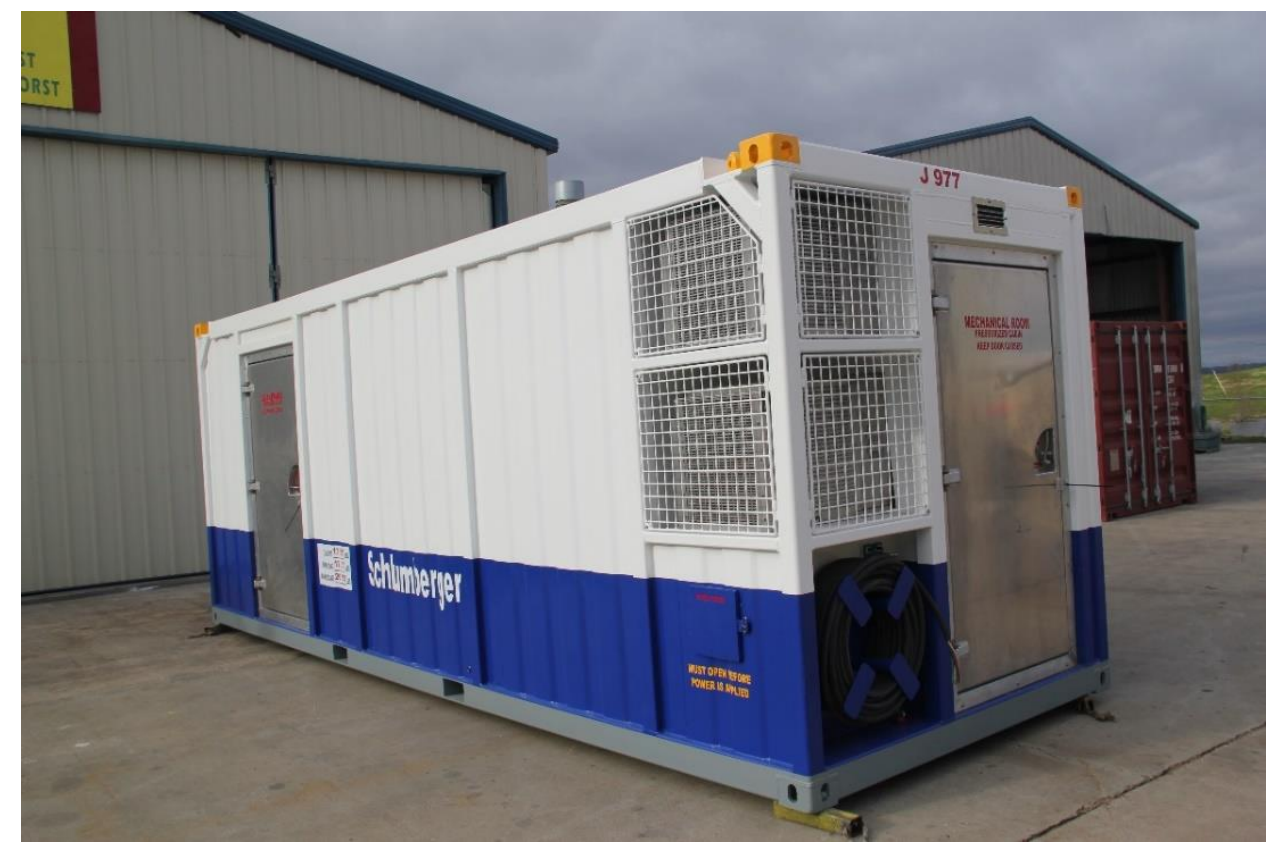

Figura 13 - Test cabin.

Fonte: https://www.oiusa.com/offshore-certified-well-testing-cabin/ [24]

\subsection{Wooden box - Caixas de madeira}

As wooden box são compartimentos de madeira utilizados para transporte de cargas. Possuem tamanhos menores e não são necessariamente padronizados como os containers de metal. São normalmente utilizados para levar ferramentas e outros materiais necessários para a campanha, como cintas, manilhas e esticadores. A Figura 14 apresenta uma wooden box típica. 


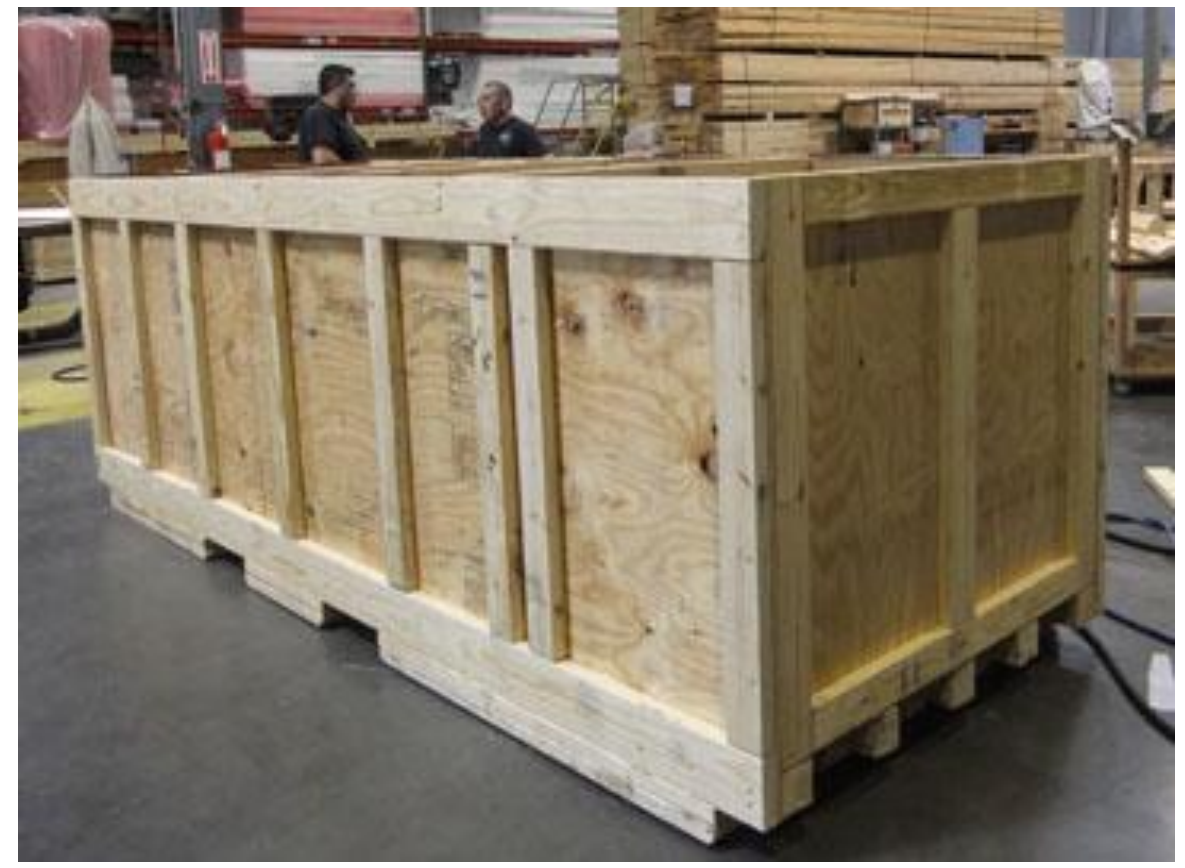

Figura 14 - Wooden box.

Fonte: https://www.meiriggingcrating.com/shipping-crates/wood-shipping-crates/ [25] 


\section{Apresentação teórica}

Neste capítulo, será apresentada, de forma sucinta, uma descrição teórica das principais variáveis necessárias para a realização do estudo de seafastening, tais como: as acelerações, a estabilidade dos equipamentos e os esforços nos batentes.

\subsection{Acelerações}

O cálculo das acelerações é influenciado por diversas variáveis, dentre as quais o tipo de embarcação que vai realizar o transporte dos equipamentos. Por esta razão, a seleção da embarcação terá uma grande influência nas cargas de projeto de seafastening. Como essa simulação está levando em conta as condições normais de navegação, que são encontradas em regiões como o Rio de Janeiro, vamos poder desprezar as forças e pressões resultantes da ação do vento sobre os equipamentos. Essa força é considerável em casos de navegações em regiões críticas, como Atlântico Norte.

Para o cálculo das acelerações foi utilizada uma planilha no software Microsoft Excel e a norma DNV Ship Rules Pt.3 Ch. 1 Sec. 4 Ref [5], que é aplicada para embarcações com 100 metros ou mais de comprimento, seguindo todas as recomendações e requisitos de cálculo propostos. Nessa planilha são inseridos os dados dos equipamentos como peso, altura, posição $x, y$ e $z$ do centro de gravidade do equipamento em relação à caverna zero do navio e altura da base em relação ao deck.

A norma define a necessidade do cálculo de 3 acelerações em função dos movimentos do navio:

- Aceleração ao longo do eixo transversal do navio combinando movimentos de sway e roll

- Aceleração ao longo do eixo longitudinal do navio combinando movimentos de surge e pitch

- Aceleração vertical combinada

A norma DNV Rules for Ships Part 3 Ch. 1 sistematiza o cálculo dessas acelerações conforme as equações a seguir: 
Para navios entre 100 e 300 metros de comprimento, o coeficiente de onda Cw é obtido por

$$
C_{w}=10,75-\left[\frac{300-L}{100}\right]^{\frac{3}{2}}
$$

Em seguida, faremos os cálculos dos coeficientes necessários para calcular as acelerações:

$$
\begin{aligned}
& C_{v}=\frac{\sqrt{L}}{50}, \text { máximo de } 0,2 \\
& C_{v 1}=\frac{V}{\sqrt{L}}, \text { minimo de } 0,8
\end{aligned}
$$

A aceleração comum, que será utilizada para calcular outros componentes como as acelerações do movimento de surge $a_{x}$, o ângulo do movimento de pitch $\theta$, a aceleração do movimento de sway $a_{y}$ e a aceleração vertical combinada $a_{v}$ é calculada da seguinte forma:

$$
a_{0}=\frac{3 \cdot C_{w}}{L}+C_{v} \cdot C_{v 1}
$$

Para realizar o cálculo da aceleração do movimento de surge, da aceleração vertical combinada e do ângulo e período do movimento de pitch, é necessário o coeficiente de block do navio, que foi estimado dados as medidas do navio como $C_{b}=0,56$.

A aceleração do movimento de surge ' $a x$ ', o ângulo ' $\theta$ ' e o período ' $T$ p' do movimento de pitch são calculados a partir das seguintes equações:

$$
\begin{gathered}
a_{x}=0,2 \cdot g_{0} \cdot a_{0} \cdot \sqrt{C_{b}} \\
\theta=0,25 \cdot \frac{a_{0}}{C_{b}}
\end{gathered}
$$




$$
T_{p}=1,8 . \sqrt{\frac{L}{g_{0}}}
$$

Para o cálculo da distância do centro de massa do equipamento ao eixo de rotação de pitch e a aceleração tangencial, é necessário definir a seção do eixo de rotação. A norma DNV a define como sendo localizada na posição $0,45 \mathrm{~L}$ do navio. Com $L=125 \mathrm{~m}$, o eixo de rotação de pitch fica definido na posição $56,25 \mathrm{~m}$.

O cálculo da distância do centro de massa do equipamento ao eixo de rotação longitudinal é realizado a partir da posição $x$ do eixo de rotação do navio $x_{e r}$, da posição $z$ do centro de gravidade do navio $z_{c g}$ e das posições $x$ e y do centro de gravidade do equipamento, respectivamente $x_{i}$ e $z_{i}$ :

$$
R_{p}=\sqrt{\left(x_{e r}-x_{i}\right)^{2}+\left(z_{i}+z_{c g}\right)^{2}}
$$

Para o cálculo da aceleração tangencial associada ao movimento de pitch $a_{p}$, vamos utilizar os valores obtidos nas Equações(6),(7) e (8):

$$
a_{p}=\theta \cdot\left[\frac{2 \pi}{T_{p}}\right]^{2} \cdot R_{p}
$$

A norma recomenda usar a projeção vertical de $R_{p}$, denominado $R_{p x}$, na Equação (9). Desta forma, obtemos diretamente a componente longitudinal da aceleração de pitch $a_{p x}$ :

$$
a_{p x}=\theta \cdot\left[\frac{2 \pi}{T_{p}}\right]^{2} \cdot R_{p x}
$$

Podemos calcular a aceleração ao longo do eixo longitudinal combinando os movimentos de sway e surge, $\mathrm{a}_{\mathrm{l}}$, a partir das equações anteriores:

$$
a_{l}=\sqrt{a_{x}^{2}+\left(g_{0} \cdot \sin (\theta)+a_{p x}\right)^{2}}
$$

A aceleração associada ao movimento de sway é dada pela seguinte equação: 


$$
a_{y}=0,3 \cdot g_{0} \cdot a_{0}
$$

Para calcular o ângulo do movimento de roll, $\varphi$, e o período do movimento de roll, Tr, é necessário o coeficiente auxiliar 'c', obtido por:

$$
c=\left(1,25-0,025 * T_{r}\right) \cdot k
$$

onde, o coeficiente k é um fator definido pela norma e, para navios que possuem quilha no porão, denominados bilge keel, é igual a 1.

O ângulo e período do movimento de roll são dados pelas equações:

$$
\begin{gathered}
\varphi=\frac{50 c}{B+75} \\
T_{r}=\frac{2 \cdot k_{r}}{\sqrt{G M}}
\end{gathered}
$$

onde o fator $k_{r}$ é o raio de giração de roll do navio. A norma define que esse fator como 0,39 B em navios com distribuição uniforme de massa no sentido transversal. No caso, com o tamanho da boca moldada B igual a $27 \mathrm{~m}$, temos que o fator $k_{r}$ é igual a $10,53 \mathrm{~m}$.

O coeficiente $G M$ é a altura do metacentro da embarcação também depende do tamanho da boca moldada do navio. Pela norma, esse coeficiente é igual a $0,12 B$, o que resulta e igual a $3,50 \mathrm{~m}$.

A distância, em metros, do centro de massa do equipamento ao eixo de rotação ' $R_{r}$ ' foi calculada da seguinte forma:

$$
R_{R}=\sqrt{y_{i}^{2}+\left(z_{i}+z_{c g}\right)^{2}}
$$

onde $z_{c g}$ é a distância vertical do centro de gravidade do navio abaixo do nível do deck e, para esta embarcação, teremos $z_{c g}=6,00 \mathrm{~m}$. 
Desta forma, foi possível obter a aceleração tangencial devido ao movimento de roll 'ar', como sendo:

$$
a_{r}=\varphi \cdot\left[\frac{2 \pi}{T_{r}}\right]^{2} \cdot R_{R}
$$

A norma também sugere usar $R_{R y}$, que é a projeção vertical de $R_{R}$ na Equação (17). Com isso, obtemos diretamente a componente transversal da aceleração de roll 'ary':

$$
a_{r y}=\varphi \cdot\left[\frac{2 \pi}{T_{r}}\right]^{2} \cdot R_{R y}
$$

Com isso, conseguimos calcular a aceleração ao longo do eixo transversal do navio da seguinte forma:

$$
a_{t}=\sqrt{a_{y}^{2}+\left(g_{0} \cdot \sin (\varphi)+a_{r y}\right)^{2}}
$$

A aceleração vertical combinada é calculada, segundo a norma, por:

$$
a_{v}=\frac{k_{v} \cdot g_{0} \cdot a_{0}}{C_{b}}
$$

onde $k_{v}$, fator de distribuição da aceleração, varia com a posição do equipamento e é dado por: 


$$
\begin{aligned}
\mathrm{k}_{\mathrm{v}} & =1.3 \text { aft of A.P. } \\
& =0.7 \text { between } 0.3 \mathrm{~L} \text { and } 0.6 \mathrm{~L} \text { from A.P. } \\
& =1.5 \text { forward of F.P. }
\end{aligned}
$$

Between mentioned regions $\mathrm{k}_{\mathrm{v}}$ shall be varied linearly

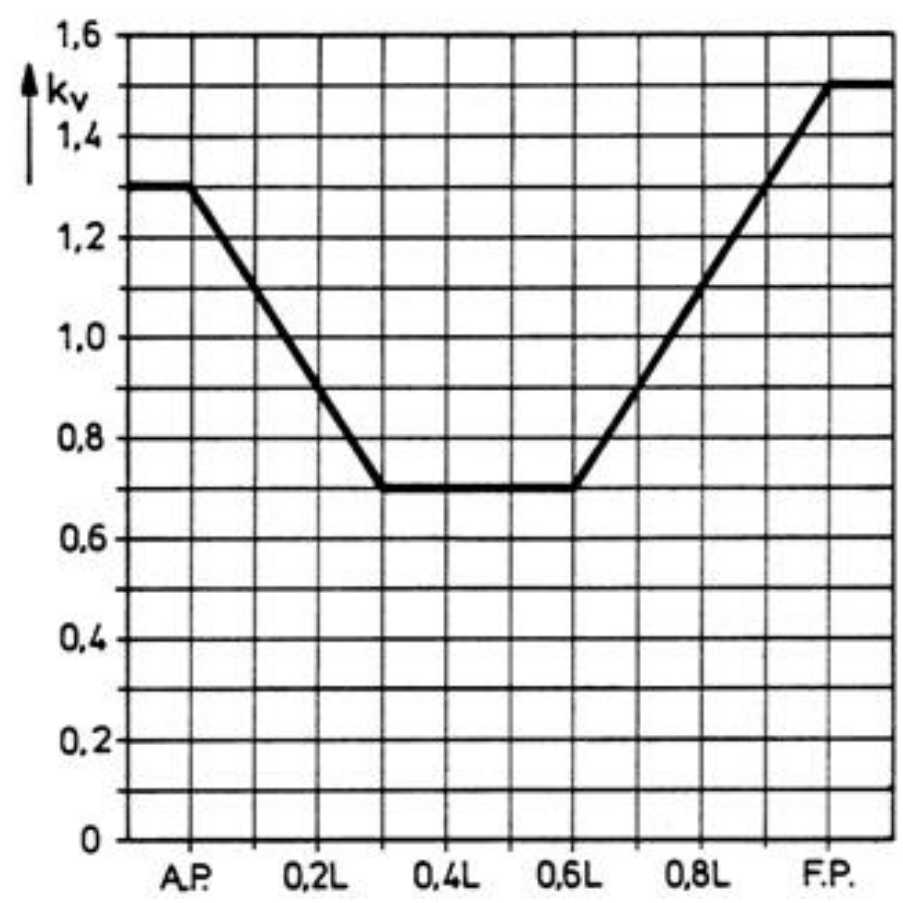

Figura 15 - Valor de kv em determinada posição Fonte: Norma DNV Rules for Ships [1]

Com todas as acelerações calculadas e utilizando a seção C500 do Capítulo 4 da norma DNV Rules for Ships, podemos calcular os valores para as forças atuantes nos equipamentos conforme as seguintes equações:

- Força vertical em combinação com força transversal:

$$
F_{y z}=g_{0} \cdot M
$$

- Força transversal em combinação com força vertical:

$$
F_{y y}=0,67 \cdot a_{t} \cdot M
$$


- Força vertical em combinação com força longitudinal:

$$
F_{x z}=\left(g_{0}+0,5 \cdot a_{v}\right) \cdot M
$$

- Força longitudinal em combinação com força vertical:

$$
F_{x x}=\left(0,67 \cdot a_{l}\right) \cdot M
$$

\subsection{Estabilidade}

O estudo da estabilidade dos equipamentos no deck foi realizado com base na norma EN 12195-1, que apresenta diferentes tipos de amarração e verifica se o equipamento estará estável ou não usando conceitos básicos da mecânica. $A$ norma também é utilizada para calcular a estabilidade de equipamentos em transporte rodoviário e, por esta razão, possui diversos modelos de amarração. Os tipos mais comuns de amarração utilizadas no seafastening são:

- Diagonal lashing to avoid tilting

- Frictional lashing to avoid sliding

- Frictional lashing to avoid tilting

O teste estabilidade/instabilidade é comum para todos os tipos de amarração descritos acima e indica se o equipamento ficará na condição estável. A Figura 16 ilustra o arranjo usado para o teste de estabilidade, onde:

1. Centro de gravidade

2. Equipamento

3. Ponto de tombamento 


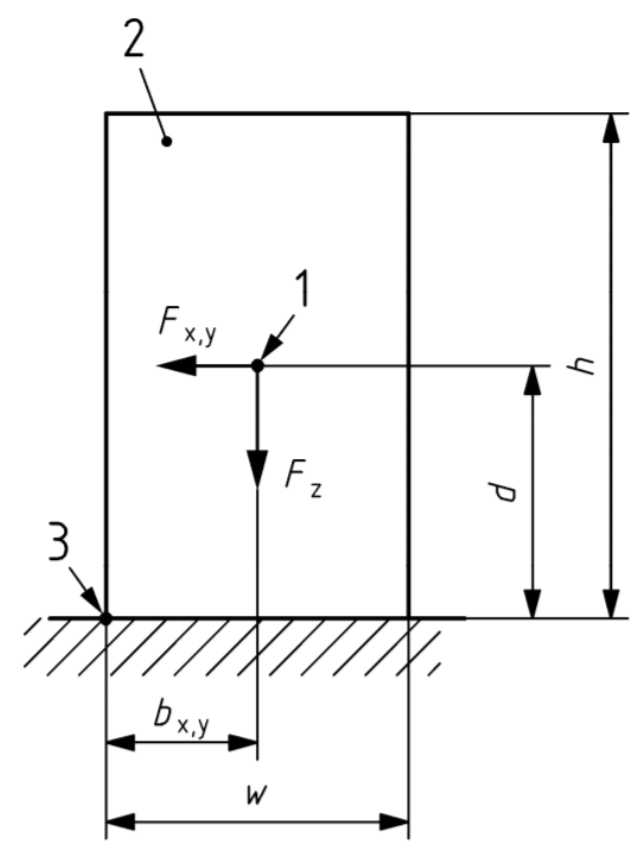

Figura 16 - Teste de estabilidade da norma EN12195-1

Fonte: Norma EN12195-1 [2]

O critério normativo para avaliar se o equipamento ficará estável no deck do navio pode ser descrito conforme a seguinte equação:

$$
F_{z} \cdot b_{x, y}>F_{x, y} \cdot d
$$

Simplificando a equação anterior:

$$
b_{x, y}>\frac{c_{x, y}}{c_{z}} \cdot d
$$

A norma EN12195-1 usa certos coeficientes de forma que a aceleração possa ser representada por uma equação dada por:

$$
g_{0} \cdot c_{x, y, z}=a_{x, y, z}
$$

No cálculo apresentado neste trabalho, não usaremos os coeficientes de aceleração dados pela norma EN12195-1, pois eles são muito abrangentes para 
esse caso de estudo de seafastening, em que temos uma embarcação grande e que as acelerações dos equipamentos variam conforme a posição de cada um deles. Usaremos os valores de aceleração calculados anteriormente pela norma DNV Rules for Ships Pt.3 Ch.1.

\subsection{Amarração diagonal para evitar o tombamento - Diagonal lashing to avoid tilting}

A amarração diagonal utilizada para evitar o tombamento é o tipo de amarração que é feita diretamente no equipamento, sendo presa por meio de cintas com tensionadores e D-rings soldados no deck do navio. Estas amarrações são feitas diagonalmente para que possam impedir o movimento do equipamento, tanto na direção transversal quanto na longitudinal. A Figura 17 ilustra o arranjo deste tipo de amarração, com os principais componentes e dispositivos:

1. Cintas

2. Centro de gravidade

3. Ponto de tombamento
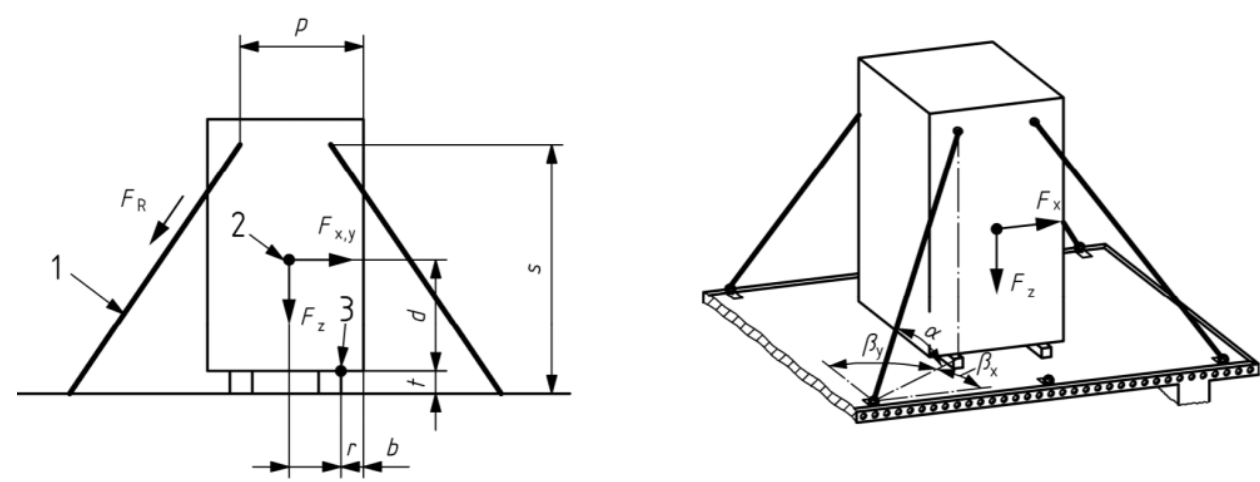

Figura 17 - Amarração direta diagonal

Fonte: Norma EN12195-1 [2]

Nesse projeto, não usaremos calços como mostrados na Figura 17, pois eles são normalmente utilizados para carregar equipamentos pesados em embarcações com deck de madeira, como indicado na Figura 1. Para este projeto, como temos um navio com deck de aço, não utilizaremos esse tipo de calço. 
A equação de equilíbrio para o sistema com esse tipo de amarração é:

m. g. $c_{x, y} \cdot d-m \cdot g \cdot c_{z} \cdot b-F_{r} \cdot\left(\sum_{i=1}^{n}\left[\cos \left(\alpha_{i}\right) \cdot \cos \left(\beta_{x_{i} y_{i}}\right) \cdot\left(s_{i}-t_{i}\right)\right]+\sum_{i=1}^{n}\left[\sin \left(\alpha_{i}\right) \cdot\left(p_{i}-r_{i}\right)\right]\right)=0$

Com isso, podemos obter a força $\left(F_{r}\right)$, na cinta, necessária para que não haja o tombamento, conforme a seguir:

$$
F_{r} \geq \frac{m \cdot g \cdot c_{x, y} \cdot d-m \cdot g \cdot c_{z} \cdot b}{\left(\sum_{i=1}^{n}\left[\cos \left(\alpha_{i}\right) \cdot \cos \left(\beta_{x_{i}, y_{i}}\right) \cdot\left(s_{i}-t_{i}\right)\right]+\sum_{i=1}^{n}\left[\sin \left(\alpha_{i}\right) \cdot\left(p_{i}-r_{i}\right)\right]\right)}
$$

Como no nosso caso vamos utilizar apenas cintas simetricamente amarradas no equipamento, podemos simplificar esta equação para:

$$
F_{r} \geq m \cdot g \cdot \frac{c_{x, y} \cdot d-c_{z} \cdot b}{2 *\left[\cos (\alpha) \cdot \cos \left(\beta_{x, y}\right) \cdot(s-t)+\sin (\alpha) \cdot(p-r)\right]}
$$

\subsubsection{Amarração por atrito para evitar o deslizamento - Frictional lashing to avoid sliding}

A amarração por atrito tem como objetivo evitar o deslizamento do equipamento e é feita com a cinta passando por cima do equipamento com tensionadores, e presa no deck do navio por meio de $D$-rings. Como a amarração é feita somente por atrito, normalmente é usada para equipamentos que são mais leves e que também possuam uma geometria que possibilite que a cinta passe por cima sem danificá-los, o que muitas vezes não é possível. A Figura 18 ilustra o arranjo deste tipo de amarração, com os principais componentes e dispositivos:
1. Equipamento
2. Eixo vertical
3. Cinta
4. Tensionador 
5. Eixo transversal

6. Ponto de amarração no deck

7. Plano horizontal

8. Eixo longitudinal

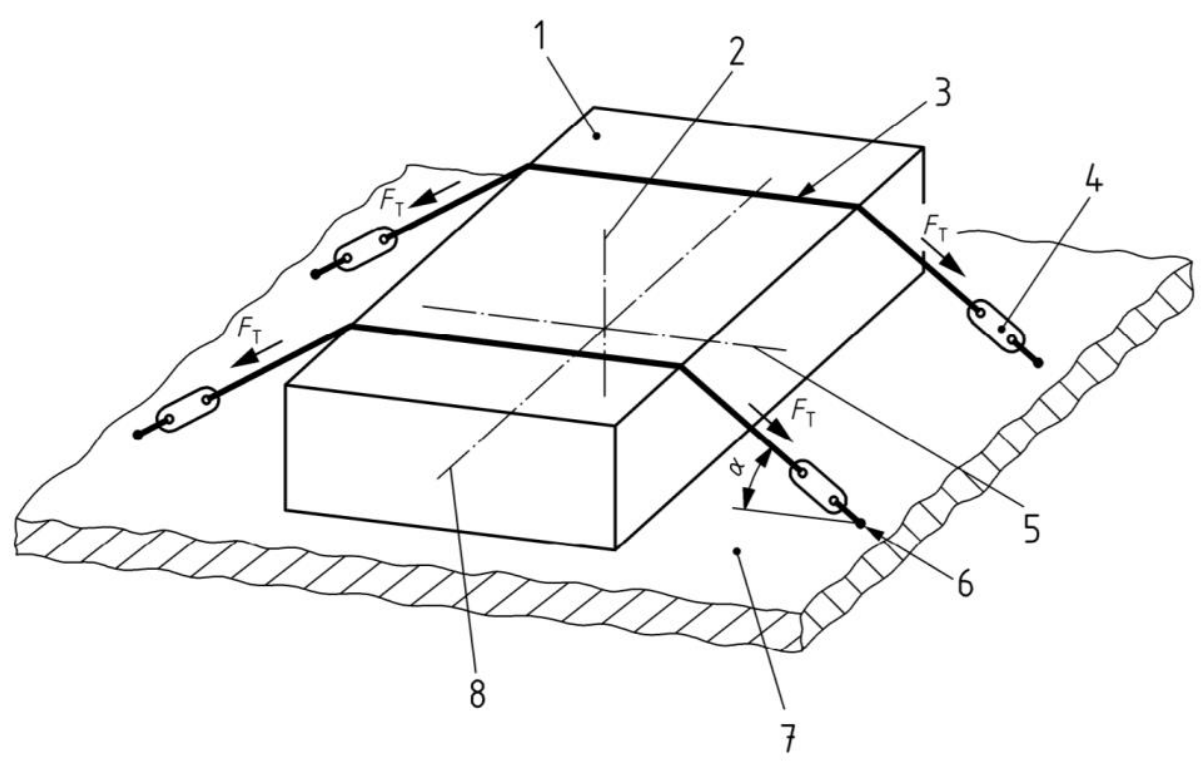

Figura 18 - Amarração por atrito para evitar deslizamento Fonte: Norma EN12195-1 [2]

Podemos obter a capacidade mínima da cinta com este tipo de amarração utilizando a equação a seguir:

$$
F_{T} \geq \frac{\left(c_{x, y}-\mu \cdot c_{z}\right) \cdot m \cdot g}{2 n \cdot \mu \cdot \sin (\alpha)} \cdot f_{s}
$$

\subsubsection{Amarração por atrito para evitar o tombamento - Frictional lashing to avoid tilting}

A amarração por atrito para evitar o tombamento é um complemento do tipo de amarração por atrito anterior. Neste tipo de amarração são utilizados stoppers soldados no deck do navio para impedir que o equipamento deslize, necessitando 
então a ação de segurar/restringir o movimento de tombamento dos equipamentos. Os stoppers soldados no deck, junto ao equipamento, são equipados com manilhas que prendem as cintas que passam por cima do equipamento. A Figura 19 ilustra de forma esquemática as componentes de força da amarração por atrito.

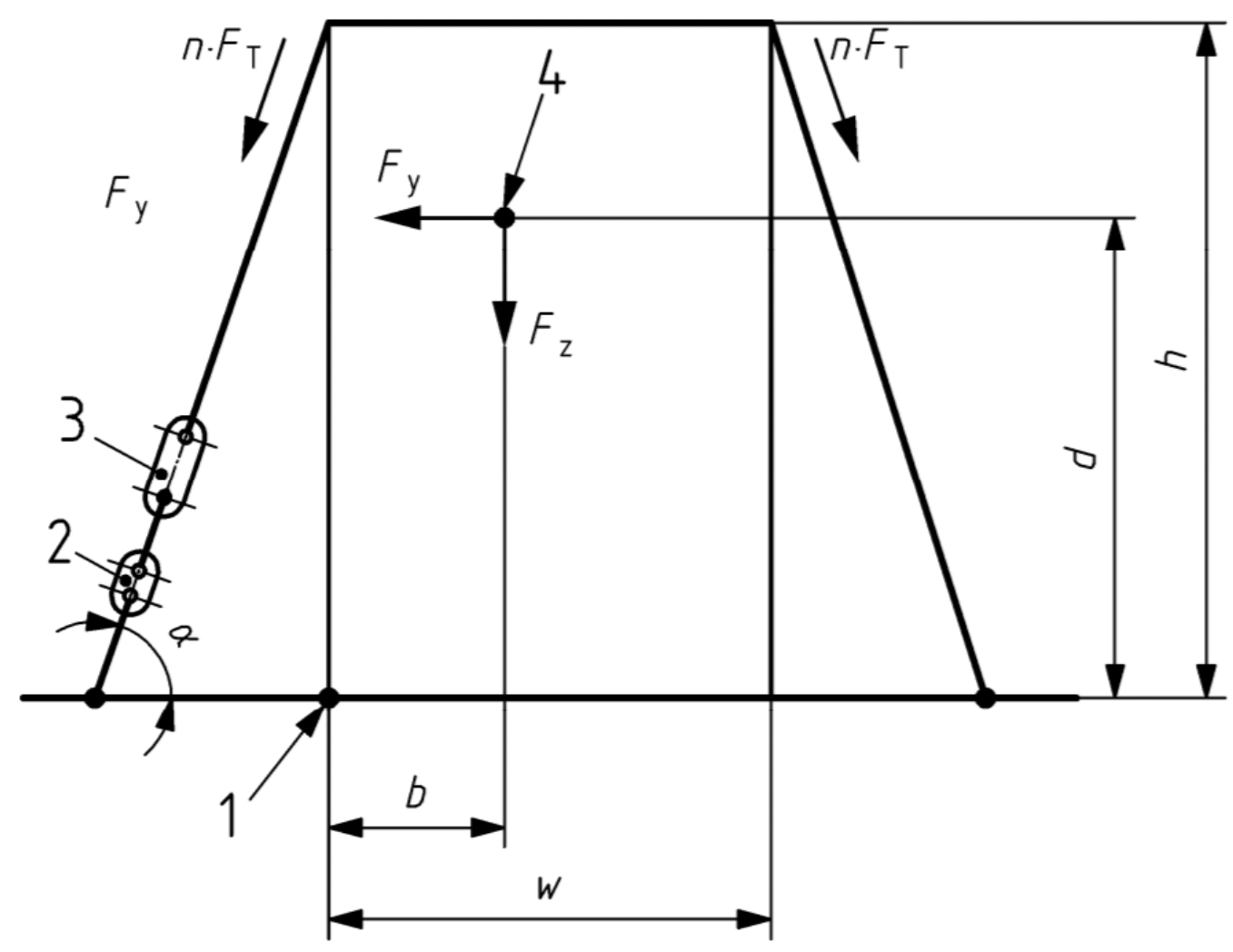

Figura 19 - Amarração por atrito para evitar o tombamento

Fonte: Norma EN12195-1 [2]

As equações que garantem o equilíbrio do sistema são diferentes para as direções transversal e longitudinal conforme mostrado a seguir:

- Para o equilíbrio do sistema na direção transversal:

$$
n \cdot F_{T} \geq \frac{m \cdot g \cdot\left(c_{y} \cdot d-c_{z} \cdot b\right)}{w \cdot \sin (\alpha)} \cdot f_{s}
$$


Em situações em que o centro de massa do corpo é simétrico, ou seja, $b=$ $w / 2$ e $d=h / 2$, a Equação (32) pode ser reescrita como:

$$
F_{T} \geq \frac{m \cdot g}{2 n \cdot \sin (\alpha)} \cdot\left(c_{y} \frac{h}{w}-c_{z}\right) \cdot f_{s}
$$

- Para o equilíbrio do sistema na direção longitudinal:

$$
2 n \cdot F_{T} \cdot \sin (\alpha) \cdot \frac{l}{2} \geq m \cdot g \cdot\left(c_{x} \cdot d-c_{z} \cdot b\right) \cdot f_{S}
$$

Reescrevendo a equação 34 em função de $F_{T}$ temos:

$$
F_{T} \geq \frac{m \cdot g \cdot\left(c_{x} \cdot d-c_{z} \cdot b\right)}{2 n \cdot \sin (\alpha) \cdot \frac{l}{2}} \cdot f_{S}
$$

\subsection{Componentes auxiliares}

\subsubsection{Batentes}

Os batentes mais utilizados são os chamados de stoppers with face plate, que são duas chapas soldadas, uma na transversal e outra na longitudinal. Eles são soldados no deck do navio em contato com o equipamento para que não haja movimento do mesmo. As Figura 20 e Figura 21 ilustram este tipo de batente, seu posicionamento e detalhes da junta soldada entre as chapas. 


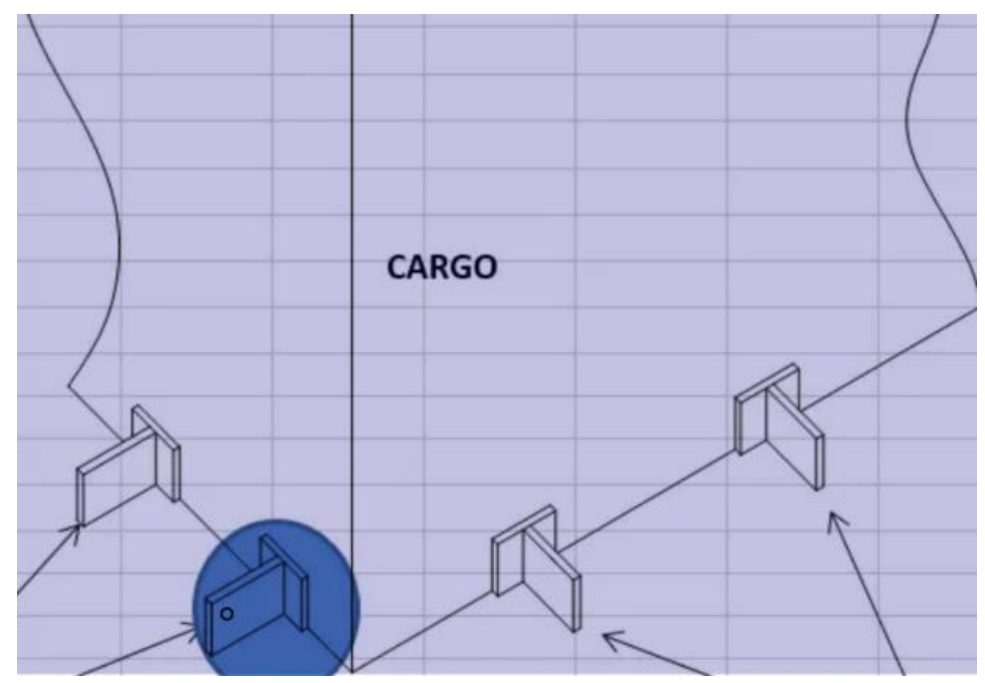

Figura 20 - Batentes posicionados em contato com o equipamento para evitar o movimento

Fonte: https://www.thenavalarch.com/cargo-stoppers-why-they-are-critical-andhow-to-design-them/ [26] - Com modificações feitas pelo autor

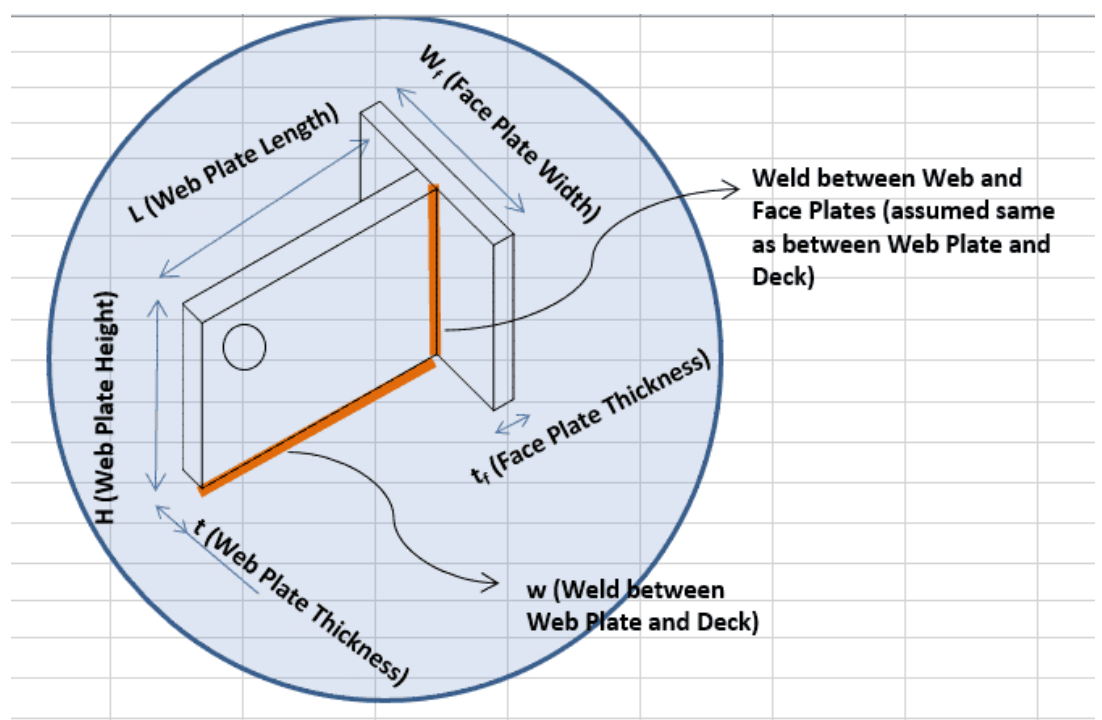

Figura 21 - Dimensões do batente e do cordão de solda

Fonte: https://www.thenavalarch.com/cargo-stoppers-why-they-are-critical-andhow-to-design-them/ [26] - Com modificações feitas pelo autor

Os batentes possuem um olhal para que seja possível colocar uma manilha e permitir passar uma cinta por cima do equipamento. Assim, caso haja um 
movimento de uplift, que é quando o equipamento tende a se desprender do deck do navio, o equipamento terá seu deslocamento restringido.

\subsubsection{Tensões no cordão de solda}

Para calcular os esforços nas soldas foi utilizada a norma DNVGL-OS-C102, também da Det Norske Veritas. Esta norma possui dois métodos de cálculo: o WSD (Working Stress Design) e o LRFD (Load and Resistance Factor Design). O método WSD trabalha com tensões no regime elástico do metal, que são menores do que as tensões no regime plástico calculadas no LRFD. Isto torna o método WSD mais utilizado para calcular estes esforços nos componentes auxiliares. A Figura 22 ilustra graficamente a relação de carga versus deslocamento destes métodos, representando os métodos WSD em vermelho, LRFD em amarelo e de tensão nominal em azul.

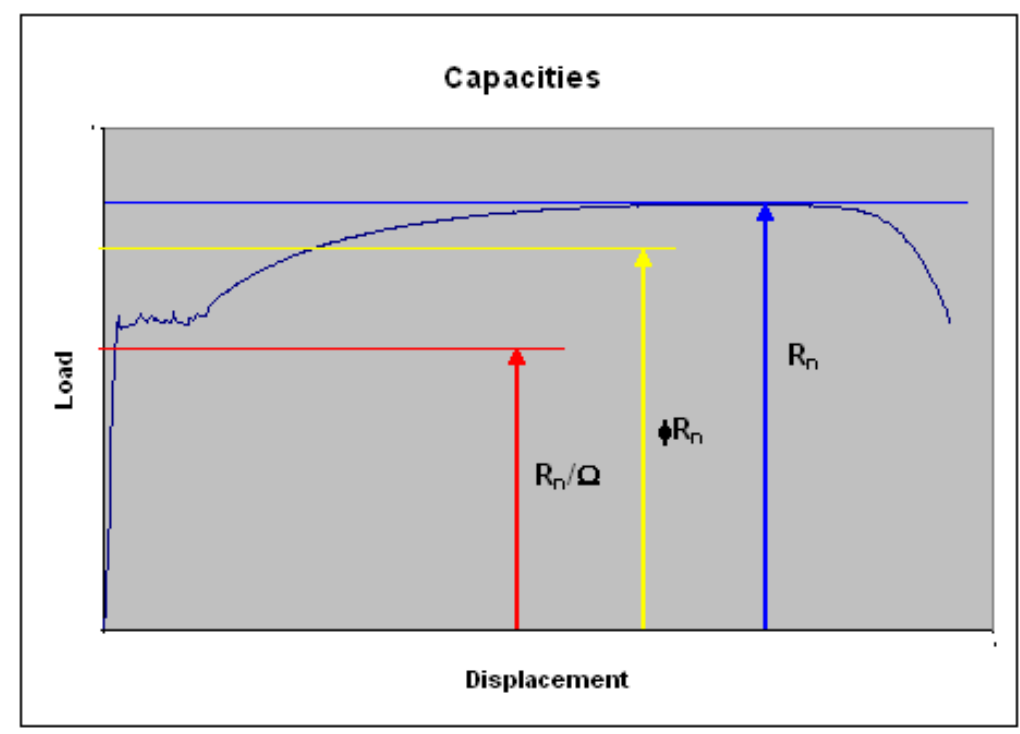

Figura 22 - Gráfico carga versus deslocamento

Fonte: https://www.bgstructuralengineering.com/BGDesign/BGDesign05.htm [27]

A Figura 23 ilustra esquematicamente a seção da garganta da solda, revelando a orientação das tensões atuantes: 


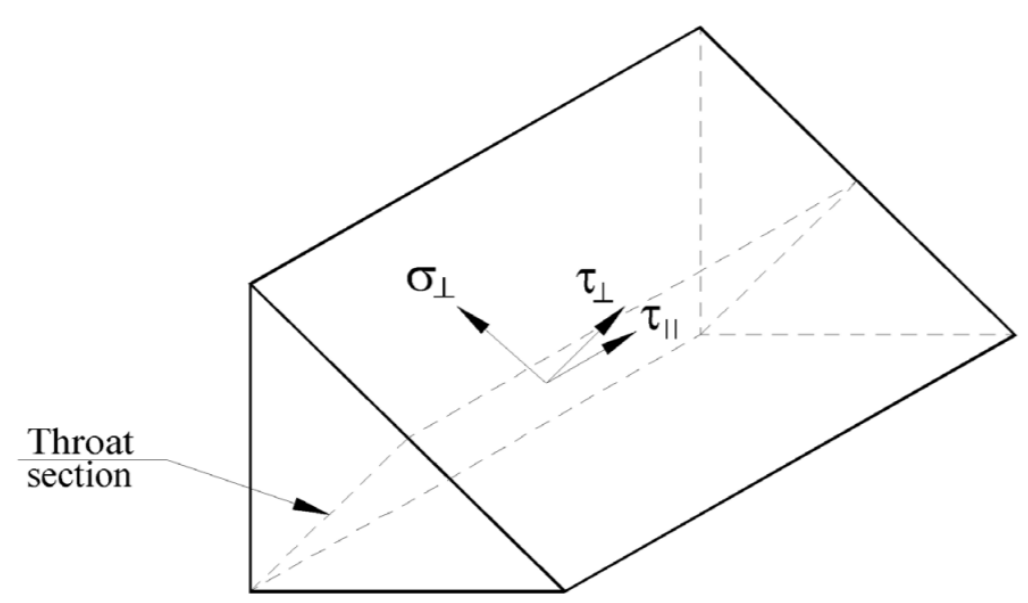

Figura 23 - Seção da garganta na solda e as tensões atuantes Fonte: Norma DNV-OS-C102 [2]

Para calcular os diversos esforços na seção da garganta da solda, como os momentos e as tensões normais e de cisalhamento, foram utilizadas as seguintes equações:

$$
\begin{gathered}
I_{s}=2 \cdot \frac{1}{12} \cdot a_{s} \cdot L_{s}{ }^{3} \\
M=F_{d} \cdot h / 2 \\
\sigma_{\perp}=\frac{M \cdot L_{s}}{2 \cdot I_{s} \cdot \sqrt{2}}=\tau_{\perp} \\
\tau_{1 \mathrm{l}}=\frac{F_{d}}{2 L_{s} \cdot a_{s}}
\end{gathered}
$$

Segundo a norma DNVGL-OS-C102, Section 9, a tensão equivalente na seção da garganta da solda foi calculada da seguinte forma:

$$
\sigma_{e q}=\sqrt{{\sigma_{\perp}{ }^{2}+3\left(\tau_{11}^{2}+\tau_{\perp}{ }^{2}\right)}^{2}}
$$


A tensão admissível na garganta da solda indicada na norma é obtida assim:

$$
\sigma_{\text {adm.solda }}=f_{u} \cdot \frac{\eta_{0}}{\beta_{w}}
$$

Para atender a todos os esforços, é necessário satisfazer os seguintes critérios indicados na norma:

$$
\begin{gathered}
\sqrt{{\sigma_{\perp}^{2}+3\left(\tau_{11}^{2}+\tau_{\perp}^{2}\right)}^{2}} \leq \sigma_{\text {adm.solda }} \\
\sigma_{\perp}<f_{u} \cdot \eta_{0}
\end{gathered}
$$

\subsubsection{Tensões no batente}

Os cálculos das tensões no batente são feitos usando conhecimentos básicos na área de comportamento mecânico dos materiais. Inicialmente calculamos a tensão equivalente na chapa da solda. Em seguida, a partir do cálculo da tensão admissível, é feita a verificação se a chapa em Aço NV36 suporta esses esforços, comparando com as tensões a que o batente está submetido.

Para calcular as tensões nos batentes utilizaremos as seguintes equações:

$$
A_{b}=L_{b} \cdot t_{b}
$$

- Momento de inércia na base do batente:

$$
I_{b}=\frac{1}{12} t_{b} \cdot L_{b}^{3}
$$

- Tensão de flexão na base do batente: 


$$
\sigma_{f}=\frac{M \cdot L_{b} \cdot 0,5}{I_{b}}
$$

- Tensão de cisalhamento na base do batente

$$
\tau_{f}=\frac{F_{d}}{A_{b}}
$$

- A tensão equivalente aplicada no batente é:

$$
\sigma_{e q_{b}}=\sqrt{\sigma_{f}^{2}+3 * \tau_{f}^{2}}
$$

- A tensão admissível no batente é dada por:

$$
\sigma_{a d m_{b}}=f_{y_{b}} \cdot \eta_{0_{b}}
$$

Para que o cordão de solda seja capaz de suportar os esforços aplicados, o seguinte critério tem que ser atendido:

$$
\sigma_{a d m_{b}}>\sigma_{e q_{b}}
$$

\subsubsection{Olhal do batente}

Para calcular os esforços no olhal do batente foi utilizada a norma Petrobras N-2683 de Dezembro/2010, específica para olhais de içamento. Embora nossos olhais não sejam para içar os equipamentos, o uso desta norma resulta em cálculos mais conservadores para o projeto em questão. Esta norma define toda a sistemática de cálculo como o dimensionamento do furo, da espessura mínima, das forças exercidas no olhal, além de indicar os critérios de aceitação e aprovação. 
- O diâmetro do furo é obtido por meio da equação:

$$
d_{\text {furo }}=d_{\text {pino }}+\text { folga }
$$

A folga apresentada na norma para $d_{\text {pino }} \leq 33 \mathrm{~mm}$ é de $1 \mathrm{~mm}$.

A norma define que a espessura $t_{\text {olhal }}$ deve ser menor do que a abertura da manilha escolhida, para que não haja interferência, da seguinte forma:

$$
t_{\text {olhal }}<A_{\text {man }}
$$

- As forças exercidas na cinta e no pino da manilha são dadas por:

$$
F_{\text {linga }}=f_{d c} \cdot f_{c p} \cdot f_{c g} \cdot F A D \cdot F_{\text {olhal }}
$$

$$
F_{\text {pino }}=1,30 . F_{\text {linga }}
$$

Em seguida, as seguintes verificações devem ser feitas:

- Na espessura total do olhal:

$$
A_{\text {manilha }}>t_{\text {olhal }}>\frac{F_{\text {pino }}}{0,9 \cdot f_{y_{b}} \cdot d_{\text {pino }}}
$$

- Na força de contato entre o pino e o furo:

$$
f_{p}=\frac{F_{\text {pino }}}{d_{\text {pino }} \cdot\left(t_{\text {olhal }}\right)} \leq 0,90 \cdot F_{y}
$$

- No cisalhamento na área efetiva: 


$$
f_{v}=\frac{F_{\text {pino }}}{\left.2 \cdot\left[\left(R-r_{\text {furo }}\right) \cdot t_{\text {olhal }}\right)\right]} \leq 0,40 \cdot F_{y}
$$

- Na tração na área líquida efetiva na região do furo:

Para este cálculo é necessário obter o valor de $b_{1}$, um coeficiente auxiliar, da seguinte forma:

$$
b_{1}=\text { Menor valor entre } 4 . t_{\text {olhal }} \text { e } 0,8 . d_{\text {furo }}
$$

Finalmente, a tração na área líquida efetiva na região do furo ' $f_{a}$ ' abaixo é dada pela seguinte expressão:

$$
f_{a}=\frac{F_{\text {pino }}}{2 \cdot b_{1} \cdot t_{\text {olhal }}} \leq 0,45 \cdot F_{y}
$$

A norma N-2683 exige a verificação de outros critérios para o caso em que o olhal apresente anéis de reforço soldados, o que não acontece nesse caso, onde o olhal é apenas uma chapa. 


\section{Componentes, embarcação e equipamentos utilizados}

Neste capítulo, vamos especificar os componentes, o tipo de embarcação e os equipamentos que foram utilizados para a simulação, descrevendo suas capacidades, medidas e materiais. Para o caso das cintas e manilhas foram selecionadas as de empresas que produzem estes componentes usados em ambiente offshore.

\subsection{Cintas}

As cintas e tensionadores utilizados para fazer a amarração de todos os equipamentos são do modelo TRIK $100 \mathrm{~mm}$, da fabricante Tecnotextil, que possuem carga de ruptura de 10 toneladas. As cintas produzidas possuem certificação da norma ABNT, o que garante a qualidade do produto.

\subsection{Manilhas}

A manilha é um componente de conexão ou fixação de cabos muito utilizado em campanhas offshore. Possuem diversos tipos, tamanhos, materiais e, consequentemente, sua capacidade de fixação é variável. Para esse trabalho, como estamos utilizando cintas com capacidade de 10 toneladas, nossas manilhas também terão a mesma capacidade. Foi escolhido o modelo 213 Carbon Round Pin, do fabricante Crosby, que possui as seguintes características:

- $d_{\text {pino }}=31,8 \mathrm{~mm}$

- $A_{\text {manilha }}=46 \mathrm{~mm}$

\subsection{D-Ring}

O D-ring é um equipamento fixado no deck do navio e usado para fazer a amarração da cinta junto ao deck. Assim como as manilhas, também varia em 
tamanho, material e capacidade de fixação. Para o presente trabalho, utilizamos o modelo S-265, com capacidade de 12 t da Crosby. A fabricante determina o tamanho mínimo da solda e com isso não será necessário fazer a verificação de esforços na garganta da solda.

\subsection{Batentes}

Para confecção dos batentes foi especificado o aço NV36. As principais características mecânicas e dimensionais foram as seguintes:

- Limite de escoamento do material: $345 \mathrm{Mpa}$

- Web plate length: $\mathrm{L}=200 \mathrm{~mm}$

- Web plate height: $\mathrm{H}=100 \mathrm{~mm}$

- Web plate thickness: $\mathrm{t}=15 \mathrm{~mm}$

- Face plate width: $\mathrm{Wf}=100 \mathrm{~mm}$

- Face plate thickness: $\mathrm{tf}=15 \mathrm{~mm}$

- Weld between web plate and deck and weld between web and face plate: $\mathrm{w}=6 \mathrm{~mm}$

- Diâmetro do furo do olhal: $d_{\text {furo }}=32,8 \mathrm{~mm}$

- Raio do olhal: $r_{\text {olhal }}=55 \mathrm{~mm}$

\subsection{Embarcação PLSV}

Os principais dados e características do PSLV utilizado neste estudo são:

- Lenght overall (LOA): 140,0 m

- Lenght between perpendiculars (LPP): 120,0 m

- Breadth: 25,0 m

- Draught: 8,5 m

- Maximum service speed: 16 nós 
- Block coefficient: 0,56

- Moulded depth: 12,0 m

- Moulded summer draft: 7,8 m

\subsection{Equipamentos}

As medidas dos equipamentos e as posições dos seus centros de gravidade, em relação à caverna zero, estão descritos na Tabela 1.

Tabela 1 - Dimensões, peso e coordenadas do centro de gravidade dos equipamentos

\begin{tabular}{|c|c|c|c|c|c|c|c|}
\hline Equipamento & Comprimento & Largura & Altura & Peso & x_cg & Y_cg & z_cg \\
\hline Container 20ft (2) & 6,00 & 2,44 & 2,59 & 9,00 & 12,50 & 0,00 & 1,30 \\
\hline Container $40 \mathrm{ft}$ & 12,00 & 2,44 & 2,59 & 20,00 & 3,00 & 5,00 & 1,30 \\
\hline $4 \times$ Concrete mattress & 6,00 & 3,00 & 1,20 & 32,00 & 25,00 & 0,00 & 0,60 \\
\hline Test cabin & 3,00 & 2,50 & 2,60 & 6,00 & 5,00 & $-2,00$ & 1,30 \\
\hline $\begin{array}{c}\text { Pig Launch Receiver - } \\
\text { PLR }\end{array}$ & 5,50 & 2,00 & 2,00 & 7,00 & 45,00 & 7,00 & 1,00 \\
\hline $\begin{array}{c}\text { Grout bag container } \\
40 \mathrm{ft}\end{array}$ & 12,00 & 2,44 & 2,59 & 15,00 & 20,00 & $-5,00$ & 1,30 \\
\hline PLEM & 10,00 & 7,00 & 5,00 & 47,00 & 45,00 & 0,00 & 2,50 \\
\hline PLET & 8,00 & 6,00 & 4,00 & 35,00 & 34,00 & 0,00 & 2,00 \\
\hline Primary compressor & 6,07 & 2,44 & 2,93 & 15,00 & 20,00 & $-8,00$ & 1,47 \\
\hline Container $20 \mathrm{ft}(1)^{(1)}$ & 6,00 & 2,44 & 2,59 & 9,00 & 12,50 & 9,00 & 4,60 \\
\hline Modular spreader bar & 5,50 & 0,30 & 0,30 & 2,70 & 20,00 & 4,00 & 0,15 \\
\hline $\begin{array}{c}\text { Modular spreader bar } \\
2^{(2)}\end{array}$ & 18,00 & 0,30 & 0,30 & 3,20 & 20,00 & 5,00 & 0,65 \\
\hline Wooden box & 1,50 & 1,00 & 0,80 & 2,00 & 5,00 & $-7,00$ & 0,40 \\
\hline
\end{tabular}


(1) Para efeito de simulação, o container 20ft (1) estará posicionado em um deck com altura de 3,30m para podermos ter acelerações diferentes do container $20 \mathrm{ft}$ (2) e ver a influência da altura nas acelerações calculadas.

(2) Pelo mesmo motivo do item (1), vamos supor que uma das spreader bar estará em cima de um trilho que possui altura de $0,50 \mathrm{~m}$

O posicionamento dos equipamentos foi feito visando priorizar a colocação dos equipamentos mais pesados, como o PLEM e PLET, em posições mais próximas do centro de giração do navio. Muitas vezes os navios possuem decks projetados para o transporte de cargas e já possuem $D$-rings fixos soldados nesse deck. Com isso, foi utilizada a amarração direta para o equipamento Container $20 \mathrm{ft}$ (1), para aproveitar a estrutura que o navio nos oferece.

Utilizando o software AutoCAD 2019 e as propriedades da Tabela 1 foi confeccionado um croqui em escala do layout do deck do navio: A Figura 24 revela esquematicamente este croqui com a distribuição dos equipamentos no deck. A spreader bar e o Container $20 \mathrm{ft}$ (2) foram feitos com hachurado diferentes para diferenciar dos equipamentos que estão posicionados no deck do navio.

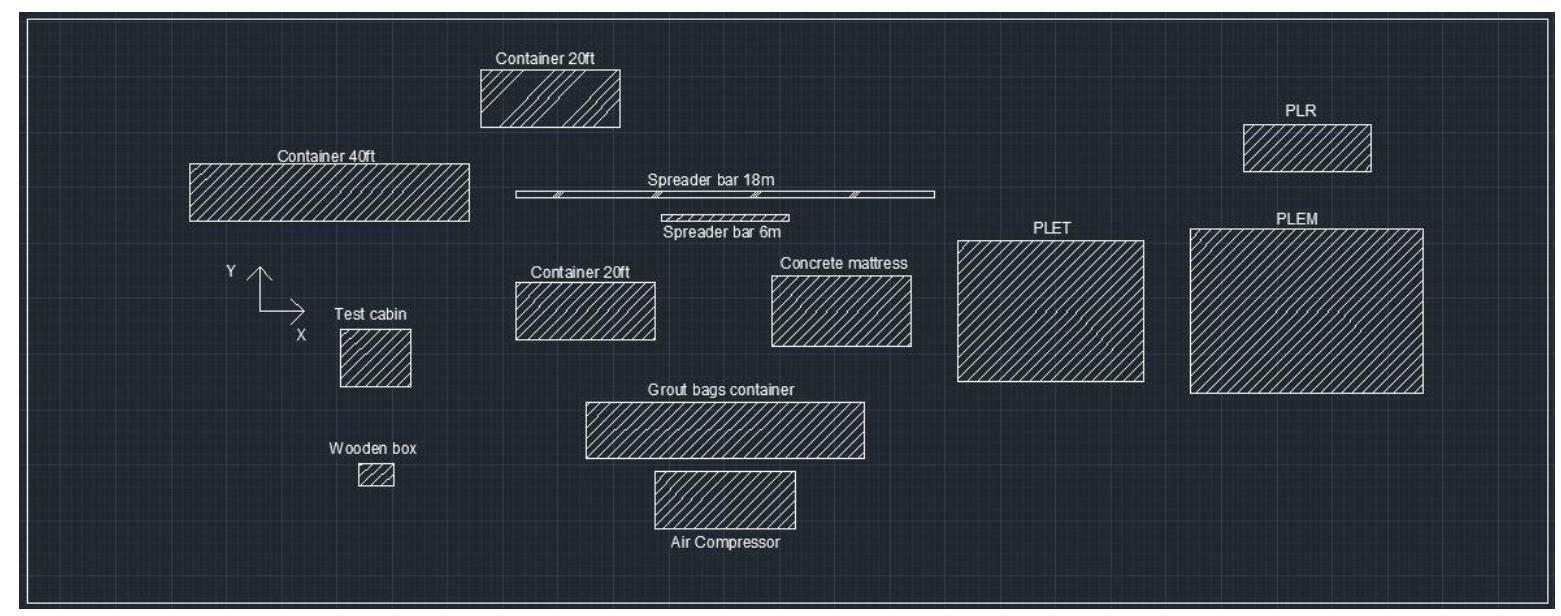

Figura 24 - Deck layout

Fonte: Autor

Os parâmetros para cálculo da estabilidade da amarração dos equipamentos com stoppers e amarração por atrito estão descritos na Tabela 2. 
Tabela 2 - Parâmetros de amarração dos equipamentos com amarração por atrito e batentes

\begin{tabular}{|c|c|c|c|c|c|c|c|c|c|}
\hline Parâmetros & $\begin{array}{l}20 f t \\
(2)\end{array}$ & $40 \mathrm{ft}$ & Mattress & $\begin{array}{l}\text { Test } \\
\text { cabin }\end{array}$ & PLR & $\begin{array}{l}\text { Grout } \\
\text { bags }\end{array}$ & PLEM & PLET & Compressor \\
\hline Massa [t] & 9,00 & 20,00 & 32,00 & 6,00 & 7,00 & 15,00 & 47,00 & 35,00 & 15,00 \\
\hline $\begin{array}{l}\text { Fator de } \\
\text { segurança }\end{array}$ & 1,10 & 1,10 & 1,10 & 1,10 & 1,10 & 1,10 & 1,10 & 1,10 & 1,10 \\
\hline$w$ [m] & 2,44 & 2,44 & 3,00 & 2,50 & 2,00 & 2,44 & 7,00 & 6,00 & 2,44 \\
\hline $\mathrm{b}[\mathrm{m}]$ & 1,22 & 1,22 & 1,50 & 1,25 & 1,00 & 1,22 & 3,50 & 3,00 & 1,22 \\
\hline I [m] & 6,00 & 12,00 & 6,00 & 3,00 & 5,50 & 12,00 & 10,00 & 8,00 & 6,07 \\
\hline$b_{2}[\mathrm{~m}]$ & 3,00 & 6,00 & 3,00 & 1,50 & 2,75 & 6,00 & 5,00 & 4,00 & 3,04 \\
\hline$h[\mathrm{~m}]$ & 2,59 & 2,59 & 1,20 & 2,60 & 2,00 & 2,59 & 5,00 & 4,00 & 2,93 \\
\hline $\mathrm{d}[\mathrm{m}]$ & 1,30 & 1,30 & 0,60 & 1,30 & 1,00 & 1,30 & 2,50 & 2,00 & 1,47 \\
\hline$\alpha$ [graus] & 85,00 & 85,00 & 80,00 & 85,00 & 85,00 & 85,00 & 85,00 & 85,00 & 85,00 \\
\hline $\sin (\alpha)[-]$ & 1,00 & 1,00 & 0,98 & 1,00 & 1,00 & 1,00 & 1,00 & 1,00 & 1,00 \\
\hline $\cos (\alpha)[-]$ & 0,09 & 0,09 & 0,17 & 0,09 & 0,09 & 0,09 & 0,09 & 0,09 & 0,09 \\
\hline $\begin{array}{l}\text { Número de } \\
\text { cintas [-] }\end{array}$ & 2,00 & 4,00 & 4,00 & 2,00 & 2,00 & 2,00 & 4,00 & 4,00 & 4,00 \\
\hline
\end{tabular}

Os parâmetros para amarração dos equipamentos com amarração direta utilizados para calcular a estabilidade estão descritos na Tabela 3. 
Tabela 3 - Parâmetros de amarração dos equipamentos com amarração direta

\begin{tabular}{|c|c|c|c|}
\hline Parâmetros & $\mathbf{2 0 f t}(\mathbf{1})$ & Spreader 1 & Spreader 2 \\
\hline Massa [t] & 9,00 & 2,70 & 3,20 \\
\hline Fator de segurança & 1,10 & 1,10 & 1,10 \\
\hline $\mathbf{w}$ [m] & 2,44 & 2,00 & 2,10 \\
\hline $\mathbf{b}$ [m] & 1,22 & 1,00 & 1,05 \\
\hline I [m] & 6,00 & 2,00 & 2,20 \\
\hline $\mathbf{b}_{\mathbf{2}}$ [m] & 3,00 & 1,00 & 1,10 \\
\hline $\mathbf{h}$ [m] & 2,59 & 1,40 & 0,53 \\
\hline $\mathbf{d}$ [m] & 1,30 & 0,70 & 0,27 \\
\hline $\boldsymbol{\alpha}$ [graus] & 45,00 & 45,00 & 45,00 \\
\hline $\cos (\boldsymbol{\alpha})$ & 0,71 & 0,71 & 0,71 \\
\hline $\boldsymbol{\beta}$ [graus] & 55,00 & 55,00 & 55,00 \\
\hline $\boldsymbol{s i n}(\boldsymbol{\beta})$ & 0,82 & 0,82 & 0,82 \\
\hline $\cos (\boldsymbol{\beta})$ & 0,57 & 0,57 & 0,57 \\
\hline Número de cintas [-] & 4,00 & 4,00 & 4,00 \\
\hline $\sin (\boldsymbol{\alpha})$ & 0,71 & 0,71 & 0,71 \\
\hline
\end{tabular}

Os parâmetros para amarração dos equipamentos com amarração por atrito utilizados para calcular a estabilidade estão descritos na Tabela 4. 
Tabela 4 - Parâmetros de amarração do equipamento com amarração por atrito

\begin{tabular}{|c|c|}
\hline Parâmetros & Wooden box \\
\hline Massa (te) & 2,00 \\
\hline Fs (dim.less) & 1,10 \\
\hline $\mathbf{w}(\mathbf{m})$ & 1,00 \\
\hline b (m) & 0,50 \\
\hline $\mathbf{w}_{2}(\mathrm{~m})$ & 1,50 \\
\hline$b_{2}(m)$ & 0,75 \\
\hline h (m) & 0,80 \\
\hline d (m) & 0,40 \\
\hline$\alpha($ deg) & 75,00 \\
\hline $\sin (\alpha)$ & 0,97 \\
\hline $\cos (\alpha)$ & 0,26 \\
\hline Number os slings $\mathbf{n}$ (dim.lass) & 1,00 \\
\hline$\mu$ (dim.lass) & 0,20 \\
\hline
\end{tabular}

O fator de atrito considerado foi o mais conservador para os equipamentos feitos de madeira, indicado pela norma EN12195-1. 


\section{Resultados e análises}

Nesse capítulo serão apresentados inicialmente, os valores de aceleração calculados para cada um dos equipamentos. Com esses valores, foram obtidas as forças nas quatro direções indicadas na norma DNV Rules for Ships. Em seguida, foi possível calcular a estabilidade/instabilidade de cada um dos equipamentos e a capacidade mínima para as cintas de amarração. Finalmente, foram calculados os esforços no cordão de solda, nas chapas e no olhal do batente. Com todos esses cálculos e critérios, foi possível fazer uma avaliação para saber se a campanha estava apta a ser realizada com segurança, com a emissão do relatório seafastening.

\subsection{Acelerações}

A partir dos dados físicos dos equipamentos e das Equações(11),(19) e (20), foi possível chegar aos valores de aceleração indicados na Tabela 5.

Tabela 5 - Acelerações nos equipamentos de amarração por atrito e batentes

\begin{tabular}{|c|c|c|c|c|c|c|c|c|c|}
\hline Acelerações & $\begin{array}{l}20 \mathrm{ft} \\
(2)\end{array}$ & $40 \mathrm{ft}$ & Mattress & $\begin{array}{l}\text { Test } \\
\text { cabin }\end{array}$ & PLR & $\begin{array}{l}\text { Grout } \\
\text { bags }\end{array}$ & PLEM & PLET & Compressor \\
\hline \multicolumn{10}{|l|}{$\begin{array}{c}\text { Vertical e } \\
\text { transversal }\end{array}$} \\
\hline Vertical $\left[\mathrm{m} / \mathrm{s}^{2}\right]$ & 9,81 & 9,81 & 9,81 & 9,81 & 9,81 & 9,81 & 9,81 & 9,81 & 9,81 \\
\hline $\begin{array}{c}\text { Transversal } \\
{\left[\mathrm{m} / \mathrm{s}^{2}\right]}\end{array}$ & 3,96 & 3,96 & 3,89 & 3,96 & 3,93 & 3,96 & 4,08 & 4,03 & 3,98 \\
\hline \multicolumn{10}{|l|}{$\begin{array}{c}\text { Vertical e } \\
\text { longitudinal }\end{array}$} \\
\hline Vertical $\left[\mathrm{m} / \mathrm{s}^{2}\right]$ & 14,88 & 15,83 & 13,74 & 15,61 & 12,31 & 14,18 & 12,31 & 13,00 & 14,18 \\
\hline $\begin{array}{l}\text { Longitudinal } \\
{\left[\mathrm{m} / \mathrm{s}^{2}\right]}\end{array}$ & 2,47 & 2,47 & 2,37 & 2,47 & 2,43 & 2,47 & 2,63 & 2,57 & 2,49 \\
\hline
\end{tabular}

A partir das acelerações foram calculadas as forças nos corpos, utilizando as Equações (21-24) conforme indicado na Tabela 6: 
Tabela 6 - Forças atuantes nos equipamentos de amarração por atrito e batentes

\begin{tabular}{|c|c|c|c|c|c|c|c|c|c|}
\hline Parâmetros & $\begin{array}{c}\mathbf{2 0 f t} \\
\mathbf{( 2 )}\end{array}$ & $\mathbf{4 0 f t}$ & Mattress & $\begin{array}{c}\text { Test } \\
\text { cabin }\end{array}$ & PLR & $\begin{array}{c}\text { Grout } \\
\text { bags }\end{array}$ & PLEM & PLET & Compressor \\
\hline Massa [t] & 9,00 & 20,00 & 32,00 & 6,00 & 7,00 & 15,00 & 47,00 & 35,00 & 15,00 \\
\hline$F_{y y}[\mathbf{k N}]$ & 35,63 & 79,19 & 124,48 & 23,76 & 27,51 & 59,39 & 191,69 & 141,01 & 59,64 \\
\hline$F_{x x}[\mathbf{k N}]$ & 22,22 & 49,37 & 75,89 & 14,81 & 16,99 & 37,03 & 123,82 & 89,78 & 37,38 \\
\hline$F_{\mathbf{y z}}[\mathbf{k N}]$ & 88,26 & 196,14 & 313,82 & 58,84 & 68,65 & 147,11 & 460,93 & 343,25 & 147,11 \\
\hline$F_{\mathbf{x z}}[\mathbf{k N}]$ & 133,95 & 316,60 & 439,55 & 93,66 & 86,17 & 212,77 & 578,57 & 454,93 & 212,77 \\
\hline
\end{tabular}

Para os equipamentos de amarração direta, foram obtidos os valores de aceleração a partir das Equações (11),(19) e (20) expressos na Tabela 7.

Tabela 7 - Acelerações nos equipamentos de amarração direta

\begin{tabular}{|c|c|c|c|}
\hline Acelerações & $20 \mathrm{ft}(1)$ & Spreader 1 & Spreader 2 \\
\hline \multicolumn{4}{|l|}{ Vertical e transversal } \\
\hline Vertical $\left[\mathrm{m} / \mathrm{s}^{2}\right]$ & 9,81 & 9,81 & 9,81 \\
\hline Transversal $\left[\mathrm{m} / \mathbf{s}^{2}\right]$ & 4,29 & 3,85 & 3,89 \\
\hline \multicolumn{4}{|l|}{ Vertical e longitudinal } \\
\hline Vertical $\left[\mathrm{m} / \mathrm{s}^{2}\right]$ & 14,88 & 14,20 & 14,18 \\
\hline Longitudinal $\left[\mathrm{m} / \mathrm{s}^{2}\right]$ & 2,93 & 2,31 & 2,38 \\
\hline
\end{tabular}

As forças atuando nos corpos para os equipamentos com amarração direta, calculadas pelas Equações (21-24) estão indicadas na Tabela 8.

Tabela 8 - Forças atuantes nos equipamentos de amarração direta

\begin{tabular}{|c|c|c|c|}
\hline Parâmetros & 20ft (1) & Spreader 1 & Spreader 2 \\
\hline Massa [t] & 9,00 & 2,70 & 3,20 \\
\hline F $_{\mathrm{yy}}[\mathbf{k N}]$ & 38,59 & 10,38 & 12,46 \\
\hline $\mathbf{F}_{\mathrm{xx}}[\mathbf{k N}]$ & 26,33 & 6,24 & 7,61 \\
\hline $\mathbf{F}_{\mathrm{yz}}[\mathbf{k N}]$ & 88,26 & 26,49 & 31,39 \\
\hline $\mathbf{F}_{\mathrm{xz}}[\mathbf{k N}]$ & 133,95 & 38,33 & 45,39 \\
\hline
\end{tabular}


Para os equipamentos de amarração por atrito os valores de aceleração, obtidos a partir das Equações (11),(19) e (20) estão indicados na Tabela 9.

Tabela 9 -Aceleração no equipamento de amarração por atrito

\begin{tabular}{|c|c|}
\hline Acelerações & Wooden box \\
\hline $\begin{array}{c}\text { Vertical e transversal } \\
\text { Vertical }\left[\mathbf{m} / \mathbf{s}^{2} \text { ] }\right.\end{array}$ & 9,81 \\
\hline Transversal $\left[\mathrm{m} / \mathbf{s}^{2}\right.$ ] & 3,87 \\
\hline Vertical e longitudinal & \\
\hline Vertical $\left[\mathbf{m} / \mathbf{s}^{2}\right]$ & 15,63 \\
\hline Longitudinal $\left[\mathbf{m} / \mathbf{s}^{2}\right]$ & 2,34 \\
\hline
\end{tabular}

O valor das forças atuantes nos equipamentos de amarração por atrito, calculadas a partir das Equações (21-24) estão indicados na Tabela 10.

Tabela 10 - Forças atuantes nos equipamentos de amarração por atrito

\begin{tabular}{|c|c|}
\hline Parâmetros & Wooden box \\
\hline Massa (te) & 2,00 \\
\hline$F_{y y}(\mathbf{k N})$ & 7,74 \\
\hline$F_{x x}(\mathbf{k N})$ & 4,69 \\
\hline$F_{y z}(\mathbf{k N})$ & 19,61 \\
\hline$F_{x z}(\mathbf{k N})$ & 31,25 \\
\hline
\end{tabular}

Com os valores descritos nas Tabela 5, Tabela 7 e Tabela 9 foi possível verificar que a diferença das acelerações quando combinamos a aceleração vertical e longitudinal é muito maior do que quando combinamos aceleração vertical e transversal. A maior diferença entre acelerações no caso de combinação das acelerações vertical e longitudinal foi de $15,83 \mathrm{~m} / \mathrm{s}^{2}$ do Container $40 \mathrm{ft}$ e 12,31 $\mathrm{m} / \mathrm{s}^{2}$ do PLEM. Esta diferença de quase $30 \%$ é bem representativa e, não coincidentemente, são os equipamentos que possuem os posicionamentos mais 
distantes (container) e mais perto (PLEM) do centro de rotação da embarcação. No caso da combinação vertical e transversal, a maior aceleração encontrada foi do equipamento que possui maior altura do centro de gravidade, o Container $20 \mathrm{ft}$ (1), que foi posicionado acima de um deck com altura de $3,30 \mathrm{~m}$. Seu centro de gravidade ficou a 4,60m acima do nível do deck, resultando em uma aceleração transversal de $4,29 \mathrm{~m} / \mathrm{s}^{2}$.

Observando as forças nos equipamentos, verificamos que mesmo acomodando o equipamento mais pesado em posição que the daria menor aceleração, as suas forças longitudinais e transversais foram as maiores. Isso nos mostra que a massa do equipamento é um dos principais fatores a serem levados em conta na hora de posicionar o equipamento. A aceleração entre dois equipamentos em posições diferentes pode variar, como podemos ver nesse caso, em valores de até aproximadamente 30\%. Já a diferença da massa de equipamentos pode variar de 2 toneladas até 47 toneladas, diferença percentualmente muito maior do que a da aceleração. Como a força é o produto dessas duas grandezas, geralmente as maiores forças são causadas pelos equipamentos com maiores massas.

\subsection{Estabilidade}

Aplicando a Equação (26) para verificar a estabilidade dos equipamentos com amarração por atrito e batente e as Equações (33) e (35) para determinar a força exigida nas cintas, foram obtidos os resultados indicados nas Tabela $11 \mathrm{e}$ Tabela 12. 
Tabela 11 - Estabilidade dos equipamentos com amarração por atrito e batente

\begin{tabular}{|c|c|c|c|c|c|c|c|c|c|}
\hline Parâmetros & 20ft (2) & 40ft & Mattress & $\begin{array}{c}\text { Test } \\
\text { cabin }\end{array}$ & PLR & $\begin{array}{c}\text { Grout } \\
\text { bags }\end{array}$ & PLEM & PLET & Compressor \\
\hline $\begin{array}{c}\text { Estabilidade de } \\
\text { tombamento - FT- } \\
\text { transversal }\end{array}$ & Estável & Estável & Estável & Estável & Estável & Estável & Estável & Estável & Estável \\
\hline $\begin{array}{c}\text { Estabilidade de } \\
\text { tombamento - FT- } \\
\text { longitudinal }\end{array}$ & Estável & Estável & Estável & Estável & Estável & Estável & Estável & Estável & Estável \\
\hline $\begin{array}{c}\text { Tombamento FT- } \\
\text { transversal (kN) }\end{array}$ & 0,00 & 0,00 & 0,00 & 0,00 & 0,00 & 0,00 & 0,00 & 0,00 & 0,00 \\
\hline $\begin{array}{c}\text { Tombamento FT- } \\
\text { longitudinal (kN) }\end{array}$ & 0,00 & 0,00 & 0,00 & 0,00 & 0,00 & 0,00 & 0,00 & 0,00 & 0,00 \\
\hline $\begin{array}{c}\text { Força de } \\
\text { deslizamento FT- } \\
\text { transversal [kN] }\end{array}$ & 0,00 & 0,00 & 0,00 & 0,00 & 0,00 & 0,00 & 0,00 & 0,00 & 0,00 \\
\hline $\begin{array}{c}\text { Força de } \\
\text { deslizamento FT- } \\
\text { longitudinal [kN] }\end{array}$ & 0,00 & 0,00 & 0,00 & 0,00 & 0,00 & 0,00 & 0,00 & 0,00 & 0,00 \\
\hline
\end{tabular}

Tabela 12 - Forças totais atuantes e capacidade mínima da cinta dos equipamentos de amarração por atrito e batente

\begin{tabular}{|c|c|c|c|c|c|c|c|c|c|}
\hline Parâmetros & $\begin{array}{c}\text { 20ft } \\
\mathbf{( 2 )}\end{array}$ & $\mathbf{4 0 f t}$ & Mattress & $\begin{array}{c}\text { Test } \\
\text { cabin }\end{array}$ & PLR & $\begin{array}{c}\text { Grout } \\
\text { bags }\end{array}$ & PLEM & PLET & Compressor \\
\hline $\begin{array}{c}\text { Força transversal } \\
{[\mathbf{k N}]}\end{array}$ & 0,00 & 0,00 & 0,00 & 0,00 & 0,00 & 0,00 & 0,00 & 0,00 & 0,00 \\
\hline $\begin{array}{c}\text { Força longitudinal } \\
{[\mathbf{k N}]}\end{array}$ & 0,00 & 0,00 & 0,00 & 0,00 & 0,00 & 0,00 & 0,00 & 0,00 & 0,00 \\
\hline $\begin{array}{c}\text { Capacidade mínima } \\
\text { da cinta [t] }\end{array}$ & 0,00 & 0,00 & 0,00 & 0,00 & 0,00 & 0,00 & 0,00 & 0,00 & 0,00 \\
\hline
\end{tabular}

Observando os resultados dos equipamentos com amarração por atrito e com batentes impedindo o deslizamento, vemos que não é necessário o uso de cintas em nenhum dos equipamentos que possuem batentes. Todavia, é recomendável que se amarre os equipamentos para evitar o movimento de uplift, quando as cargas tendem a deixar o deck do navio. Esse tipo de movimento não foi considerado neste trabalho.

Podemos observar também o quanto os batentes-são importantes para manter os equipamentos estáveis. Porém, não é todo equipamento que permite esse tipo de amarração, como, por exemplo, os que possuem base circular, como 
um MCV (Módulo de Conexão Vertical) ou que possuam uma forma geométrica não usual para equipamento, como uma barra de içamento.

Aplicando a Equação (26) para verificar a estabilidade do equipamento com amarração direta com cinta e D-rings e a Equação (30) para determinar a força exigida nas cintas, foram obtidos os resultados indicados na Tabela 13 e na Tabela 14.

Tabela 13 - Estabilidade dos equipamentos com amarração direta

\begin{tabular}{|c|c|c|c|}
\hline Parâmetros & 20ft (1) & Spreader 1 & Spreader 2 \\
\hline Estabilidade de tombamento - $\mathbf{F}_{\text {T-transversal }}$ & Estável & Estável & Estável \\
\hline Estabilidade de tombamento - $\mathbf{F}_{\text {T-longitudinal }}$ & Estável & Estável & Estável \\
\hline Tombamento $\mathbf{F}_{\text {T-transversal }}(\mathbf{k N})$ & 0,00 & 0,00 & 0,00 \\
\hline Tombamento $\mathbf{F}_{\text {T-longitudinal }}(\mathbf{k N})$ & 0,00 & 0,00 & 0,00 \\
\hline Força de deslizamento $\mathbf{F}_{\text {T-transversal }}[\mathbf{k N}]$ & 18,32 & 4,93 & 5,92 \\
\hline Força de deslizamento $\mathbf{F}_{\text {T-longitudinal }}[\mathbf{k N}]$ & 17,85 & 4,87 & 5,01 \\
\hline
\end{tabular}

Tabela 14 - Forças totais atuantes e capacidade mínima da cinta dos equipamentos de amarração direta

\begin{tabular}{|c|c|c|c|}
\hline Parâmetros & 20ft (1) & Spreader 1 & Spreader 2 \\
\hline Força transversal [kN] & 18,32 & 4,93 & 5,92 \\
\hline Força longitudinal [kN] & 17,85 & 4,87 & 5,01 \\
\hline Capacidade mínima da cinta [t] & 3,66 & 0,99 & 1,18 \\
\hline
\end{tabular}

Por fim, aplicando-se a Equação (26) para verificar a estabilidade do equipamento com amarração por atrito e a Equação (31) para determinar a força exigida nas cintas, foram obtidos os resultados indicados na Tabela 15 e na Tabela 16. 
Tabela 15 - Estabilidade dos equipamentos com amarração por atrito

\begin{tabular}{|c|c|}
\hline Parâmetros & Wooden box \\
\hline Estabilidade de tombamento $-\mathbf{F}_{\text {T-transversal }}$ & Estável \\
\hline Estabilidade de tombamento $-\mathbf{F}_{\text {T-longitudinal }}$ & Estável \\
\hline Tombamento $\mathbf{F}_{\text {T-transversal }}(\mathbf{k N})$ & 0,00 \\
\hline Tombamento $\mathbf{F}_{\text {T-longitudinal }}(\mathbf{k N})$ & 0,00 \\
\hline Força de deslizamento $\mathbf{F}_{\text {T-transversal }}(\mathbf{k N})$ & 10,87 \\
\hline Força de deslizamento $\mathbf{F}_{\text {T-longitudinal }}(\mathbf{k N})$ & 4,45 \\
\hline
\end{tabular}

Tabela 16 - Forças totais atuantes e capacidade mínima da cinta dos equipamentos de amarração por atrito

\begin{tabular}{|c|c|}
\hline Parâmetros & Wooden box \\
\hline TRANSVERSAL Force $(\mathbf{k N})$ & 10,87 \\
\hline LONGITUDINAL Force $(\mathbf{k N})$ & 4,45 \\
\hline Min Cargo Strap Capacity (te) & 2,17 \\
\hline
\end{tabular}

Podemos verificar que todos os equipamentos contemplados neste estudo são estáveis, quando aplicadas as acelerações calculadas. Estes resultados eram esperados, uma vez que os equipamentos comuns a uma campanha offshore já são projetados para serem estáveis dentro das acelerações dessa ordem de grandeza. Por esta razão, normalmente são colocados em skids, que são armações que facilitam a amarração dos equipamentos, os equipamentos que possuem dimensões não usuais, com um centro de gravidade muito alto, dimensões da base pequenas ou com geometria cilíndrica. A Figura 25 mostra um tanque acondicionado dentro de um skid, pronto para ser movimentado. 


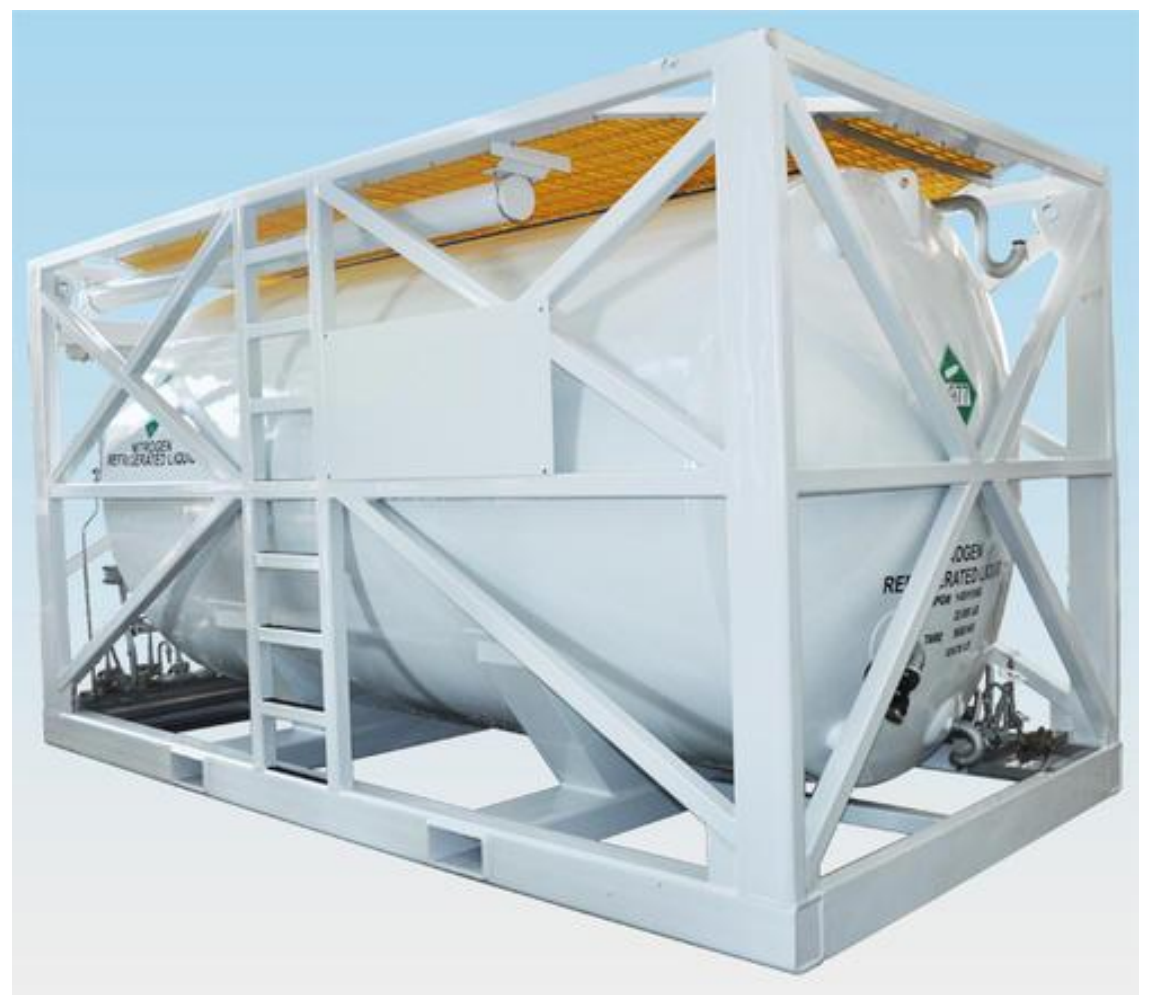

Figura 25 - Tanque dentro de um skid

Fonte: https://www.indiamart.com/proddetail/offshore-skid-tank15452923933.html* [28]

\subsection{Batentes}

Para o cálculo dos esforços dos batentes, foi necessário considerar apenas as maiores forças na transversal e na longitudinal e dividir pelo número de batentes. A partir da Tabela 6 , as maiores forças por batente encontradas foram:

$$
\begin{aligned}
& F_{\text {max.long }}=144,64 k N \\
& F_{\text {max.trans }}=115,23 \mathrm{kN}
\end{aligned}
$$




\subsubsection{Esforços na solda}

De acordo com as Equações (38) e (39) e aplicando as forças máximas nos batentes, foram obtidos os seguintes valores para as tensões nas soldas nos batentes posicionados nos sentidos longitudinal e transversal, respectivamente:

$$
\begin{gathered}
\sigma_{\text {eq.long }}=140,0 \mathrm{MPa} \\
\sigma_{\text {eq.transv }}=111,6 \mathrm{MPa}
\end{gathered}
$$

O valor da tensão de cisalhamento na seção paralela à seção da garganta, calculada pela Equação (41) foi de:

$$
\sigma_{a d m \cdot s o l d a}=262,9 \mathrm{MPa}
$$

Os valores calculados para as tensões normal e de cisalhamento perpendicular à seção da garganta no sentido longitudinal e transversal, obtida com a Equação (38) foram:

$$
\begin{gathered}
\sigma_{\perp . \text { long }}=54,2 \mathrm{MPa} \\
\sigma_{\perp . \text { transv }}=43,2 \mathrm{MPa}
\end{gathered}
$$

O valor calculado para a tensão admissível na seção da garganta da solda obtida pela Equação (41) foi de:

$$
f_{u} \cdot \eta_{0}=234,0 M P a
$$


Com esses resultados podemos avaliar o atendimento aos critérios definidos nas Equações (42) e (43):

\author{
$\sigma_{\text {adm.solda }}>\sigma_{\text {eq.long }}, \sigma_{\text {eq.transv }}$ \\ 262,9 MPa $>140,0 M p a, 111,6 M P a$ \\ $f_{u} \cdot \eta_{0}>\sigma_{\perp . \text { long }}, \sigma_{\perp . \text { transv }}$ \\ 234,0 MPa $>$ 54,2 Mpa,43,2 Mpa
}

Como ambos os critérios da norma foram atendidos, concluímos que as soldas atendem às cargas de projeto.

\title{
7.3.2. Esforços no batente
}

De acordo com a Equação (38) e aplicando as forças máximas nos batentes, foram obtidos os seguintes valores para as tensões nas soldas nos batentes posicionados nos sentidos longitudinal e transversal, respectivamente:

$$
\begin{gathered}
\sigma_{e q_{b} . l o n g}=110,5 \mathrm{MPa} \\
\sigma_{e q_{b} . t r a n s v}=88,0 \mathrm{MPa}
\end{gathered}
$$

O valor calculado para a tensão admissível do batente, obtida pela Equação (49) foi de: 


$$
\sigma_{\text {adm.batente }}=207,0 \mathrm{MPa}
$$

Com esses resultados foi possível avaliar o atendimento aos critérios definidos na norma para verificação dos esforços no batente. Para que o cordão de solda seja capaz de suportar os esforços aplicados, o critério definido na Equação (50) tem que ser atendido:

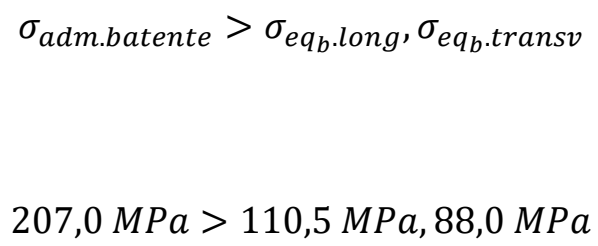

Como o critério da norma foi atendido concluímos que o batente atende às cargas de projeto.

\subsubsection{Esforços nos olhais}

De acordo com os critérios apresentados pela norma NB2683 e utilizando a Equação (50) foram obtidos o valor da espessura mínima do olhal conforme a seguir:

$$
t_{\min }=9,7 \mathrm{~mm}
$$

O valor nominal da espessura foi definido como sendo:

$$
t_{\text {olhal }}=15,0 \mathrm{~mm}
$$

O valor da força de contato entre o pino e o furo foi obtida utilizando a Equação (56) conforme a seguir:

$$
f_{p}=200,4 M P a
$$


O valor $0,9 . F_{y}$ calculado foi de $310,5 \mathrm{MPa}$, que é maior do que $f_{p}$, ou seja, atendendo o critério da norma definido também na Equação (56).

O valor da força de cisalhamento na área efetiva do olhal foi obtido utilizando a Equação (57), ou seja:

$$
f_{v}=82,6 \mathrm{MPa}
$$

O valor $0,4 . F_{\mathrm{y}}$ calculado foi de $138,0 \mathrm{MPa}$, que é maior do que $f_{V^{\prime \prime}}$, ou seja, atendendo o critério da norma definido também na Equação (57)

O valor da força de tração na área líquida efetiva, na região do furo, foi obtido utilizando a Equação (58), ou seja:

$$
f_{a}=93,4 M P a
$$

O valor $0,45 . \mathrm{F}_{\mathrm{y}}$ calculado foi de $155,2 \mathrm{MPa}$, que é maior do que $f_{V}$, ou seja, atendendo o critério da norma definido também na Equação (57).

Como todos os critérios e requisitos da norma foram atendidos concluímos que o olhal está apto a suportar as cargas de projeto nele exercidas. O maior fator de utilização no olhal foi de $60 \%$, que acontece no caso da tração na área líquida efetiva na região do furo. 


\section{Conclusões}

O presente trabalho objetivou desenvolver uma metodologia para elaboração de um relatório de seafastening com diretrizes definidas em normas internacionais. Foram utilizados os dados típicos de navios, equipamentos e dispositivos de fixação, utilizados em projetos atuais de campanhas offshore. Os resultados permitem concluir que:

1. A aplicação da sistemática de cálculos por meio das equações definidas nas normas se mostrou muito prática e eficaz. Os valores de aceleração obtidos mostraram que a utilização dos dispositivos de fixação aplicados resultou na estabilidade de todos os equipamentos;

2. Os batentes estão aptos ao projeto, uma vez que as soldas, as chapas e os olhais estão atendendo às normas de segurança com folga. Foi possível verificar que o uso de batentes juntos aos equipamentos torna a operação muito mais segura, embora nem sempre seja possível;

3. Com a instalação de stoppers capazes de impedir o deslizamento do equipamento, não há necessidade de usar cintas puxando-o para baixo, embora seja uma prática recomendada a fim de garantir o impedimento do movimento de uplift, que não foi calculado neste trabalho.

4. Em relação aos tipos de amarração, foi observado também que, dados os pesos e acelerações dos equipamentos, a amarração direta se mostrou mais eficaz que a amarração por atrito, como já era esperado;

5. Os cálculos a partir dos dados típicos mostrou que a maioria dos equipamentos de uma campanha offshore já possui um design que objetiva dar estabilidade ao componente e que não tenda a tombar com as acelerações. 


\section{Sugestões para trabalhos futuros}

Embora a metodologia utilizando as fórmulas e a sistemática de avaliação indicadas nas normas tenham sido plenamente satisfatórias, acreditamos que estes estudos poderão ser estendidos, com as seguintes propostas de trabalhos futuros:

1. Análise dos esforços nos batentes usando o software Ansys;

2. Análise das diversas acelerações usando o software Orcaflex;

3. Desenvolvimento de metodologia de cálculo dos esforços de uplift e quartering e análise dos esforços no deck do navio. 


\section{Referências Bibliográficas}

[1]. DET NORSKE VERITAS AS. Rules for Ships - Newbuildings - Hull and Equipment Main Class - Hull Structural Design, Ships with Length 100 Meters and Above. January 2011

[2]. Dansk Standard. Lastsikring på vejtransportkøretøjer - Sikkerhed - Del 1: Beregning af surringskræfter - Load restraining on road vehicles - Safety Part 1: Calculation of securing forces. DS/EN 12195-1. November/2010

[3]. DET NORSKE VERITAS AS. Offshore Standard DNV-OS-C102 - Structural Design of Offshore Ships. July 2015

[4]. PETROBRAS. Estruturas oceânicas - Olhal de Içamento Dimensionamento. N2683 REV. B. 12/2010

[5]. DET NORSKE VERITAS AS. Standard for certification No. 2.22- Lifting Appliances. October 2011

[6]. Ladungssicherungseinrichtungen auf Straßenfahrzeugen - Teil 2: Zurrgurte aus Chemiefasern - Load Restraining on Road Vehicles - Safety - Part 2: Web Lashing Made from Man-Made Fibres. DS/EN 12195-2. February/2001

[7]. DET NORSKE VERITAS AS. Offshore Standard DNV-OS-H102 - Marine Operations, Design and Fabrication. January 2012

[8]. http://www.awsservice.com.br/2019/04/11/6-forcas-que-as-cargas-saosubmetidas-em-alto-mar/ - Acessado em 09/04/2020

[9]. https://setxind.com/midstream/what-are-pig-launchers-and-receivers/ Acessado em 09/04/2020

[10]. https://www.thecrosbygroup.com/catalog/shackles/crosby-213-carbonround-pin-anchor-shackles/ - Acessado em 15/05/2020

[11]. https://www.tecnotextil.com.br/pdfs/catalogos/amarracao/2019/secoes/catal ogo-amarracao-tecnotextil-2019-secao-trik.pdf - Cinta de amarração TRIK $100 \mathrm{~mm}$ - Acessado em 15/05/2020

[12]. http://www.g-omo.info/wp-content/uploads/2016/09/20160613-NonRoutine-Cargo-Shipments.pdf - Árvore de natal molhada da FMC Technologies - Acessado em 
[13]. https://www.subsea7.com/ - PLSV Seven Oceans da Subsea 7

[14]. ]https://www.researchgate.net/figure/Six-degrees-of-freedom-for-shipmotion_fig1_327901742 - Movimentos de um navio

[15]. https://joidesresolution.org/moon-pool-2/ - Moonpool

[16]. https://fas.org/man/dod-101/sys/ship/beginner.htm - Estrutura do casco de um navio

[17]. https://vismar.co.uk/portfolio/subsea-mattress/ - Concrete mattress

[18]. http://www.sectionlift.co.uk/_content/modular_spreader_beams.html Spreader bar

[19]. http://nfatmala.blogspot.com/2016/02/pipeline-ending-manifoldplemplet.html - PLET

[20]. https://sal-heavylift.com/uploads/tx_salext/gallery/plem06_01.jpg - PLEM

[21]. https://www.fogt.com/subsea-pig-launchers-and-receiver-systems-plr PLR

[22]. https://coregrouting.com/services/integrity-repair-grout-bags/ - Grout bags

[23]. https://www.halliburton.com/content/dam/ps/public/bc/contents/Data_She ets/1525SCFM-1300SCFM-Primary-Compressor-H012676.pdf - Primary compressor

[24]. https://www.oiusa.com/offshore-certified-well-testing-cabin/ - Test cabin

[25]. https://www.meiriggingcrating.com/shipping-crates/wood-shipping-crates/ - Wooden box

[26]. https://www.thenavalarch.com/cargo-stoppers-why-they-are-critical-andhow-to-design-them/ - Stoppers

[27]. https://www.bgstructuralengineering.com/BGDesign/BGDesign05.htm Método LRFD e WSD

[28]. https://www.indiamart.com/proddetail/offshore-skid-tank15452923933.html - SKID 


\section{ANEXO 1 - Cálculo das acelerações}

\begin{tabular}{|c|c|}
\hline L [m] & 125,00 \\
\hline V [knots] & 16,00 \\
\hline$B$ [m] & 27,00 \\
\hline $\mathrm{Cb}[-]$ & 0,56 \\
\hline $\mathrm{g} 0\left[\mathrm{~m} / \mathrm{s}^{2}\right]$ & 9,81 \\
\hline Cw [-] & 8,43 \\
\hline Cv [-] & 0,20 \\
\hline Cv1 [-] & 1,43 \\
\hline $\mathrm{a} 0[\mathrm{~m} / \mathrm{s}]$ & 0,49 \\
\hline $\operatorname{ax}[\mathrm{m} / \mathrm{s}]$ & 0,54 \\
\hline tetha [rad] & 0,22 \\
\hline $\mathrm{Tp}[\mathrm{s}]$ & 6,43 \\
\hline ay $[\mathrm{m} / \mathrm{s}]$ & 1,44 \\
\hline c [-] & 1,00 \\
\hline $\mathrm{fi}$ [rad] & 0,49 \\
\hline k_r $[\mathrm{m}]$ & 10,53 \\
\hline $\mathrm{GM}[\mathrm{m}]$ & 3,50 \\
\hline $\operatorname{Tr}[\mathbf{s}]$ & 11,26 \\
\hline
\end{tabular}

\begin{tabular}{|c|c|c|c|c|c|c|c|c|c|}
\hline \multicolumn{10}{|c|}{ Stopper } \\
\hline & $20 \mathrm{ft}$ & $40 \mathrm{ft}$ & Mattress & Test cabin & PLR & $\begin{array}{l}\text { Grout } \\
\text { bags }\end{array}$ & PLEM & PLET & $\begin{array}{c}\text { Compres } \\
\text { sor }\end{array}$ \\
\hline k_v & 1,19 & 1,41 & 0,92 & 1,36 & 0,58 & 1,02 & 0,58 & 0,75 & 1,02 \\
\hline a_v & 10,15 & 12,05 & 7,86 & 11,61 & 5,01 & 8,76 & 5,01 & 6,38 & 8,76 \\
\hline R_r & 7,30 & 8,85 & 6,60 & 7,57 & 9,90 & 8,85 & 8,50 & 8,00 & 10,95 \\
\hline R_ry & 7,30 & 7,30 & 6,60 & 7,30 & 7,00 & 7,30 & 8,50 & 8,00 & 7,47 \\
\hline a_ry & 1,11 & 1,11 & 1,01 & 1,11 & 1,07 & 1,11 & 1,30 & 1,22 & 1,14 \\
\hline$a_{-} t$ & 5,91 & 5,91 & 5,81 & 5,91 & 5,87 & 5,91 & 6,09 & 6,01 & 5,93 \\
\hline R_p & 43,50 & 52,90 & 31,10 & 50,90 & 12,50 & 36,10 & 13,40 & 22,80 & 36,10 \\
\hline R_px & 7,30 & 7,30 & 6,60 & 7,30 & 7,00 & 7,30 & 8,50 & 8,00 & 7,47 \\
\hline a_px & 1,52 & 1,52 & 1,38 & 1,52 & 1,46 & 1,52 & 1,77 & 1,67 & 1,56 \\
\hline a_I & 3,68 & 3,68 & 3,54 & 3,68 & 3,62 & 3,68 & 3,93 & 3,83 & 3,72 \\
\hline
\end{tabular}

\begin{tabular}{|c|c|c|c|}
\hline \multicolumn{4}{|c|}{ Direct } \\
\hline & $\mathbf{2 0 f t} \mathbf{1}$ & $\begin{array}{c}\text { Spreader } \\
\mathbf{1}\end{array}$ & $\begin{array}{c}\text { Spreader } \\
\mathbf{2}\end{array}$ \\
\hline k_v & 1,19 & 1,02 & 1,02 \\
\hline a_v & $\mathbf{1 0 , 1 5}$ & $\mathbf{8 , 7 8}$ & $\mathbf{8 , 7 6}$ \\
\hline R_r & 13,91 & 7,34 & 8,32 \\
\hline R_ry & 10,60 & 6,15 & 6,65 \\
\hline a_ry & 1,62 & 0,94 & 1,02 \\
\hline a_t & $\mathbf{6 , 4 0}$ & $\mathbf{5 , 7 4}$ & $\mathbf{5 , 8 1}$ \\
\hline R_p & 44,10 & 35,90 & 36,10 \\
\hline R_px & 10,60 & 6,15 & 6,65 \\
\hline a_px & $\mathbf{2 , 2 1}$ & 1,28 & 1,39 \\
\hline a_I & $\mathbf{4 , 3 7}$ & $\mathbf{3 , 4 5}$ & $\mathbf{3 , 5 5}$ \\
\hline
\end{tabular}




\section{ANEXO 2 - Cálculo dos esforços no batente}

Batentes posicionados na longitudinal

\begin{tabular}{|c|c|c|c|}
\hline Grandeza & Símbolo & Valor & Unidade \\
\hline Altura & $\mathrm{h}$ & 100,00 & $\mathrm{~mm}$ \\
\hline Comprimento chapa da frente & $\mathrm{L} 1$ & 100,00 & $\mathrm{~mm}$ \\
\hline Espessura chapa da frente & $\mathrm{t} 1$ & 15,00 & $\mathrm{~mm}$ \\
\hline Comprimento chapa de tras & $\mathrm{L} 2$ & 200,00 & $\mathrm{~mm}$ \\
\hline Espessura chapa de tras & $\mathrm{t} 2$ & 15,00 & $\mathrm{~mm}$ \\
\hline Carregamento & $\mathrm{F}$ & 144640,00 & $\mathrm{~N}$ \\
\hline Perna da solda & $\mathrm{Ps}$ & 10,00 & $\mathrm{~mm}$ \\
\hline Garganta da solda & $\mathrm{gs}$ & 7,07 & $\mathrm{~mm}$ \\
\hline Comprimento da solda & $\mathrm{Ls}$ & 200,00 & $\mathrm{~mm}$ \\
\hline Limite de escoamento do material & $\mathrm{Fy}$ & 345,00 & $\mathrm{MPa}$ \\
\hline Limite de ruptura do material & $\mathrm{Fu}$ & 450,00 & $\mathrm{MPa}$ \\
\hline Fator de utilização da solda & $\mathrm{\eta} 0 \mathrm{~s}$ & 0,52 & - \\
\hline Fator de utilização do batente & $\eta \mathrm{b}$ & 0,60 & - \\
\hline Fator de correlação & $\beta \mathrm{w}$ & 0,89 & - \\
\hline Fator do material & $\mathrm{\gamma}$ & 1,00 & - \\
\hline
\end{tabular}

\begin{tabular}{|c|c|c|c|}
\hline \multicolumn{4}{|c|}{ NA SOLDA } \\
\hline Grandeza & Símbolo & Valor & Unidade \\
\hline Momento & $\mathrm{M}$ & 7232000,00 & $\mathrm{~N} . \mathrm{mm}$ \\
\hline Momento de inércia solda & $\mathrm{Is}$ & 9428090,42 & $\mathrm{~mm} \wedge$ \\
\hline Sigma transversal & $\sigma \mathrm{t}$ & 54,24 & $\mathrm{MPa}$ \\
\hline Tau transversal & $\mathrm{tt}$ & 54,24 & $\mathrm{MPa}$ \\
\hline Tau paralelo & $\tau \mathrm{p}$ & 51,14 & $\mathrm{MPa}$ \\
\hline Tensão equivalente & $\sigma$ & 140,05 & $\mathrm{MPa}$ \\
\hline Tensão teste & $\mathrm{Fu}^{*} \eta 0 \mathrm{~s} / \beta \mathrm{w}$ & 262,92 & \\
\hline Teste1 & & Aprovado & \\
\hline Teste2 & & Aprovado & \\
\hline
\end{tabular}

\begin{tabular}{|c|c|c|c|}
\hline \multicolumn{4}{|c|}{ NO BATENTE } \\
\hline Grandeza & Símbolo & Valor & Unidade \\
\hline Área da base & $\mathrm{Ab}$ & 3000,00 & $\mathrm{~mm}^{2}$ \\
\hline Momento de inércia na base & $\mathrm{lb}$ & 10000000,00 & $\mathrm{~mm}^{\wedge} 4$ \\
\hline Tensão de flexão na base & $\sigma \mathrm{t}$ & 72,32 & $\mathrm{MPa}$ \\
\hline Tensão cisalhante na base & $\mathrm{tt}$ & 48,21 & $\mathrm{MPa}$ \\
\hline Tensão equivalente & $\sigma$ & 110,47 & $\mathrm{MPa}$ \\
\hline Tensão admissível & $\sigma \_a d m$ & 207,00 & $\mathrm{MPa}$ \\
\hline Teste & & Aprovado & \\
\hline
\end{tabular}


Batentes posicionados na transversal

\begin{tabular}{|c|c|c|c|}
\hline Grandeza & Símbolo & Valor & Unidade \\
\hline Altura & $\mathrm{h}$ & 100,00 & $\mathrm{~mm}$ \\
\hline Comprimento chapa da frente & $\mathrm{L} 1$ & 100,00 & $\mathrm{~mm}$ \\
\hline Espessura chapa da frente & $\mathrm{t} 1$ & 15,00 & $\mathrm{~mm}$ \\
\hline Comprimento chapa de tras & $\mathrm{L} 2$ & 200,00 & $\mathrm{~mm}$ \\
\hline Espessura chapa de tras & $\mathrm{t} 2$ & 15,00 & $\mathrm{~mm}$ \\
\hline Carregamento & $\mathrm{F}$ & 115230,00 & $\mathrm{~N}$ \\
\hline Perna da solda & $\mathrm{Ps}$ & 10,00 & $\mathrm{~mm}$ \\
\hline Garganta da solda & $\mathrm{gs}$ & 7,07 & $\mathrm{~mm}$ \\
\hline Comprimento da solda & $\mathrm{Ls}$ & 200,00 & $\mathrm{~mm}$ \\
\hline Limite de escoamento do material & $\mathrm{Fy}$ & 345,00 & $\mathrm{MPa}$ \\
\hline Limite de ruptura do material & $\mathrm{Fu}$ & 450,00 & $\mathrm{MPa}$ \\
\hline Fator de utilização da solda & $\eta \mathrm{n}$ & 0,52 & - \\
\hline Fator de utilização do batente & $\eta \mathrm{b}$ & 0,60 & - \\
\hline Fator de correlação & $\beta \mathrm{s}$ & 0,89 & - \\
\hline Fator do material & $\mathrm{\gamma}$ & 1,00 & - \\
\hline
\end{tabular}

\begin{tabular}{|c|c|c|c|}
\hline \multicolumn{4}{|c|}{ NA SOLDA } \\
\hline Grandeza & Símbolo & Valor & Unidade \\
\hline Momento & $\mathrm{M}$ & 5761500,00 & $\mathrm{~N} . \mathrm{mm}$ \\
\hline Momento de inércia solda & $\mathrm{Is}$ & 9428090,42 & $\mathrm{~mm}^{\wedge} 4$ \\
\hline Sigma transversal & $\sigma \mathrm{t}$ & 43,21 & $\mathrm{MPa}$ \\
\hline Tau transversal & $\tau \mathrm{t}$ & 43,21 & $\mathrm{MPa}$ \\
\hline Tau paralelo & $\tau \mathrm{p}$ & 40,74 & $\mathrm{MPa}$ \\
\hline Tensão equivalente & $\sigma$ & 111,57 & $\mathrm{MPa}$ \\
\hline Tensão teste & Fu*n0s/ $\beta \mathrm{w}$ & 262,92 & \\
\hline Teste & & Aprovado & \\
\hline Teste2 & & Aprovado & \\
\hline
\end{tabular}

\begin{tabular}{|c|c|c|c|}
\hline \multicolumn{4}{|c|}{ NO BATENTE } \\
\hline Grandeza & Símbolo & Valor & Unidade \\
\hline Área da base & $\mathrm{Ab}$ & 3000,00 & $\mathrm{~mm}^{2}$ \\
\hline Momento de inércia na base & $\mathrm{Ib}$ & 10000000,00 & $\mathrm{~mm}^{\wedge} 4$ \\
\hline Tensão de flexão na base & $\sigma \mathrm{t}$ & 57,62 & $\mathrm{MPa}$ \\
\hline Tensão cisalhante na base & $\mathrm{tt}$ & 38,41 & $\mathrm{MPa}$ \\
\hline Tensão equivalente & $\sigma$ & 88,01 & $\mathrm{MPa}$ \\
\hline Tensão admissível & $\sigma \_\mathrm{adm}$ & 207,00 & $\mathrm{MPa}$ \\
\hline Teste & & Aprovado & \\
\hline
\end{tabular}




\section{ANEXO 3 - Cálculo dos esforços nos olhais}

$$
\begin{aligned}
& \mathrm{F}_{\mathrm{y}}:=345 \mathrm{MPa} \\
& \text { Limite de escoamento do material } \\
& \mathrm{d}_{\text {pino }}:=31.8 \mathrm{~mm} \\
& \mathrm{~d}_{\text {furo }}:=\mathrm{d}_{\text {pino }}+1 \mathrm{~mm}=32.8 \cdot \mathrm{mm} \\
& \mathrm{r}_{\text {furo }}:=\frac{\mathrm{d}_{\text {furo }}}{2}=16.4 \cdot \mathrm{mm} \\
& \mathrm{R}_{\text {olhal }}:=55 \mathrm{~mm} \\
& \mathrm{~F}_{\text {olhal }}:=3.98 \text { tonnef } \\
& \mathrm{f}_{\mathrm{dc}}:=1.25 \\
& \mathrm{f}_{\mathrm{cp}}:=1.1 \\
& \mathrm{f}_{\mathrm{cg}}:=1.05 \\
& \mathrm{FAD}:=1.30 \\
& \text { alfa }:=85 \mathrm{deg} \\
& F_{\text {linga }}:=f_{d c} \cdot f_{c p} \cdot f_{c g} \cdot F A D \cdot \frac{F_{\text {olhal }}}{\sin (\text { alfa })}=7.498 \cdot \text { tonnef } \\
& \mathrm{F}_{\text {pino }}:=1.3 \cdot \mathrm{F}_{\text {linga }}=9.748 \cdot \text { tonnef } \\
& \text { Diâmetro do pino da manilha } \\
& \text { Diâmetro do furo do olhal } \\
& \text { Raio do furo do olhal } \\
& \text { Raio do olhal } \\
& \text { Reação teórica no olhal } \\
& \text { Fator de desvio de carga } \\
& \text { Fator de contingência do peso } \\
& \text { Fator de incerteza do centro de gravidade } \\
& \text { Fator de amplificação dinâmica } \\
& \text { Ângulo alfa com a horizontal } \\
& \text { Força resultante da linga no olhal } \\
& \text { Força atuante no pino da manilha da } \\
& \text { lingada }
\end{aligned}
$$


Teste espessura do olhal

$\mathrm{t}_{\min }:=\frac{\mathrm{F}_{\text {pino }}}{\left(0.9 \cdot \mathrm{F}_{\mathrm{y}} \cdot \mathrm{d}_{\text {pino }}\right)}=9.682 \cdot \mathrm{mm}$
$\mathrm{t}_{\text {olhal }}:=15 \mathrm{~mm}$

Teste Contato entre o furo e o pino

$\mathrm{f}_{\mathrm{p}}:=\frac{\mathrm{F}_{\text {pino }}}{\left(\mathrm{d}_{\text {pino }} \cdot \mathrm{t}_{\text {olhal }}\right)}=200.41 \cdot \mathrm{MPa}$

\section{Teste Cisalhamento na area efetiva}

$$
\mathrm{f}:=\frac{\mathrm{F}_{\text {pino }}}{2 \cdot\left[\left(\mathrm{R}_{\text {olhal }}-\mathrm{r}_{\text {furo }}\right) \cdot \mathrm{t}_{\text {olhal }}\right]}=82.552 \cdot \mathrm{MPa} \quad 0.4 \cdot \mathrm{F}_{\mathrm{y}}=138 \cdot \mathrm{MPa}
$$

Teste Tração na area li uida efetiva na região do furo

$$
\begin{aligned}
& 1:=\mid \begin{array}{l}
\left(0.8 \cdot \mathrm{d}_{\text {furo }}\right) \text { if } 0.8 \cdot \mathrm{d}_{\text {furo }}<4 \cdot \mathrm{t}_{\text {olhal }} \\
\left(4 \cdot \mathrm{t}_{\text {olhal }}\right) \text { other ise }
\end{array} \\
& \mathrm{f}_{\mathrm{a}}:=\frac{\mathrm{F}_{\text {pino }}}{2 \cdot 1_{1} \cdot \mathrm{t}_{\text {olhal }}}=121.438 \cdot \mathrm{MPa}
\end{aligned}
$$$$
0.45 \cdot \mathrm{F}_{\mathrm{y}}=155.25 \cdot \mathrm{MPa}
$$

espessura do olhal

$0.9 \cdot \mathrm{F}_{\mathrm{y}}=310.5 \cdot \mathrm{MPa}$

\section{G-213 / S-213 Round Pin Anchor Shackles}
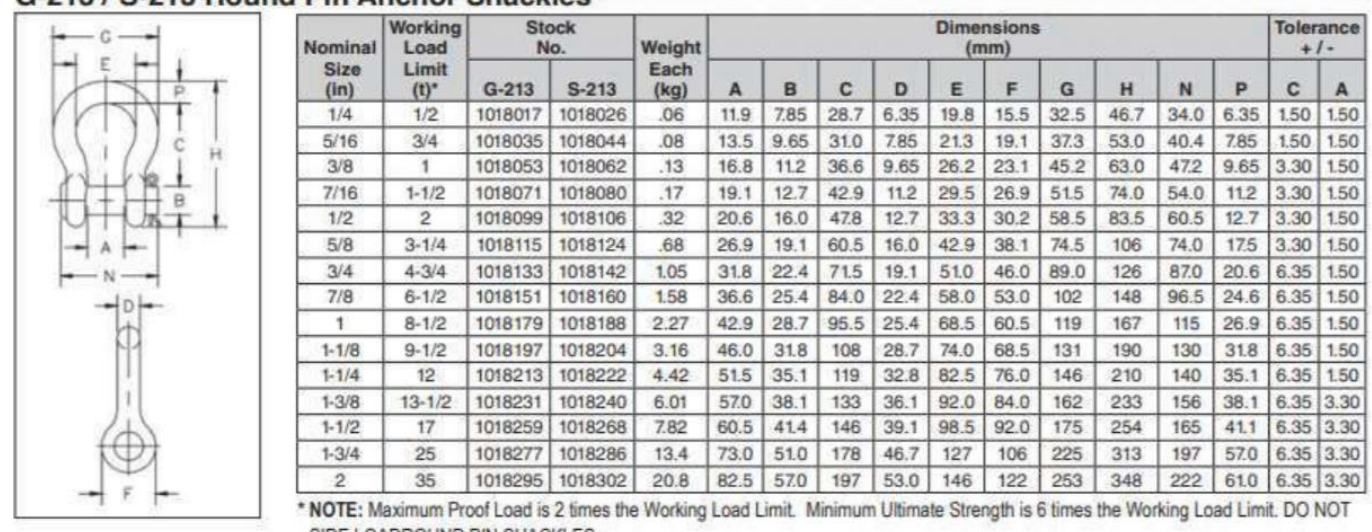

"NOTE: Maximum Proof Load is 2 times the Working Load Limit. Minimum Ultimate Strength is 6 times the Working Load Limit. DO NOT SIDE LOADROUND PIN SHACKLES. 


\section{ANEXO 4 - Datasheet da cinta}

\section{CATRACAMÓVEL SISTEMA IVIK}

\section{Caracteristicas}

Os Sistema TRIK é leve e compacto, composto por cintas confeccionadas com fios de poliéster de alta tenacidade, que são tratados no processo de pigmentação para garantir alta resistência à abrasão e ao envelhecimento do tecido. Fabricados em aço galvanizado e bicromatizado, todos os componentes aplicados são tratados no processo de galvanização, proporcionando maior resistência à corrosão.

Os kits com catraca TRIK possuem trava de segurança e são ideais para amarração de grandes máquinas, equipamentos e tubos. São fornecidas com uma gama de terminais próprios para qualquer carroceria, o que permite sua utilização nos sistemas envolvente, amarração direta ou enlaçada.

Uma parte (cinta continua)

Informar comprimento

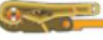

\section{Duas partes}

Informar comprimento das partes fixa e móvel

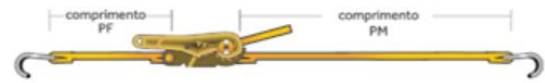

\section{trik $100 \mathrm{~mm}$}

- Ideal para amarração de grandes máquinas, equipamentos e tubos:

- Maior capacidade de carga para amarração direta;

- Maior área de contato com a carga.
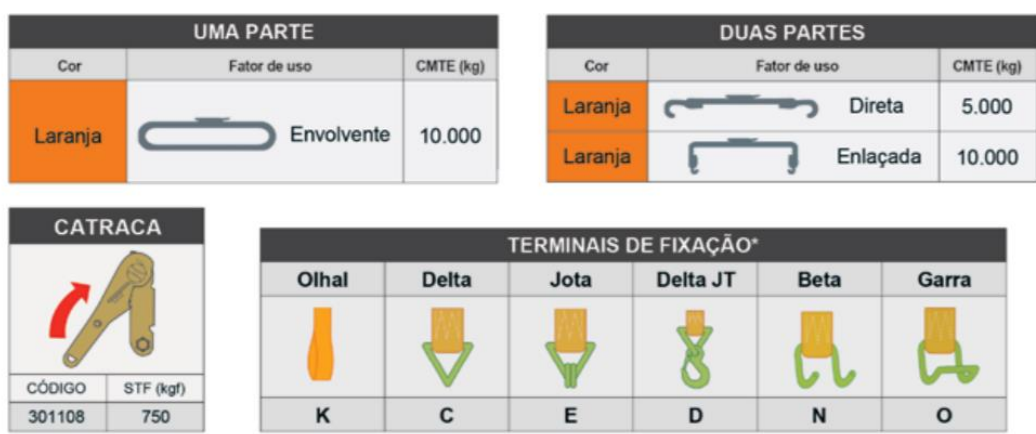

* Podem ser solicitados terminais diferentes para a parte fixa (PF) e parte móvel (PM). 


\section{ANEXO 5 - Datasheet da manilha}

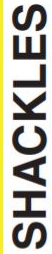

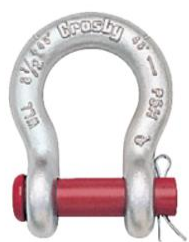

G-213/S-213

equirements of Fed

Specification RR-C-271G, Ty

NA, Grade A, Class 1 , except

the contractor. For addition

\section{Crosby ${ }^{\circledast}$ Round Pin Shackles}

- Capacities $1 / 2$ through 35 metric tons.

- Forged - Quenched and Tempered, with alloy pins.

- Working Load Limit permanently shown on every shackle.

- Hot Dip galvanized or Self Colored.

- Sizes $3 / 8$ inch and below are mechanically galvanized.

- Fatigue rated.

- Shackles $25 t$ and larger are RFID EQUIPPED.

Shackles can be furnished proof tested with certificates to des gnated standards, such as ABS, DNV, Lloyds, or other certification. Charges for proof testing and certification available when requested at the time of orde.

- Shackles are Quenched and Tempered and can meet DNV impact requirements of 42 Joules ( $31 \mathrm{ft} \cdot \mathrm{lbf}$ ) at -20 degrees $\mathrm{C}(-4$ degrees F).

- Look for the Red Pin ${ }^{\circledast}$... the mark of genuine Crosby quality.

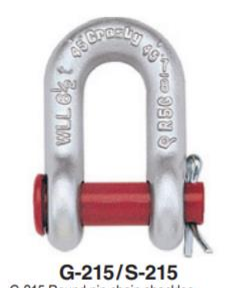

meet the performance requirements
of Federal Specification RR-C-2716 Type INB, Grade A, Class 1 , except for those provisions required of the
contractor. For additional info see page 476 .

\section{G-213 / S-213 Round Pin Anchor Shackles}

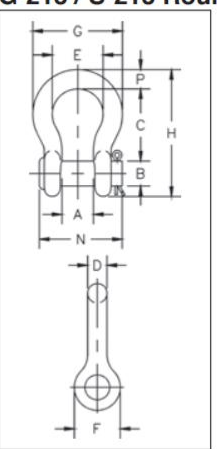

\begin{tabular}{|c|c|c|c|c|c|c|c|c|c|c|c|c|c|c|c|c|}
\hline \multirow{2}{*}{$\begin{array}{l}\text { Nominal } \\
\text { Size } \\
\text { (in) }\end{array}$} & \multirow{2}{*}{$\begin{array}{c}\text { Working } \\
\text { Load } \\
\text { Limit } \\
(\mathrm{t})^{*}\end{array}$} & \multicolumn{2}{|c|}{$\begin{array}{l}\text { Stock } \\
\text { No. }\end{array}$} & \multirow{2}{*}{$\begin{array}{l}\text { Weight } \\
\text { Each } \\
\text { (kg) }\end{array}$} & \multicolumn{10}{|c|}{$\begin{array}{c}\text { Dimensions } \\
(\mathrm{mm})\end{array}$} & \multicolumn{2}{|c|}{$\begin{array}{l}\text { Tolerance } \\
+/ 1-\end{array}$} \\
\hline & & 213 & S-213 & & A & B & c & D & $E$ & $\mathbf{F}$ & G & H & $\mathbf{N}$ & $P$ & c & A \\
\hline $1 / 4$ & $1 / 2$ & 1018017 & 18026 & .06 & 11.9 & 7.85 & 28.7 & 6.35 & \begin{tabular}{|l|l|}
19.8 \\
\end{tabular} & 15.5 & 32.5 & 46.7 & 34.0 & 6.35 & 1.50 & 1.50 \\
\hline $5 / 16$ & $3 / 4$ & 101 & 10180 & .08 & 13.5 & 9.65 & 31.0 & 7.85 & 21.3 & 19.1 & 37.3 & 3.0 & 40.4 & 7.85 & 1.50 & 1.50 \\
\hline $3 / 8$ & & 8053 & 18062 & & 16.8 & 11.2 & 36.6 & 9.65 & 26.2 & \begin{tabular}{|l|}
23.1 \\
\end{tabular} & 45.2 & 63.0 & 47.2 & 9.65 & 3.30 & 1.50 \\
\hline $7 / 16$ & $1-1$ & 8071 & 10 & .17 & 19.1 & 12.7 & 42.9 & 11.2 & 29.5 & 26.9 & 51.5 & 4.0 & 54.0 & 11.2 & 3.30 & 1.50 \\
\hline $1 / 2$ & & 1018099 & 1018106 & .32 & 20.6 & 16.0 & \begin{tabular}{|l|l|}
77.8 \\
\end{tabular} & \begin{tabular}{|l|l|} 
& 12.7 \\
\end{tabular} & 33.3 & 30.2 & 58.5 & 83.5 & 60.5 & 12.7 & 3.30 & 1.50 \\
\hline $5 / 8$ & & & & & & & 60.5 & \begin{tabular}{|l|}
16.0 \\
\end{tabular} & 9 & & & & 74.0 & 17.5 & & 1.50 \\
\hline $3 / 4$ & $4-3 / 4$ & 1018133 & 1018142 & 1.05 & 31.8 & 22.4 & 71.5 & \begin{tabular}{|l|l|}
19.1 \\
\end{tabular} & 51.0 & 46.0 & 89.0 & 126 & 87.0 & 20.6 & \begin{tabular}{ll|}
6.35 \\
\end{tabular} & 1.50 \\
\hline $7 / 8$ & & 10 & 11 & & & 25.4 & 84.0 & \begin{tabular}{|l|}
22.4 \\
\end{tabular} & 58 & 3.0 & 102 & 48 & 96.5 & 24.6 & 6.35 & 1.50 \\
\hline 1 & $8-$ & 1018179 & 1018188 & 2.2 & 42.9 & 28.7 & 95.5 & 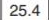 & 68.5 & 60.5 & 119 & 167 & 115 & 26.9 & 6.35 & \begin{tabular}{|l|l|} 
\\
\end{tabular} \\
\hline $1-1 / 8$ & & 1018197 & 10 & & 46.0 & 31.8 & \begin{tabular}{|l|}
108 \\
\end{tabular} & \begin{tabular}{|l|}
28.7 \\
\end{tabular} & 74.0 & 68.5 & 131 & 190 & 30 & 31.8 & \begin{tabular}{|l|}
6.35 \\
\end{tabular} & 1.50 \\
\hline $1-1 / 4$ & & 213 & 18 & & 51 & 35.1 & 119 & 32.8 & 82 & 76.0 & & 10 & 40 & 35.1 & & \\
\hline $1-3 / 8$ & $13-1 / 2$ & 1018231 & 1018240 & & 57.0 & 38.1 & 133 & 36.1 & 92.0 & 84.0 & 162 & 233 & 156 & 38.1 & 6.35 & 3.30 \\
\hline $1-1 / 2$ & & 1018259 & 10 & 7.8 & 60.5 & \begin{tabular}{|l|l|}
41.4 \\
\end{tabular} & 146 & 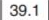 & \begin{tabular}{|l|l|}
98.5 \\
\end{tabular} & 92.0 & 175 & 254 & 165 & 41.1 & 6.35 & 3.30 \\
\hline $1-3 / 4$ & 25 & 1018277 & 1018286 & 13 & 73.0 & 51.0 & 178 & 46.7 & 127 & 106 & 225 & 313 & 197 & 57.0 & $\begin{array}{l}6.35 \\
\end{array}$ & 3.30 \\
\hline 2 & 35 & 1018295 & 1018302 & 20.8 & 82.5 & 57.0 & 197 & 53.0 & 146 & 122 & 253 & 348 & 222 & 61.0 & \begin{tabular}{|l|}
6.35 \\
\end{tabular} & 33 \\
\hline
\end{tabular}

" NOTE: Maximum Proof Load is 2 times the Working Load Limit. Minimum Ultimate Strength is 6 times the Working Load Limit. DO NOT SIDE LOADROUND PIN SHACKLES.

\section{G-215 / S-215 Round Pin Chain Shackles}

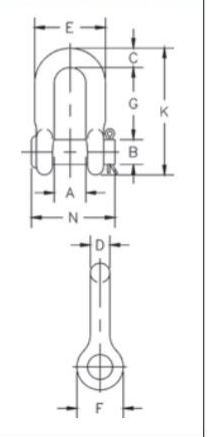

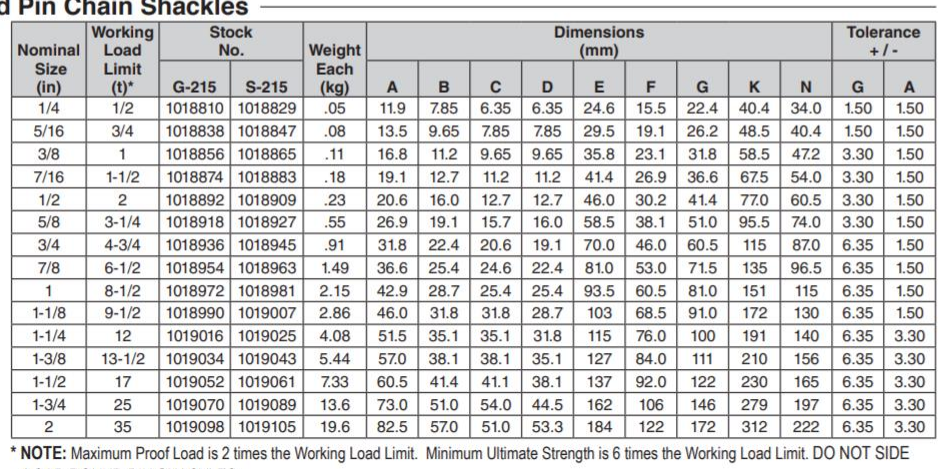

Proof $L$ ad is 2 imes the Working Load Limit Minimum Ullimate Strongth is 6 times the Working Load Limit DO NOT SIDE LOAD ROUND PIN SHACKLES. Page 92 of the General Catalog 


\section{ANEXO 6 - Datasheet do D-ring}

\section{Lifting Points}
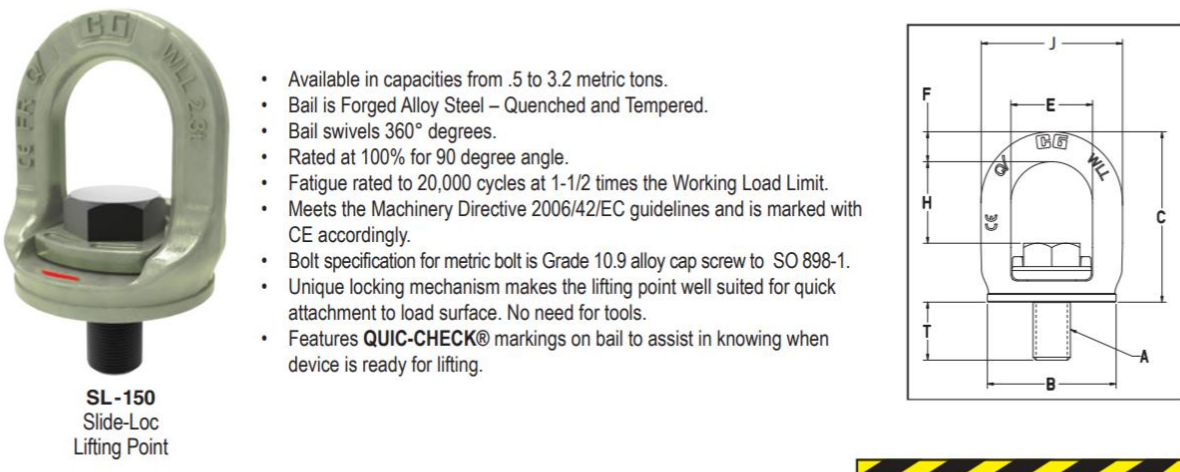

Lifting Point

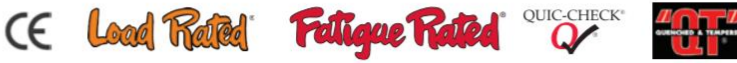

SL-150 UNC SLIDE-LOC'M LIFT POINT

\begin{tabular}{|c|c|c|c|c|c|c|c|c|c|c|}
\hline \multirow{2}{*}{$\begin{array}{l}\text { Weight } \\
\text { Each } \\
\text { (lb) }\end{array}$} & \multirow[b]{2}{*}{$\begin{array}{l}\text { SL-150 } \\
\text { Stock No. }\end{array}$} & \multirow{2}{*}{$\begin{array}{l}\text { Working } \\
\text { Load Limit } \\
\text { (t)* }\end{array}$} & \multicolumn{7}{|c|}{$\begin{array}{l}\text { Dimensions } \\
\text { (in) }\end{array}$} & \multirow{2}{*}{$\begin{array}{c}\begin{array}{c}\text { Effective Thread } \\
\text { Projection Length }\end{array} \\
\text { T } \\
\end{array}$} \\
\hline & & & $\begin{array}{c}\text { Bolt Size } \\
\text { A }\end{array}$ & B & $c$ & $E$ & $\mathbf{F}$ & $\mathrm{H}$ & J & \\
\hline 0.30 & 1068407 & 0.50 & $3 / 8-16 \times 1$ & 1.40 & 2.09 & 1.10 & 0.33 & 1.11 & 1.77 & $\begin{array}{c}1 \\
0.60\end{array}$ \\
\hline 0.53 & 1068416 & 0.75 & $1 / 2-13 \times 1-1 / 4$ & 1.67 & 2.47 & 1.30 & 0.41 & 1.30 & 2.13 & 0.79 \\
\hline 1.10 & 1068425 & 1.50 & $5 / 8-11 \times 1-5 / 8$ & $\begin{array}{ll}2.17 \\
\end{array}$ & 2.98 & 1.46 & 0.52 & 1.46 & 2.50 & 1.01 \\
\hline 2.05 & 1068434 & 2.30 & $3 / 4-10 \times 2$ & 2.71 & 3.59 & 1.72 & 0.63 & 1.72 & 2.98 & 1.26 \\
\hline 2.16 & 1068443 & 2.30 & $7 / 8-9 \times 2$ & 2.71 & 3.61 & 1.72 & 0.63 & 1.72 & 2.98 & 1.23 \\
\hline 3.73 & 1068452 & 3.20 & $1-8 \times 2-1 / 2$ & 3.25 & 4.33 & 2.08 & 0.76 & 1.93 & 3.59 & 1.59 \\
\hline
\end{tabular}

SL-150 M Metric SLIDE-LOC ${ }^{\text {TM }}$ LIFT POINT

\begin{tabular}{|c|c|c|c|c|c|c|c|c|c|c|}
\hline \multirow{2}{*}{$\begin{array}{l}\text { Weight } \\
\text { Each } \\
(\mathrm{kg})\end{array}$} & \multirow[b]{2}{*}{$\begin{array}{l}\text { SL-150M } \\
\text { Stock No. }\end{array}$} & \multirow{2}{*}{$\begin{array}{l}\text { Working } \\
\text { Load Limit } \\
\text { (t) }\end{array}$} & \multicolumn{7}{|c|}{$\begin{array}{c}\text { Dimensions } \\
(\mathrm{mm})\end{array}$} & \multirow{2}{*}{$\begin{array}{c}\text { Effective Thread } \\
\text { Projection Length } \\
\text { T }\end{array}$} \\
\hline & & & $\begin{array}{c}\text { Bolt Size } \\
\text { A }\end{array}$ & B & c & $E$ & $\mathbf{F}$ & H & J & \\
\hline .14 & 1068515 & 0.50 & M10X1.5 $\times 25$ & 35.5 & 53.0 & 28.0 & 8.5 & 27.8 & 45.0 & 14.6 \\
\hline .23 & 1068524 & 0.75 & M12×1.75×30 & 42.5 & 62.6 & 33.0 & 10.5 & 32.9 & 54.0 & 18.3 \\
\hline .50 & 1068533 & 1.50 & M16x2x40 & 55.0 & 75.7 & 37.0 & 13.2 & 37.0 & 63.4 & 24.5 \\
\hline 94 & 1068542 & 230 & $M 20 \times 2.5 \times 50$ & 68.8 & 911 & 439 & 16.0 & 436 & 75.6 & 310 \\
\hline 1.60 & 1068551 & 3.20 & $M 24 \times 3 \times 60$ & 82.5 & 110.0 & 52.8 & 19.2 & 52.8 & 91.2 & 37.0 \\
\hline
\end{tabular}

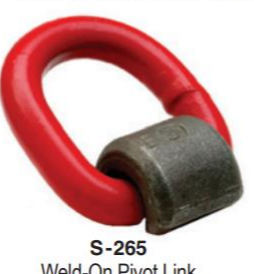

Weld-On Pivot Link
- Forged Steel - Quenched and Tempered.

- Excellent welding qualities.

Widely used on farm machinery, trucks, steel hulled marine vessels and material handling equipment.

Reference American Welding Society specifications for proper welding procedures.

\section{विन्य}

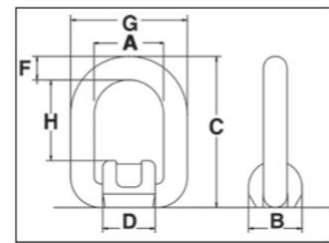

S-265 Weld-On Pivot Link

\begin{tabular}{|c|c|c|c|c|c|c|c|c|c|c|c|}
\hline \multicolumn{2}{|c|}{ Working Load Limit (t) } & \multirow[b]{2}{*}{$\begin{array}{l}\text { S-265 } \\
\text { Stock No }\end{array}$} & \multirow[b]{2}{*}{$\begin{array}{l}\text { Weight Each } \\
(\mathrm{kg})\end{array}$} & \multicolumn{7}{|c|}{$\begin{array}{l}\text { Dimensions } \\
(\mathrm{mm})\end{array}$} & \multirow{2}{*}{$\begin{array}{l}\text { Minimum Fillet } \\
\text { Weld Size } \\
(\mathrm{mm})\end{array}$} \\
\hline $\begin{array}{l}\text { Design Factor } \\
5: 1\end{array}$ & $\begin{array}{l}\text { Design Factor } \\
4: 1\end{array}$ & & & A & B & c & D & $\mathbf{F}$ & G & H & \\
\hline 1 & 1.2 & 1290740 & .40 & 40 & 36 & 83 & 35 & 13 & 66 & 42 & 3 \\
\hline 2.5 & 3.2 & 1290768 & .60 & 45 & 44 & 99 & 42 & 18 & 81 & 48 & 3 \\
\hline 4.2 & 5.3 & 1290786 & 1.20 & 55 & 50 & 123 & 49 & 22 & 99 & 57 & 6 \\
\hline 6.4 & 8 & 1290802 & 2.40 & 70 & 64 & 144 & 64 & 26 & 122 & 67 & 6 \\
\hline 12 & 15 & 1290820 & 5.90 & 97 & 90 & 193 & 86 & 34 & 165 & 94 & 8 \\
\hline
\end{tabular}

